\title{
Effect of oxidative stress induced by low-level engineered nanoparticles on microbial viability and resistance to UV irradiation
}

Hang Li

West Virginia University

Follow this and additional works at: https://researchrepository.wvu.edu/etd

\section{Recommended Citation}

$\mathrm{Li}$, Hang, "Effect of oxidative stress induced by low-level engineered nanoparticles on microbial viability and resistance to UV irradiation" (2007). Graduate Theses, Dissertations, and Problem Reports. 4316. https://researchrepository.wvu.edu/etd/4316

This Thesis is protected by copyright and/or related rights. It has been brought to you by the The Research Repository @ WVU with permission from the rights-holder(s). You are free to use this Thesis in any way that is permitted by the copyright and related rights legislation that applies to your use. For other uses you must obtain permission from the rights-holder(s) directly, unless additional rights are indicated by a Creative Commons license in the record and/ or on the work itself. This Thesis has been accepted for inclusion in WVU Graduate Theses, Dissertations, and Problem Reports collection by an authorized administrator of The Research Repository @ WVU. For more information, please contact researchrepository@mail.wvu.edu. 


\title{
Effect of Oxidative Stress Induced by Low-Level Engineered Nanoparticles on Microbial Viability and Resistance to UV Irradiation
}

\section{Hang Li}

Thesis submitted to the

\author{
College of Engineering and Mineral Resources \\ at West Virginia University \\ in partial fulfillment of the requirements \\ for the degree of \\ Master of Science \\ In \\ Civil Engineering
}

\author{
Lian-Shin Lin, Ph.D., Chair \\ Ray Y.K. Yang, Ph.D. \\ Jianbo Yao, Ph.D.
}

Department of Civil and Environmental Engineering

\author{
Morgantown, West Virginia \\ 2007
}

Keywords: Metal-oxide nanoparticles, oxidative stress, ROS, Bacterial resistance, UV disinfection, water treatment

Copyright 2007 Hang Li 


\section{ABSTRACT \\ Effect of Oxidative Stress Induced by Low-Level Engineered Nanoparticles \\ on Microbial Viability and Resistance to UV Irradiation}

\section{Hang Li}

Introduction of engineered nanomaterials into water systems has potential of affecting microbial viability and resistance to commonly used disinfectants. We studied how photocatalytically induced oxidative stress by engineered nanoparticles can affect bacterial viability and resistance to UVC at $254 \mathrm{~nm}$. Flow cytometry analysis, fecal viability analysis and respiratory measurements showed that oxidative stress induced by engineered $\mathrm{TiO}_{2}$ nanoparticles with concentrations in ppb range can cause sublethal effects and lowered oxygen utilization rate. Respiratory measurements showed that degree of reduction in oxygen utilization depended on exposure time to oxidative stress but was not sensitive to nanoparticle concentrations examined in the study.

Fecal coliforms in mixed culture displayed enhanced resistance to UVC irradiation as a result of the oxidative treatment. Degree of resistance enhancement increased with nanoparticle concentration and exposure time. The higher survival percentages were attributed to two possible reasons. First, the oxidative treatment caused a bacterial community shift due to diverse bacterial sensitivity to oxidative damages among different species. Second, the oxidative stress induced bacterial defense mechanisms such as induction of ROS-counteracting enzymes and those for DNA repair so that the bacterial species became more resistant to the oxidative damages caused by UVC irradiation.

To further clarify the causes of the enhanced resistance with the mixed culture, we conducted a similar experiment on an Escherichia coli strain (DH10B). The pure culture exhibited a similar enhancement in resistance to UVC irradiation as the mixed culture. The data corroborate that induction of microbial activities of counteracting the oxidative stress and its damages is a cause for the observation concerning bacterial resistance.

To elucidate possible bacterial activities counteracting the oxidative stress and its damages, we measured intracellular ROS level of the mixed culture with and without the oxidative treatment. Fluorimetric measurements showed that oxidative stress caused by low-level engineered $\mathrm{TiO}_{2}$ nanoparticles could trigger bacterial defense mechanisms that counteracted intracellular reactive oxygen species. The data suggest that induction of bacterial activities that counteracting intracellular ROS is a cause for the enhanced resistance observed. 


\section{DEDICATION}

To my parents, my fiance and his parents

for

their love, support and encouragement to me. 


\section{ACKNOWLEDGEMENT}

It is with pleasure that I thank many people who made this thesis possible.

I thank Dr.Lin, my advisor and committee chairperson for his help, support, and patience

during the pursuit of my Master of Science degree. Dr. Lin's insight and advice was particularly valuable in my research.

I thank Dr. Yao, who had trained me with many of the lab technique in biotechnology and also had been helpful to me with research problems I encountered including provide me some material and equipment.

I would also like to thank Dr. Yang for his time and willingness to serve on my committee.

I express gratitude to lab colleagues for their timely help and suggestions. Thank Dr. Cynthia Cunningham for her assistance in conducting the flow cytometry analysis,

Lastly and most importantly, I would like to thank my parents, my fiancé's family and my friends for their love and support. Especially my fiancé Yuncheng Wang, whose love, patience and encouragement had been a constant motivation to me. 


\section{TABLE OF CONTENTS}

ABSTRACT

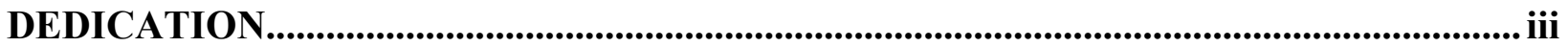

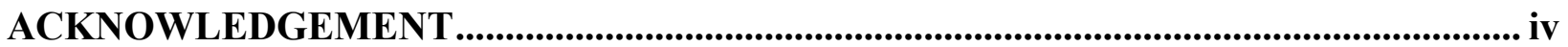

TABLE OF CONTENTS …............................................................................................................... v

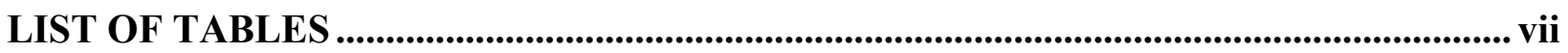

LIST OF FIGURES .......................................................................................................................... viii

LIST OF NOMENCLATURE ....................................................................................................... xii

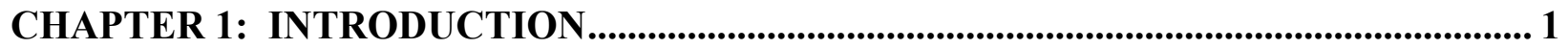

1.1 Background ............................................................................................................................. 1

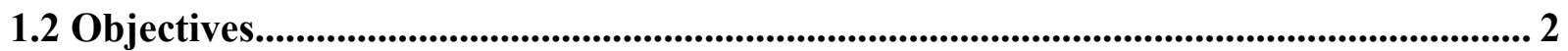

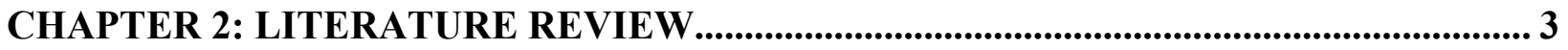

2.1 Engineered Nanometerials ..................................................................................................... 3

2.2 Potential Impacts of Engineered Nanomaterials ..................................................................... 4

2.2.1 Effect of ROS.................................................................................................................... 4

2.2.2 Response of Cells to ROS ................................................................................................. 5

2.2.3 Microbial Defense System ........................................................................................ 6

CHAPTER 3: METHODS AND MATERIALS ................................................................ 9

3.1 Model Nanoparticles................................................................................................................... 9

3.2 Mixed Culture Preparation............................................................................................................. 9

3.3 Oxidative Stress Exposure ..................................................................................................... 10

3.4 Oxygen Utilization Rate Measurement................................................................................. 15

3.5 Cell Enumeration and Viability Characterization.......................................................... 15

3.6 Cell Sorting and Cultivation ................................................................................................... 20

3.7 Microbial Resistance Characterization................................................................................ 20

3.8 Intracellular ROS Level Measurement.................................................................... 23 
3.9 Microbial Resistance of Pure Culture................................................................................... 23

3.10 Growth Delay Effect of Pure Culture ......................................................................... 24

3.11 Effect of ROS Scavengers on Microbial Resistance.................................................. 24

CHAPTER 4: RESULTS AND DISCUSSION .................................................................... 26

4.1 Mixed Culture Characterization ......................................................................... 26

4.2 Effect on Microbial Activity and Viability ....................................................... 26

4.3 Flow Cytometry Analysis and Validation......................................................................... 39

4.4 Microbial Resistance...................................................................................... 46

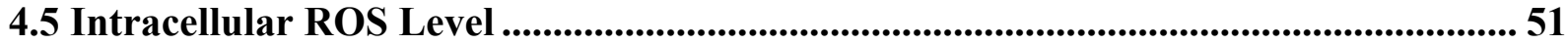

4.6 Microbial Resistance of Pure Culture................................................................................ 55

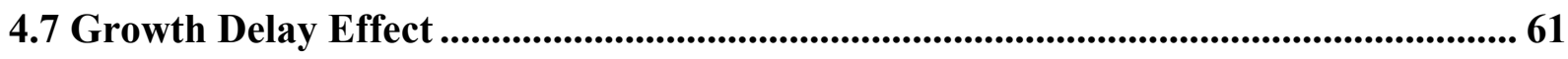

4.8 Effect of ROS Scavengers on Microbial Resistance.................................................. 61

CHAPTER 5: CONCLUTION .............................................................................................. 64

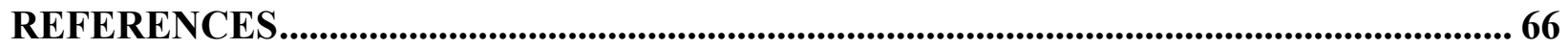

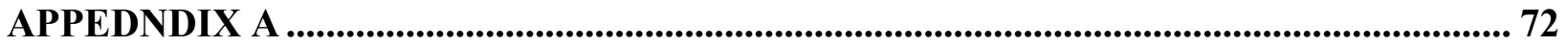

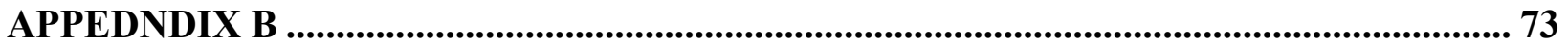

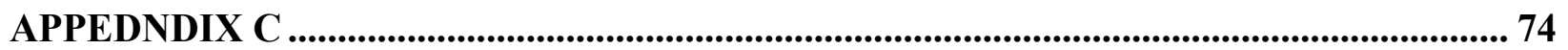

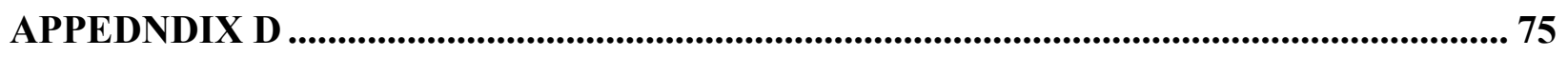

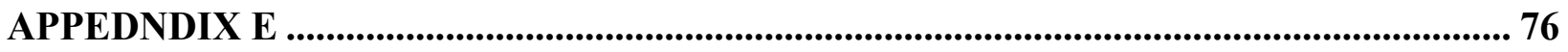

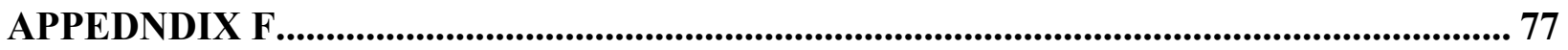

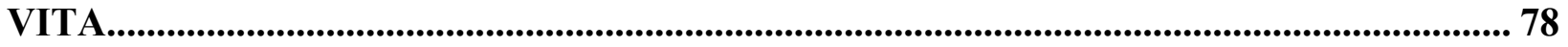




\section{LIST OF TABLES}

Table 1. Mean Values $(\mu)$ and Standard Deviations $(\sigma)$ of the Ratio of Bacterial Concentration with Intact Membranes to Total Bacterial Concentration of the Mixed Culture Treated with $\mathrm{TiO}_{2}$ Nanoparticles and $\mathrm{UV}_{365}$ at $0.6 \mathrm{~mW} / \mathrm{cm}^{2}$. The Concentrations were Measured in Triplicate.

Table A. Log-inactivation of Fecal Coliforms to UV Disinfection (254 nm) after Treated with Different $\mathrm{TiO}_{2}$ Concentration and 365nm UV $\left(0.6 \mathrm{~mW} / \mathrm{cm}^{2}\right)$ 19hrs.

Table B. Log-inactivation of Fecal Coliforms to UV Disinfection (254 nm) after Treated with $\mathrm{TiO}_{2}$ Concentration $5 \mu \mathrm{g} / \mathrm{L}$ and $365 \mathrm{~nm} \mathrm{UV}\left(0.6 \mathrm{~mW} / \mathrm{cm}^{2}\right)$ in Different Exposure Time.

Table C. Log-inactivation of Fecal Coliforms to UV Disinfection (254 $\mathbf{~ m})$ after Treated with Different Sunscreen $\mathrm{TiO}_{2}$ Concentration and $365 \mathrm{~nm} \mathrm{UV}\left(0.6 \mathrm{~mW} / \mathrm{cm}^{2}\right) 19 \mathrm{hrs}$.

Table D. Log-inactivation of $E$. coli to UV Disinfection (254 $\mathrm{nm}$ ) after Treated with Different $\mathrm{TiO}_{2}$ Concentration, $\mathrm{UV}_{365}$ Intensity and Exposure Time. 75

Table E. Log-inactivation of $E$. coli to UV Disinfection (254 nm) after Treated with Different $\mathrm{TiO}_{2}$ Concentration, $\mathrm{UV}_{365}$ Intensity, $\mathrm{UV}_{365}$ Exposure Time and Post-irradiation Incubation Time. 76

Table F. Percent Survival of $E$. coli to $\mathrm{UV}_{254}$ Disinfection $\left(0.16 \mathrm{~mW} / \mathrm{cm}^{2}\right) 30$ Does after Treated with $\mathrm{TiO}_{2} 20 \mu \mathrm{g} / \mathrm{L}, \mathrm{UV}_{365}\left(0.3 \mathrm{~mW} / \mathrm{cm}^{2}\right) 3$ Hours and Different Post-irradiation Incubation Time. 


\section{LIST OF FIGURES}

Figure 2.1. Potential Effects of Low-level Oxidative Stress Induced by Metal-oxide Nanoparticles on Microbial Resistance to Short UV (254 nm) Radiation........................ 8

Figure 3.1. Bioreactor with $1 \mathrm{~L}$ of Mixed Culture Grown over 4-5 Days.............................. 12

Figure 3.2. Overall Experimental Designs and Analyses Performed in This Research...... 13

Figure 3.3. Experimental Setup for Oxidative Treatment of Bacterial Cultures. ............... 14

Figure 3.4. Displaying of Flow Cytometry Image ........................................................ 16

Figure 3.5. Fecal Coliform Filtration Experiment Setup. .................................................... 18

Figure 3.6. Fecal Coliform Filtration Dish after Incubation at $45^{\circ} \mathrm{C}$ for 24 Hours............. 19

Figure 3.7. UV-disinfection Experiments to Characterize Microbial Resistance................ 22

Figure 4.1. Cytogram for (a) a Control Sample of the Mixed Culture and (b) a $\mathrm{TiO}_{2} / \mathrm{UV}_{365}$ (10 $\mu \mathrm{g} / \mathrm{L}$ Degussa P25, $0.6 \mathrm{~mW} / \mathrm{cm}^{2}$ for 19 Hours) Treated Sample. The Bacterial Populations were Stained with Syto9 (Green Fluorescence) and Propidium Iodide (Red Fluorescence) to Indicate Bacterial Viability. 27

Figure 4.2. Oxygen Utilization Rate (OUR) of a Mixed Culture Exposed to $\mathrm{TiO}_{2}$

Nanoparticles (Degussa, P25) with Concentration Ranging from 0-600 $\mu \mathrm{g} / \mathrm{L}$, Expose to $365 \mathrm{~nm}$ UV at $0.6 \mathrm{mw} / \mathrm{cm}^{2}$ for 2 Hours. 28

Figure 4.3. Oxygen Utilization Rate (OUR) of a Mixed Culture Exposed to $\mathrm{TiO}_{2}$

Nanoparticles (Degussa, P25) with Concentration Ranging from 0-2000 $\mu \mathrm{g} / \mathrm{L}$, Expose to $365 \mathrm{~nm} \mathrm{UV}$ at $0.6 \mathrm{mw} / \mathrm{cm}^{2}$ for 2 Hours. 29 
Figure 4.4. Viable Fecal Coliform Concentrations and Optical Density of the Mixed Culture Treated with Degussa P25 and $U_{365}$ at $0.6 \mathrm{~mW} / \mathrm{cm}^{2}$ for 2 Hours.

Figure 4.5. Oxygen Utilization Rate Values of the Mixed Culture Treated with Degussa $P 25$ and $U_{365}$ at $0.6 \mathrm{~mW} / \mathrm{cm}^{2}$ for 2 Hours. 32

Figure 4.6. Viable Fecal Coliform Concentrations and Optical Density of the Mixed Culture Treated with Degussa $P 25$ and $U_{365}$ at $0.6 \mathrm{~mW} / \mathrm{cm}^{2}$ for 19 Hours. 34

Figure 4.7. Oxygen Utilization Rate Values of the Mixed Culture Treated with Degussa $P 25$ and $U_{365}$ at $0.6 \mathrm{~mW} / \mathrm{cm}^{2}$ for 19 Hours. 35

Figure 4.8. Viable Fecal Coliform Concentrations and Optical Density of the Mixed Culture Treated with Degussa P25 and $\mathrm{UV}_{365}$ at $0.6 \mathrm{~mW} / \mathrm{cm}^{2}$ for 19 Hours.

Figure 4.9. Oxygen Utilization Rate Values of the Mixed Culture Treated with Sunscreen $\mathrm{TiO}_{2}$ Nanoparticles and $\mathrm{UV}_{365}$ at $0.6 \mathrm{~mW} / \mathrm{cm}^{2}$ for 19 Hours. 38

Figure 4.10. Total Bacterial Population (Upper Whisker Boxes), and Intact Cell Membrane Population (Lower Whisker Boxes) of the Mixed Culture Samples Treated with Different $\mathrm{TiO}_{2}$ (Degussa, P25) Concentration and $365 \mathrm{~nm} \mathrm{UV}\left(0.6 \mathrm{~mW} / \mathrm{cm}^{2}\right)$ for 2 Hours.

Figure 4.11. Total Bacterial Population (Upper Whisker Boxes), and Intact Cell Membrane Population (Lower Whisker Boxes) of the Mixed Culture Samples Treated with Different $\mathrm{TiO}_{2}$ (Degussa, P25) Concentration and $365 \mathrm{~nm} \mathrm{UV}\left(0.6 \mathrm{~mW} / \mathrm{cm}^{2}\right)$ for 19 Hours. 43

Figure 4.12. Total Bacterial Population (Upper Whisker Boxes), and Intact Cell Membrane Population (Lower Whisker Boxes) of the Mixed Culture Samples Treated 
with Different $\mathrm{TiO}_{2}$ (Sunscreen nanopartical) Concentration and $365 \mathrm{~nm} \mathrm{UV} \mathrm{(0.6}$

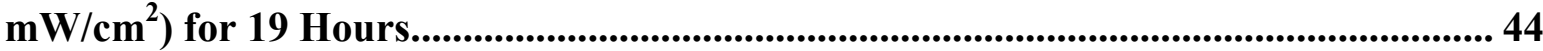

Figure 4.13. E. coli Cells Sort from Intact Cell Portion Recognized by Flow Cytometry and Grow in LB Agar Plate for 24 Hours. 45

Figure 4.14. Log-inactivation of Fecal Coliforms as a Result of UV Disinfection (254 nm) for a Control and a Sample Treated with $\mathrm{UV}_{365}$ at $0.6 \mathrm{~mW} / \mathrm{cm}^{2}$ and (a) $20 \mu \mathrm{g} / \mathrm{L}$ and (b) $5 \mu \mathrm{g} / \mathrm{L}$ of Degussa P25 for 19 Hours 47

Figure 4.15. Values of $\Delta S$ for the Mixed Culture after Treatment of $U V_{365}$ at $0.6 \mathrm{~mW} / \mathrm{cm}^{2}$ and a Range of Degussa P25 and Sunscreen Nanoparticle Concentration for 19 Hours.

Figure 4.16. Values of $\Delta S$ for the Mixed Culture after Treatment of $U V_{365}$ at $0.6 \mathrm{~mW} / \mathrm{cm}^{2}$ and $5 \mu \mathrm{g} / \mathrm{L}$ of Degussa P25 for Various Exposure Times. 50

Figure 4.17. Intracellular ROS Level Indicated by Mean CM-H $\mathrm{H}_{2} \mathrm{DCF}$ Fluorescent Intensity after Exposure to $\mathrm{UV}_{365}$ at $0.6 \mathrm{~mW} / \mathrm{cm}^{2}$ and Degussa $\mathrm{P} 25$ for 2 Hours. 52

Figure 4.18. Intracellular ROS Level Indicated by Mean CM- $\mathrm{H}_{2} \mathrm{DCF}$ Fluorescent Intensity after Exposure to $\mathrm{UV}_{365}$ at $0.6 \mathrm{~mW} / \mathrm{cm}^{2}$ and Degussa P25 for 19 Hours. 53

Figure 4.19. Intracellular ROS Level Indicated by Mean CM- $\mathrm{H}_{2} \mathrm{DCF}$ Fluorescent Intensity after Exposure to $\mathrm{UV}_{365}$ at $0.6 \mathrm{~mW} / \mathrm{cm}^{2}$ and Sunscreen Nanoparticles for 19 Hours. . 54

Figure 4.20. (a) Log-inactivation and (b) Percent Survival of $E$. coli as a Result of $\mathbf{U V}_{254}$ Disinfection (intensity: $0.07 \mathrm{~mW} / \mathrm{cm}^{2}$, Dose: $30 \mathrm{~J} / \mathrm{m}^{2}$ ) for Control and Treated Samples with $\mathrm{UV}_{365}$ at $0.3 \mathrm{~mW} / \mathrm{cm}^{2}, 20 \mu \mathrm{g} / \mathrm{L}$ of Degussa P25 for 3 Hours and after 3hrs Post Irradiation Incubation. 
Figure 4.21. Percent Survival of E. coli from UV ${ }_{254}$ Disinfection (intensity: $0.07 \mathrm{~mW} / \mathrm{cm}^{2}$, dose: $30 \mathrm{~J} / \mathrm{m}^{2}$ ). The results are for a Control Culture (No Nanoparticles and $\mathrm{UV}_{365}$ ) and a Culture Treated with $\mathrm{TiO}_{2} 20 \mu \mathrm{g} / \mathrm{L}$ and $\mathrm{UV}_{365}\left(0.3 \mathrm{~mW} / \mathrm{cm}^{2}\right)$ for $3 \mathrm{Hours}$, Followed by Different Post-irradiation Incubation Times in a LB Medium at $37^{\circ} \mathrm{C} . .58$

Figure 4.22 Percent Survival of E. coli to UVC Irradiation (Dose: $30 \mathrm{~J} / \mathrm{m}^{2}$ ) of Offspring of a $\mathrm{TiO}_{2} / \mathrm{UVA}$ Treated Culture after 4-hour Post-treatment Incubation and of a Control Culture without UVC Irradiation after 4-hour Incubation.

Figure 4.23. Percent Survival of $E$. coli from UV ${ }_{254}$ Disinfection (Intensity: $0.07 \mathrm{~mW} / \mathrm{cm}^{2}$, Dose: $\mathbf{3 0 ~ J} / \mathrm{m}^{2}$ ). The Results are for a Control Culture (No Nanoparticles and $\mathrm{UV}_{365}$ ) and a Culture Treated with Different $\mathrm{TiO}_{2}$ Concentration and $\mathrm{UV}_{365}\left(0.3 \mathrm{~mW} / \mathrm{cm}^{2}\right)$ for 3 Hours, Followed by 4 Hours Post-irradiation Incubation Times in a LB Medium at $37^{\circ} \mathrm{C}$. 60

Figure 4.24. Growth Curve of $E$. coli for Control and Treated Samples after $\mathbf{U V}_{365}$ at 0.3

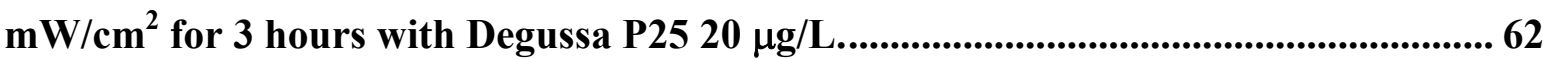

Figure 4.25. Percent survival of $E$. coli as a result of UV disinfection (254 nm, Dose: 20 $\left.\mathrm{mJ} / \mathrm{cm}^{2}\right)$ for control and $\mathrm{TiO}_{2} / \mathrm{UVA}$ treated samples $\left(7.5 \mu \mathrm{g} / \mathrm{L}, 0.7 \mathrm{~mW} / \mathrm{cm}^{2}\right.$ for 20 hours) with methanol $30 \mathrm{mM}$ or sodium azide $1 \mathrm{mM}$ 


\section{LIST OF NOMENCLATURE}

1. ROS - Reactive oxygen species

2. UVA - Long-wave ultraviolet radiation

3. UVC - Short-wave ultraviolet radiation

4. OUR - Oxygen utilization rate

5. BER - Base excision repair

6. NER - Nucleotide excision repair

7. SOD - Superoxide dismutase

8. PI - Propidium iodide

9. OD - Optical density

10. LB - Luria Bertani

11. PBS - Phosphate Buffered Saline

12. CFU - Colony-forming unit

13. MeOH - Methanol 


\section{CHAPTER 1: INTRODUCTION}

\subsection{Background}

Increased use of engineered nano-sized materials has raised concerns for their potential adverse impact on the environment and human health. In this regard, the number and quantity of nanomaterials have increased dramatically in recent years and the annual value for all nanotechnology-related products was estimated to be around \$ 1 trillion by 2011-2015 (National Science Foundation (NSF), 2001). The relatively small size and large specific area make these nano-sized materials more biologically active than their bulk materials and is projected to cause significant ecotoxicological effects in the environment (Oberdörster et al., 2005).

Engineered nanomaterials can enter wastewater via discharge of industrial effluents, washing off of the consumer products, and rainfall runoff. They can interact with and be concentrated by microbes via mechanisms such as sorption and uptake in environmental systems and potentially in hospital settings. Examples include biological systems for wastewater treatment, surface waters, bottom sediments of aquatic ecosystems, and biosolid disposal on farm and forestry lands.

Constant exposure of bacteria to increased amounts of nano-sized materials is highly likely to affect the microbes, including pathogens, in multiple ways. In particular, many engineered nanomaterials have been known to catalyze production of reactive oxygen species (ROS) in the presence of photo-energy. The reactive species are strong oxidants and known to show cytotoxic effects on microorganisms. Nanoparticle with concentration higher than $1 \mathrm{~g} / \mathrm{L}$ was used to inactivate microorganisms more efficiently. However, under low nanoparticle 
concentration, the introduced oxidative stress is not stronger enough to kill the bacteria. In response to the oxidative stress, microbial defense mechanisms can be triggered to protect microorganisms from the oxidative stress and its damages. Those mechanisms can potentially alter bacterial resistance to UV, a natural and engineered radiation source for inactivating microorganisms. This microbial cross-resistance could increase risks for human health; however, information of such effect is currently not well understood. This research aims to study such effect using engineered $\mathrm{TiO}_{2}$ nanoparticles as model nanomaterials.

\subsection{Objectives}

The scientific objective of this research is to determine the role of low-level engineered nanomaterials in inducing the enhanced bacterial resistance to UV irradiation. We hypothesized that low-level engineered nanoparticles will induce bacterial defense mechanisms that counteract the cytotoxic effect of UV irradiation on bacteria. Several tasks were performed in this research to study the objectives. For mixed culture, we did tasks on effect of oxidative stress on microbial activity and microbial resistance to short-wavelength UV, intracellular ROS level measurements, and sunscreen $\mathrm{TiO}_{2}$ nanopartical comparison. For pure culture, the effects of oxidative stress on microbial resistance to short-wavelength UV and effect of ROS scavengers on microbial resistance were performed. 


\section{CHAPTER 2: LITERATURE REVIEW}

\subsection{Engineered Nanometerials}

Production and uses of engineered nanomaterials in many areas of manufacturing and technologies, such as biomedicine, cosmetics, opto-electronic nanodevices, and composite materials have grown dramatically in recent years (Paull et al., 2003). The annual US federal investment in nanotechnology R\&D has expanded from \$464 million in 2001 to approximately \$1 billion in 2005 (USEPA, 2005). The annual value for all nanotechnologies-related products was estimated to be around \$ 1 trillion by 2011-2015 (NSF, 2001). Examples of the nanomaterials include metal-oxide nanoparticles in a wide variety of personal care and household products (e.g., sunscreen, cosmetics, paints, toothpaste), carbon nanotubes, quantum dots, fullerenes, and dendrimers (The Royal Society, 2004). Relatively small size and large specific surface area make these nano-sized materials more active biologically than bulk materials containing the same chemical constituents. The greater biological activity can either have positive (e.g., antioxidant activity) or negative (e.g., toxicity or induction of oxidative stress or cellular dysfunction) effects on living organisms (Oberdörster et al., 2005).

Many of these engineered nanomaterials enter wastewater via discharge of industrial effluents, washing off of the consumer products, and surface runoff (Daughton and Ternes, 1999). They can interact with and be concentrated by microbes via mechanisms such as sorption and uptake in environmental systems and potentially in hospital settings. Examples include biological systems for wastewater treatment, surface waters, bottom sediments of aquatic ecosystems, and biosolid disposal on farm and forestry lands. Constant exposure of bacteria to increased amounts 
of nano-sized materials is highly likely to affect the microbes, including pathogens, in multiple ways. Many of the engineered nanoparticles are known to generate reactive oxygen species (ROS) in the presence of oxygen and photo-energy, and can therefore impose oxidative stress to the microorganisms. Review of potential interacting mechanisms and their effects is summarized in the rest of this section.

\subsection{Potential Impacts of Engineered Nanomaterials}

\subsubsection{Effect of ROS}

Metal oxide particles, fullerenes, and carbon nanotubes (CNTs) have been found to catalyze the production of reactive oxygen species (ROS) in the presence of photo-energy and oxygen (Oberdörster et al., 2005; Yamokoshi et al., 2003; Srinivasan and Somasundaram, 2003). Excessive oxidative stress caused by ROS (e.g., hydroxyl radical (.OH), hydrogen peroxide $\left(\mathrm{H}_{2} \mathrm{O}_{2}\right)$, superoxide ion $\left(\mathrm{O}_{2}{ }^{-}\right)$and singlet oxygen $\left.\left({ }^{1} \mathrm{O}_{2}\right)\right)$ can lead to membrane lipid peroxidation and subsequent cell wall disruption (Kiwi and Nadtochenko, 2005; Coronado et al., 2005; Amézaga-Madrid et al., 2003; Sunada et al., 2003; Maness et al., 1999), enzyme inactivation (Haas and Engelbrecht, 1980), and DNA damage (Gort and Imlay, 1998; Keyer and Imlay, 1996). Susceptibility of cells to the oxidative stress depends on various factors. It was reported that efficacy of photocatalytic inactivation of microorganisms with metal-oxide materials was found to be very different depending on the specific microorganisms involved (Cho et al., 2005; Coronada et al., 2005; Rincón and Pulgarin, 2004a) and affected by metal-oxide concentration (Kim et al., 2003) and other dissolved constituents (Rincón and Pulgarin, 2004b). ROS can cause structural alterations in DNA, e.g. base pair mutations, rearrangements, deletions, insertions and sequence amplification. ROS also modulate the activity of the proteins and genes 
that respond to stress and which act to regulate the genes that are related to cell proliferation, differentiation and apoptosis (Wiseman, 1996).

\subsubsection{Response of Cells to ROS}

The response of cells to oxidative stress is a hierarchical process containing multiple lines of defense (Slupphaug et al., 2003). First, synthesis of superoxide dismutase (SOD) enzymes is one of the major defense mechanisms used by microbes against oxidation. The enzyme catalyzes the conversion of superoxide anions $\left(\bullet \mathrm{O}_{2}^{-}\right)$into highly reactive hydrogen peroxide $\left(\mathrm{H}_{2} \mathrm{O}_{2}\right)$ and molecular oxygen. Hydrogen peroxide can be further degraded by the enzyme catalase to oxygen and water molecules. Catalase, peroxidases, and glutathione peroxidase are synthesized to scavenge ROS too (Olga Blokhina et al. 2003).

Second, ROS can modify various DNA bases and more than 20 types of base damages have been identified (Fortini et al., 2003; Slupphaug et al., 2003; Seeberg et al., 1995). The most prevalent damage to purine is 7,8-dihydro-8-oxoguanine (8-oxoG) while the most common damage to pyrimidine is formation of thymine glycol (Slupphaug et al., 2003; Dizdaroglu, 1999). The oxidized DNA bases are essentially removed by two types of microbial defense activity as DNA repair mechanisms: base excision repair (BER) and nucleotide excision repair (NER). The base excision repair (BER) system recognizes and repairs oxidative damaged chromosomal DNA. Nucleotide excision repair (NER) involves a protein complex, which probably recognizes the relatively large structural changes caused by UV damage in DNA (Lehmann, 1995). BER is one of the principal pathways of DNA repair responsible for replacement of modified nucleotides and restoration of spontaneous apurinic/apyrimidinic sites. NER is present from bacteria to humans and plays a critical role in protecting cells from a variety of DNA-damaging agents since 
it can recognize a broad range of DNA lesions, including ionizing radiation-induced purine damage, ROS-induced base loss, and UV-induced pyrimidine dimmers (Sancar and Tang, 1993).

Third, ROS can modulate the activity of the proteins and genes that respond to the oxidative stress and act to regulate the genes that are related to cell proliferation, differentiation and apoptosis (Wiseman and Hallinwell, 1996).

Finally, a rise in ROS levels may also constitute a stress signal that activates specific redox-sensitive signaling pathways, which may have either damaging or potentially protective functions (Finkel and Holbrook, 2000). In this regard, Kim et al. (2004) reported enhanced proliferation of SOD-deficient mutant of Escherichia coli under sublethal oxidative stress induced by photoexcited $\mathrm{TiO}_{2}$. The phenomenon was attributed to an up-regulated expression of specific genes (Kim et al., 2005).

\subsubsection{Microbial Defense System}

Due to the fact that large amounts of wastewater generated each day, nanoparticles are expected to be present in wastewater at relatively low levels. However, low-level oxidative stress caused by metal-oxide nanoparticles in wastewater may cause sublethal effect and/or trigger microbial defense mechanisms as described above. The microbial defense mechanisms against oxidative stress induced by engineered nanomaterials can potentially alter microbial physiology and enzymatic activities; equip microbes, including pathogens, with ability to counteract the stress and DNA damages caused by UVC irradiation. Microbial inactivation with germicidal UV primarily relies on induction of mutagenic and cytotoxic DNA lesions as a result of absorption of photo-energy of the UV radiation. Two of the most abundant lesions are cyclobutane pyrimidine dimers (CPDs) and pyrimidine pyrimidone photoproducts (6-4 PPs) 
(Härder and Sinha, 2005; Yoon et al., 2000). UVC also can cause damages to bacteria by producing ROS. Wei and Cai (1997) reported that ${ }^{1} \mathrm{O}_{2}$ and $\cdot \mathrm{OH}$, are the important mediators in UVC-induced oxidative damage to purified DNA. UVC may also involve ROS such as hydrogen peroxide $\left(\mathrm{H}_{2} \mathrm{O}_{2}\right)$ or singlet oxygen $\left({ }^{1} \mathrm{O}_{2}\right)$ in causing oxidative damages (Gomes, 2005; Zhang, 1997). In response to the DNA damage, repair mechanisms such as BER and NER similar to those that repair DNA damages caused by ROS can be triggered (Kaur and Doetsch, 2000; Shiota and Nakayama, 1997), in addition to other mechanisms such as photoreactivation (Oguma et al., 2002). These repair processes involve glycosylase or polymerase enzymes (Härder and Sinha, 2005).

Several mechanisms and sequences of actions may induce microbial resistance to UV disinfection. First, low-level oxidative stress by metal-oxide nanoparticles may become a selection process of more oxidant-tolerant species at microbial community level. Second, DNA base modification caused by ROS may result in lower absorption of photo-energy of the germicidal UV radiation, thereby affecting the disinfection efficiency. Subtle alterations in structure of the DNA molecules (e.g., tautomeric changes) can have a large effect on the absorption (Jagger, 1967). Third, the up-regulated enzymes that counteract ROS oxidative stress and repair DNA damages can potentially protect the cells from UV irradiation. All these mechanisms can possibly lead to higher survival rate of microorganisms, including pathogens, from UV irradiation. Figure 2.1 illustrates the mechanisms discussed above. 


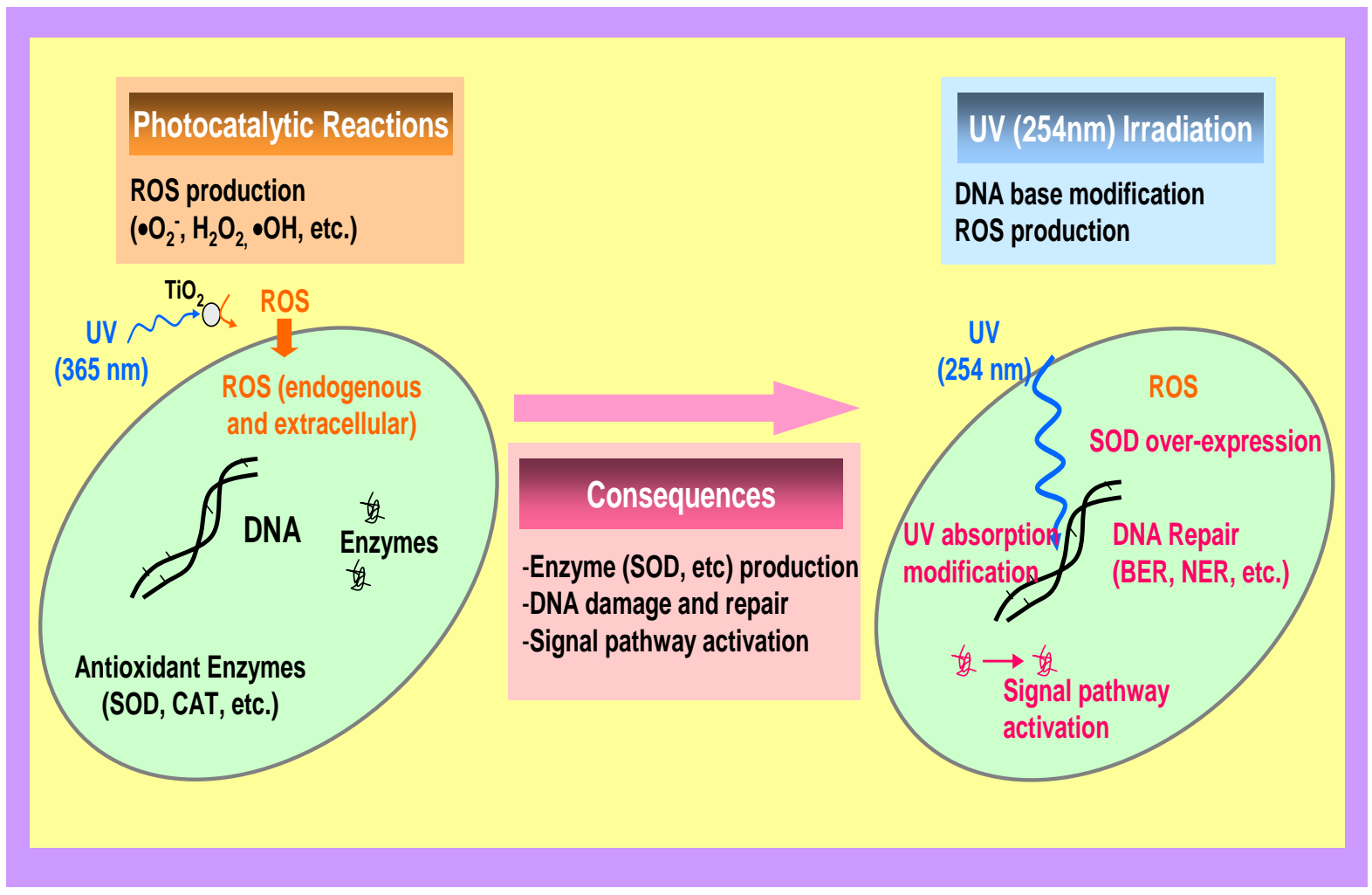

Figure 2.1. Potential Effects of Low-level Oxidative Stress Induced by Metal-oxide Nanoparticles on Microbial Resistance to Short UV (254 nm) Radiation. 


\section{CHAPTER 3: METHODS AND MATERIALS}

\subsection{Model Nanoparticles}

Engineered $\mathrm{TiO}_{2}$ nanoparticles, Degussa P25 (average primary size $21 \mathrm{~nm}$, ca. $80 \%$

anatase and $20 \%$ rutile, BET surface area ca. $50 \mathrm{~m}^{2} / \mathrm{g}$ ) and $\mathrm{TiO}_{2}$ nanoparticles extracted from a commercial sunscreen product (Bullfrog, kids UV defender, spf40, $\mathrm{TiO}_{2} 4.5 \%$ ) were used as model nanoparticles in this study. The extraction was performed according to Dunford et al. (1997). Briefly, the sunscreen containing $\mathrm{TiO}_{2}$ nanoparticles was mixed with de-ionized water, vortexed, and centrifuged at 5,000 $\mathrm{xg}$ for 4 minutes to obtain a nanoparticle pellet. The white pellet was washed 3 times with a mixture of chloroform and methanol (1:1), and then washed once with methanol alone. After each wash, the mixture was centrifuged to separate the nanoparticles from the solvent, re-suspend in wash solution and vortexed. The white pellet after the final wash was mixed with de-ionized water to obtain $\mathrm{TiO}_{2}$ suspension. Nanoparticle concentration was estimated based on the volume of sunscreen extracted and labeled $\mathrm{TiO}_{2}$ concentration $(4.5 \%)$ in the sunscreen product.

\subsection{Mixed Culture Preparation}

An inoculum culture was first prepared by adding $0.8 \mathrm{~g}$ (dry weight) of the seed inoculum material (BI-CHEM DC 2010 XL, Novozymes Biologicals, Inc.) to 0.1 L of a dilution culture medium. The inoculum material contains 10 - 15 non-pathogenic bacterial species commonly found in wastewater, including both rods and cocci. The dilution culture medium was prepared by adding $1 \mathrm{~mL}$ of each of the following solutions per liter of de-ionized water: phosphate buffer 
solution (PBS), magnesium sulfate (0.2 M), calcium chloride $(0.25 \mathrm{M})$, and ferric chloride $(1.5 \times$ $\left.10^{-3} \mathrm{M}\right)$ (APHA, 1998). The inoculum culture was then stirred for 1 hour followed by 15 minutes without mixing to allow sedimentation of bran materials. A 1 L Erlenmeyer flask was filled with $1 \mathrm{~L}$ dilution culture medium and $10 \mathrm{~mL}$ seed inoculum solution to start up a bioreactor. The bioreactor as in Figure 3.1 was continuously aerated using an air diffuser and fed with a synthetic wastewater solution prepared with peptone, meat extract (Oxoid Ltd., Hampshire, UK), urea, $\mathrm{NaCl}, \mathrm{CaCl}_{2} \cdot 2 \mathrm{H}_{2} \mathrm{O}, \mathrm{MgSO}_{4} \cdot 7 \mathrm{H}_{2} \mathrm{O}, \mathrm{K}_{2} \mathrm{HPO}_{4}$, and $\mathrm{KH}_{2} \mathrm{PO}_{4}$ (USEPA, 1996). The bioreactor was allowed to stabilize at room temperature for $4-5$ days before the mixed culture was taken for experiments. Figure 3.2 illustrates the design of the experiments and analyses conducted to achieve the study objective.

\subsection{Oxidative Stress Exposure}

A series of $10 \mathrm{~mL}$ mixed culture sub-samples taken from the bioreactor were held in shallow quartz dishes and placed on a 5-position magnetic stirrer to provide mixing. Each dish received different amounts of the $\mathrm{TiO}_{2}$ nanoparticles and was covered with a thin quartz plate with small openings on the sides to minimize evaporation during extended exposure periods while allowing air exchange. As in Figure 3.3, control one was kept in dark, which didn't expose to $\mathrm{UV}_{365}$ light. Periodic feeding of the synthetic wastewater to the dishes was performed to sustain bacterial growth. A UV lamp (UVP Inc., CA) that predominantly emits UV at $365 \mathrm{~nm}$ was used as a source of long-wavelength UV to produce ROS by $\mathrm{TiO}_{2}$-facilitated photocatalytic reactions. The degree of oxidative stress exposure was controlled by $\mathrm{TiO}_{2}$ concentration and exposure time. Nanoparticle concentration ranged from 0 to $20 \mu \mathrm{g} / \mathrm{L}$ and exposure time ranged 
from 2 to 24 hours. $\mathrm{UV}_{365}$ intensity was measured with a UV detector (International Light, SEL005) and a radiometer (International Light, IL1400A). 


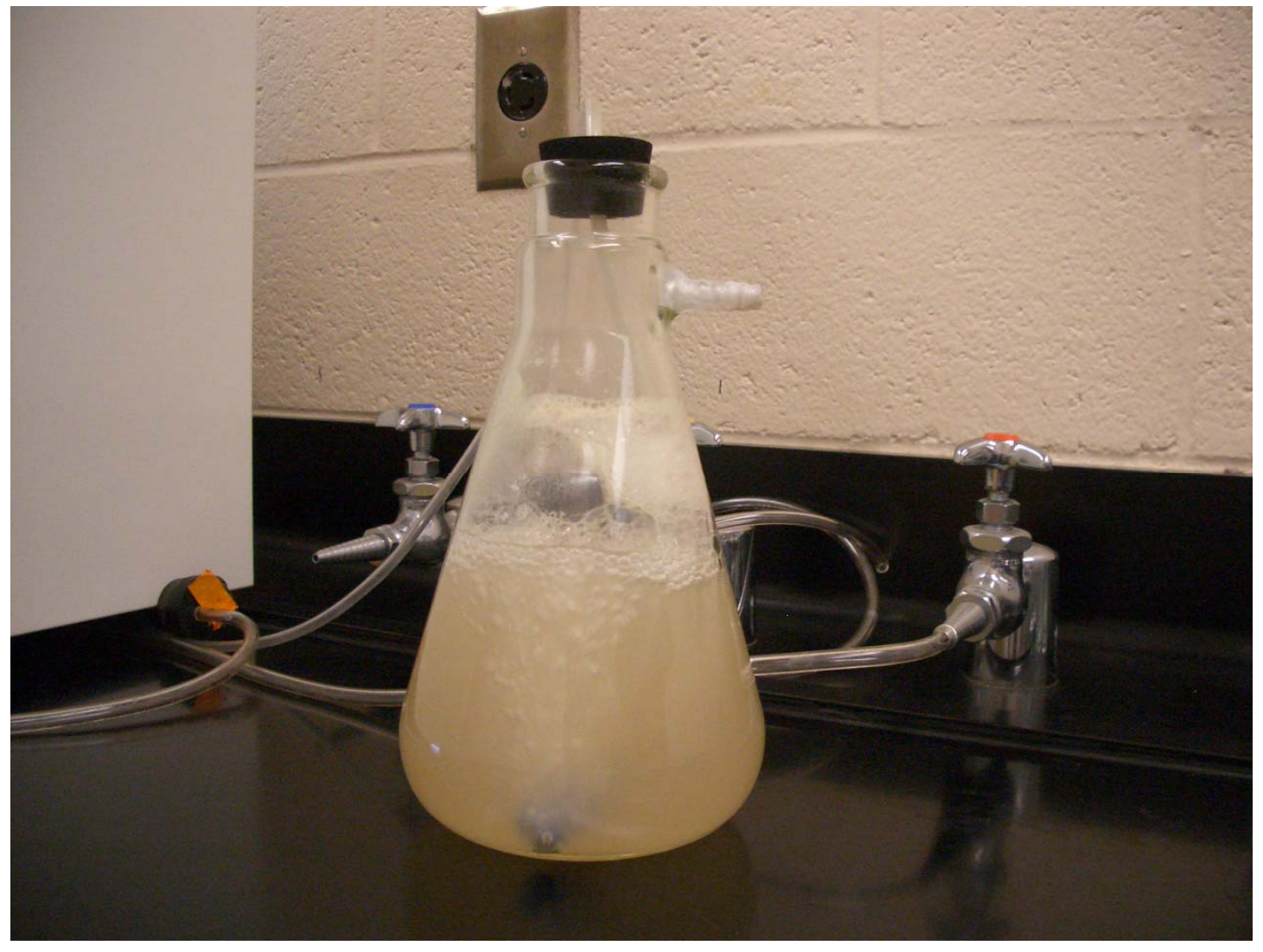

Figure 3.1. Bioreactor with $1 \mathrm{~L}$ of Mixed Culture Grown over 4-5 Days. 


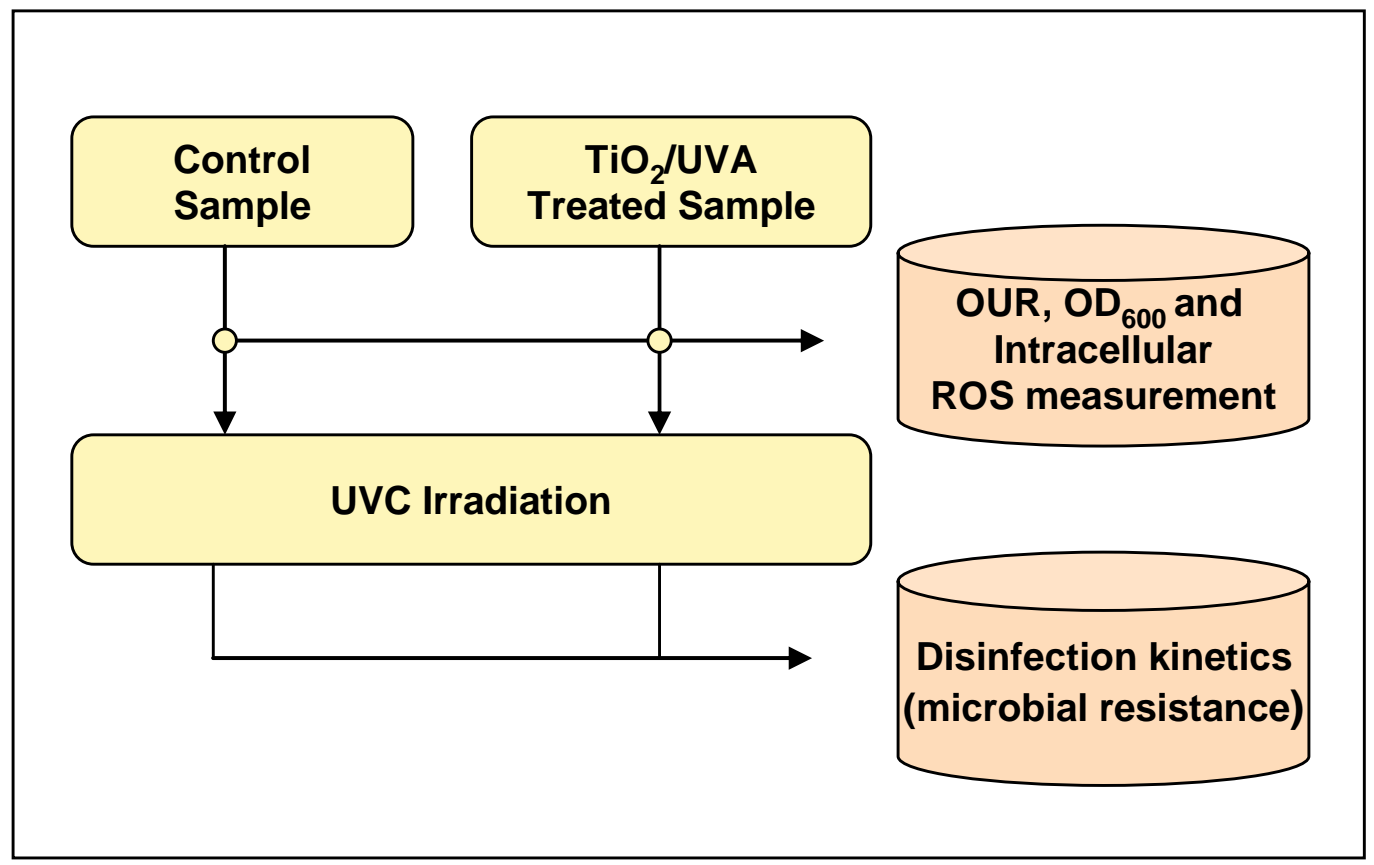

Figure 3.2. Overall Experimental Designs and Analyses Performed in This Research. 


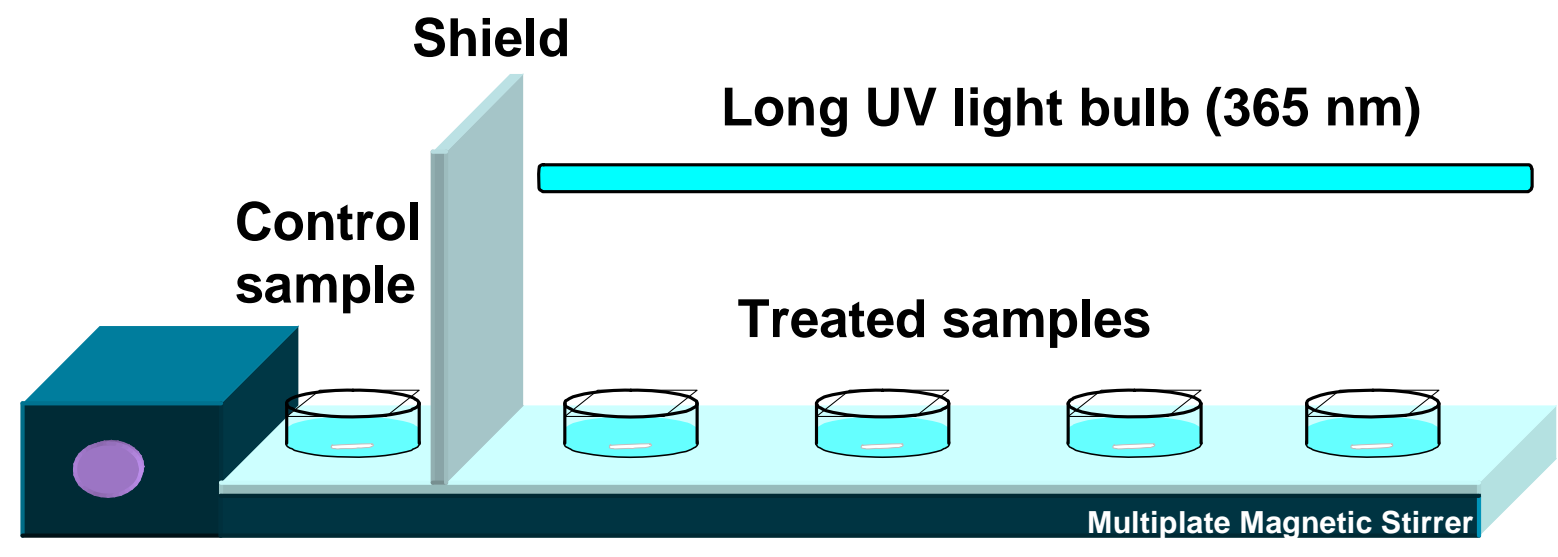

Figure 3.3. Experimental Setup for Oxidative Treatment of Bacterial Cultures. 


\subsection{Oxygen Utilization Rate Measurement}

The effect of oxidative stress on microbial activity was monitored by oxygen utilization rate (OUR) measurements with a biological oxygen monitor (Analytical Technologies, YSI 5300A). The monitor is equipped with a temperature-control batch assembly that hosts three sample chambers which are maintained at $20^{\circ} \mathrm{C}$ with water circulation. For each OUR measurement, a $3 \mathrm{ml} \mathrm{sub-sample} \mathrm{was} \mathrm{withdrawn} \mathrm{from} \mathrm{a} \mathrm{quartz} \mathrm{dish} \mathrm{and} \mathrm{transferred} \mathrm{to} \mathrm{a} \mathrm{sample}$ chamber. The sample was mixed for 1 minute with a stirrer and an oxygen probe was then inserted into this sample chamber to record the oxygen content at the beginning and end of the predetermined period (e.g., 20 seconds) to calculate OUR. The measurements were conducted in triplicate.

\subsection{Cell Enumeration and Viability Characterization}

Flow cytometry (Becton-Dickinson, FACSCalibur) was used to enumerate the bacteria's population and assess membrane integrity. The mixed culture samples were first diluted 1:10 with PBS. To a $500 \mu \mathrm{L}$ diluted sample, $0.2 \mu \mathrm{L}$ of Syto9 (green fluorescence) and $2 \mu \mathrm{L}$ propidium iodide (PI, red fluorescence) dyes were used to stain the bacteria. The Syto9 molecule binds to nucleic acids and its green fluorescence indicates organisms containing nucleic acids. The propidium iodide molecule only binds to nucleic acids of bacteria with damaged cell membrane. Therefore, PI is excluded from cells that retain intact cell membrane (Figure 3.4) (Nebe-von, 1995). 


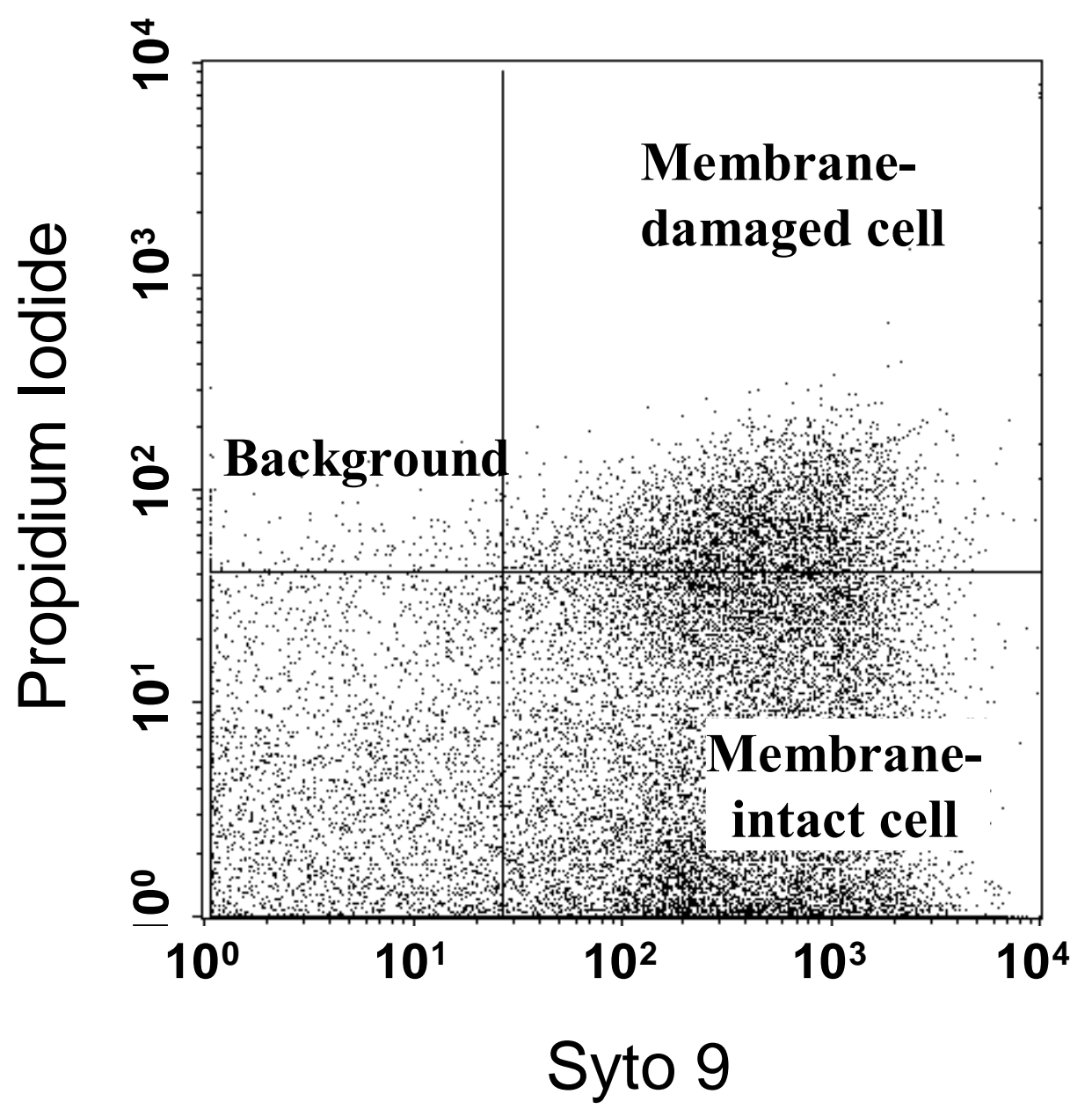

Figure 3.4. Displaying of Flow Cytometry Image 
The UV-Vis spectrophotometer (Varian, Cary 50 Series) was used to measure optical density at $600 \mathrm{~nm}\left(\mathrm{OD}_{600}\right)$, which corresponds to the total cell number. Higher absorption data detect at $600 \mathrm{~nm}$ indicates higher cell density. In addition, fecal coliforms were used as a model organism to indicate cell viability. Fecal coliform concentrations were determined by membrane filtration (Figure 3.5) (Standard Methods 9222 D, Fecal Coliform Membrane Filter Procedure and petri dish cultivation (APHA 1998)). Briefly, a presterilized membrane was loaded on a filter holder support base with grid-side facing up followed by pouring $20 \mathrm{~mL}$ of sterile buffer into the funnel and vacuuming the filter. A $20 \mathrm{~mL}$ of sterile buffer solution $\left(\mathrm{KH}_{2} \mathrm{PO}_{4} 0.3 \mathrm{mM}, \mathrm{MgCl}_{2}\right.$ $2 \mathrm{mM}, \mathrm{pH} 7.2)$ into the funnel, followed by adding sample $(10 \mu \mathrm{L}, 100 \mu \mathrm{L}$ or $1 \mathrm{~mL})$, and vacuuming the filter. Rinse the funnel walls with the sterile buffer. The membrane filter was then removed using sterilized forceps and transferred immediately to prepared Petri dishes with broth medium. The Petri dish cultures were incubated at $45^{\circ} \mathrm{C}$. Fecal colonies formed (Figure 3.6) which have blue color were enumerated after 24 hours incubation. The disinfection resistance was examined by log-inactivation of fecal coliform counts, $\log \left(N / N_{0}\right)\left(N_{0}\right.$ is the fecal coliform counts at zero $\mathrm{UV}_{254}$ dose, $\mathrm{CFU} / 100 \mathrm{~mL}$ ), as a function of $\mathrm{UV}_{254}$ dose. 


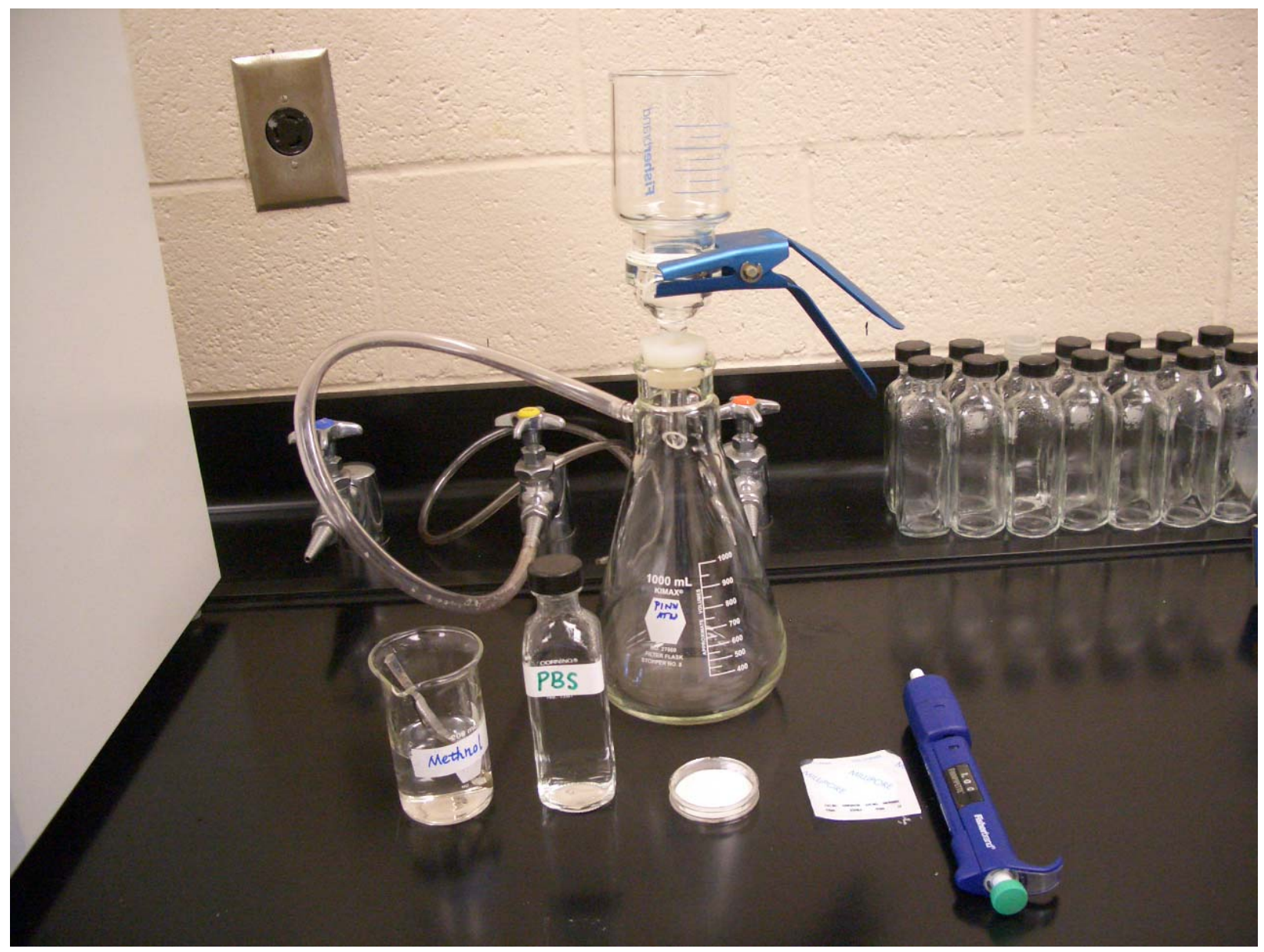

Figure 3.5. Fecal Coliform Filtration Experiment Setup. 


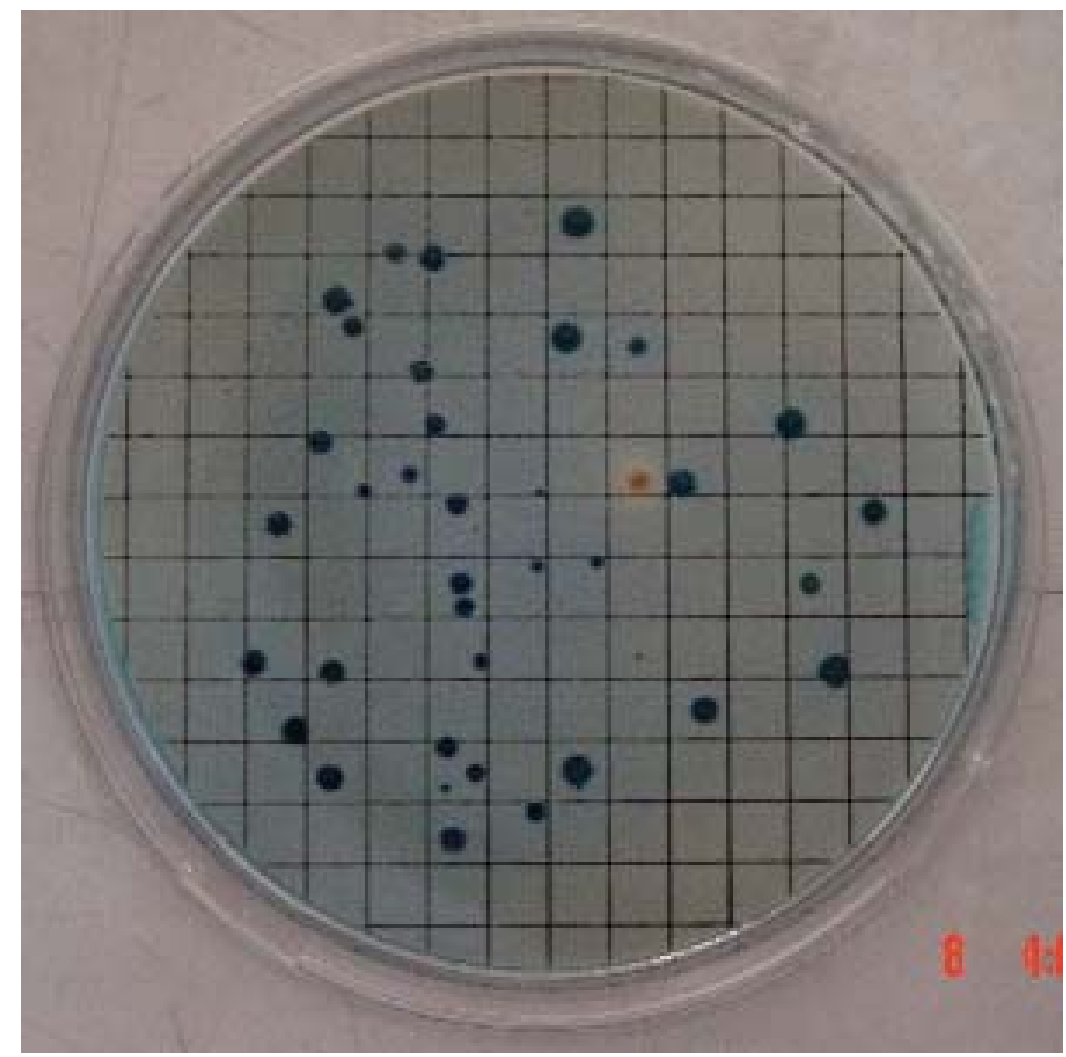

Figure 3.6. Fecal Coliform Filtration Dish after Incubation at $45^{\circ} \mathrm{C}$ for $24 \mathrm{Hours.}$ 


\subsection{Cell Sorting and Cultivation}

To complement the use of flow cytometry analysis for bacterial viability, a pure culture of E. coli (DH10B) were sorted onto nutrient agar plates and incubation for colony counts. A pure culture of E. coli was grown in LB broth in a shaker incubator at $37^{\circ} \mathrm{C}$ and $150 \mathrm{rpm}$ overnight. The cells were then centrifuged at 5,000 rpm for 2 minutes, washed, and resuspension in $0.1 \mathrm{M}$ PBS $(\mathrm{pH}=7)$. The $E$. coli cells were exposure to $\mathrm{UV}_{365}\left(0.6 \mathrm{mw} / \mathrm{cm}^{2}\right) / \mathrm{TiO}_{2}$ $(200 \mu \mathrm{g} / \mathrm{L})$ for 5 hours. Syto9 and PI were added to the samples as in section 3.5. During the flow cytometry analysis, cells were sorted base on Syto9 and PI fluorescence signals using a BD FACSAria high speed bench top cell sorter. In our analysis, 44 single "membrane-intact" and 44 single "membrane-damaged" cells were sorted onto the LB agar plates. The total number of grown colonies from the "membrane-intact" plates and "membrane-damaged" plates were counted after incubate at $37^{\circ} \mathrm{C}$ for 24 hours, and compared to the total number of cells sorted (44) to obtain a viable percentage.

\subsection{Microbial Resistance Characterization}

Both control sample and treated samples were subjected to UVC irradiation to characterize microbial resistance to UV disinfection. A collimated UV beam unit that house a low-pressure mercury lamp (Atlantic Ultraviolet Corp., NY) was used as a source of UV radiation at $254 \mathrm{~nm}$ (Figure 3.7 ). The $\mathrm{UV}_{254}$ intensity was measured with a detector (International Light Inc., SEL240) and a radiometer (International Light Inc., IL1400A). UV dose examined in this study ranged from 0 to $40 \mathrm{~mJ} / \mathrm{cm}^{2}$. For each of the doses, a $2 \mathrm{~mL}$ sample of the control and $\mathrm{TiO}_{2} / \mathrm{UV}_{365}$ treated samples was transferred to a shallow quartz dish and exposed to the collimated UV beam with mixing for a predetermined exposure time, $t$, to obtain 
the desired dose. Given that $\mathrm{UV}_{254}$ inactivation of bacteria mostly relies on photoproduction of pyrimidine dimers, the flow cytometry analysis with syto9 and PI does not allow effective quantification of microbial inactivation by $\mathrm{UV}_{254}$. Instead, fecal coliform concentrations, $N$ (CFU/100mL), determined by membrane filtration and petri dish cultivation (APHA, 1998) were used as a model organism for the mixed culture in the resistance study. The disinfection resistance was examined by log-inactivation of fecal coliform counts, $\log \left(N / N_{0}\right)\left(N_{0}\right.$ is the fecal coliform counts at zero $\mathrm{UV}_{254}$ dose, $\mathrm{CFU} / 100 \mathrm{~mL}$ ), as a function of $\mathrm{UV}_{254}$ dose. 


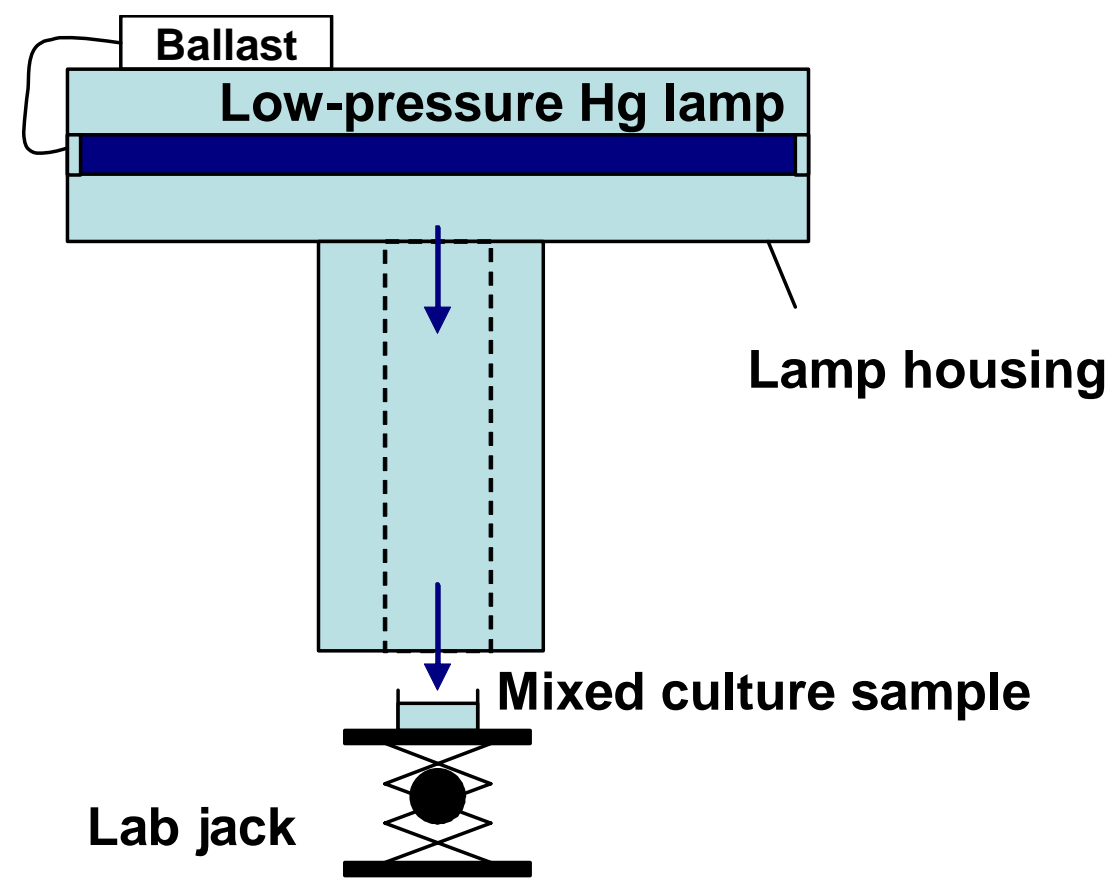

Figure 3.7. UV-disinfection Experiments to Characterize Microbial Resistance. 


\subsection{Intracellular ROS Level Measurement}

A sub-sample $(0.5 \mathrm{~mL})$ of the mixed culture was transferred to a microcentrifuge tube and centrifuged at $10,000 \mathrm{xg}$ for 4 minutes to obtain a microbial pellet, followed by removing the supernatant, adding $3 \mathrm{~mL}$ of PBS, and then vortex to resuspend the microbial pellet. A freshly made stock solution of 5-(and-6)-chloromethyl-2', 7'-diclorofluorescin diacetate (CM- ${ }_{2}$ DCFDA, Invitrogen Inc. C-6827) in ethanol was then added to the microbial suspension to obtain a final concentration of $9 \mu \mathrm{M}$ of the chemical, followed by incubation at $37^{\circ} \mathrm{C}$ for 1 hour according to Kim et al. (2004). CM- $\mathrm{H}_{2}$ DCFDA is a cell-permeant indicator for ROS that is nonfluorescent until removal of the acetate groups by intracellular esterase and oxidation by ROS. The flow cytometer was used to quantify the resulting fluorescence intensity of the suspension solution with excitation and emission wavelengths at $488 \mathrm{~nm}$ and $525 \mathrm{~nm}$, respectively. The emission fluorescence intensity was then used to reflect intracellular ROS level.

\subsection{Microbial Resistance of Pure Culture}

Escherichia coli (DH10B) culture was used as a pure model culture to elucidate bacterial resistance to UV irradiation. A pure E. coli culture grown in LB broth overnight in a shaker (150 rpm) at $37^{\circ} \mathrm{C}$ was centrifuged and resuspend in $0.1 \mathrm{M} \mathrm{PBS}(\mathrm{pH}=7)$ to avoid any interference of organic molecules with UVA radiation. The E. coli was diluted in PBS until an optical density $\left(\mathrm{OD}_{600}\right)$ of $0.4-0.6$ was reached. The sample was treated with oxidative stress caused by UVA (365 nm, UVP, XX-40BLB) at $0.3 \mathrm{~mW} / \mathrm{cm}^{2}$ and $\mathrm{TiO}_{2}$ nanoparticles at concentrations $20 \mu \mathrm{g} / \mathrm{L}$. In addition, a culture sample without nanoparticles was kept in the dark to serve as a control. Another culture without nanoparticles was exposed to UVA for comparison. After exposure to UVA for 3 hours, the three samples were centrifuged, transfer to LB broth and keep in shaker 
$\left(150 \mathrm{rpm}, 37^{\circ} \mathrm{C}\right)$ for 3 hours to allow for induction of microbial activities that counteract the oxidative stress. They were then subjected to UVC irradiation as described above for the mixed culture to characterize microbial resistance to UVC disinfection. The dependence of oxidative stress-induced resistance to UVC disinfection on post-treatment incubation time was examined too. Samples were taken out from control and UVA/TiO 2 treated sample at post-treatment incubation time 0-hour, 2-hour, 4-hour, 6-hour and 8-hour to investigate their microbial resistance to UVC. We also study the effect of nanoparticle concentration on the resistance of E. coli to UVC disinfection. Similar to above experiment process, treated samples in PBS with different $\mathrm{TiO}_{2}$ concentration up to $80 \mu \mathrm{g} / \mathrm{L}$ were exposure to UVA $\left(0.3 \mathrm{~mW} / \mathrm{cm}^{2}\right)$ for 3 hours, transfer to LB broth and incubation in shaker for 4 hours. Then they were subjected to UVC irradiation to examine resistant ability.

\subsection{Growth Delay Effect of Pure Culture}

To study UVA induced growth delay, growth curve for both control and treated E. coli cultures was developed. The E. coli cells grown overnight in LB broth were transferred to $0.1 \mathrm{M}$ PBS. The cultures kept in dark, treated with UVA only and treated with $\mathrm{UVA} / \mathrm{TiO}_{2}$ were reincubated in the nutrient medium and allowed to grow with shaking $(150 \mathrm{rpm})$ at $37^{\circ} \mathrm{C}$ after irradiated by UVA at $0.3 \mathrm{~mW} / \mathrm{cm}^{2}$ for 3 hours. Samples were taken every half hour to $\mathrm{OD}_{600}$ measurements.

\subsection{Effect of ROS Scavengers on Microbial Resistance}

The E. coli culture in a LB medium were transferred to four shallow dishes, one control and three treated containing $7.5 \mu \mathrm{g} / \mathrm{L}$ Degussa P25. Two of the nanoparticle-containing cultures 
were added with methanol $(\mathrm{MeOH}, 30 \mathrm{mM})$ and sodium azide $\left(\mathrm{NaN}_{3}, 1 \mathrm{mM}\right)$ separately to eliminate mostly hydroxyl radical and singlet oxygen, respectively during the oxidative treatment. After exposure to UVA intensity $0.7 \mathrm{mw} / \mathrm{cm}^{2}$ for 20 hours, the four treated samples were centrifuged and re-suspended in a LB medium to remove possible effect of methanol and sodium azide during the subsequent UVC irradiation. The bacterial suspensions were then subjected to $20 \mathrm{~mJ} / \mathrm{cm}^{2}$ of UVC irradiation. 


\section{CHAPTER 4: RESULTS AND DISCUSSION}

\subsection{Mixed Culture Characterization}

Figure 4.1 shows a cytogram for a control microbial population and a $\mathrm{TiO}_{2} / \mathrm{UV}_{365}$ treated population from the flow cytometry analysis. Bacteria with high syto9 and low PI intensities are considered cells with intact membranes (lower right quadrant). The upper right quadrant contains cells with damaged membrane. Responses that appear in the two left quadrants are assumed to be attributable to particles lacking nucleic acids; these could include inorganic particles or debris from the synthetic wastewater and small bran particles from the seed inoculum. Quadrants are applied to control and treated samples to allow direct comparison between them and study the treatment effects. The cytograms show an increased bacterial population in upper right quadrant with the treated sample, indicating the effect of the oxidative treatment on membrane integrity.

\subsection{Effect on Microbial Activity and Viability}

Figure 4.2 and 4.3 show the effect of oxidative stress on OUR after the treatment of $\mathrm{TiO}_{2}$ nanoparticles (Degussa, P25) and UVA at $0.6 \mathrm{~mW} / \mathrm{cm}^{2}$ for 2 hours. The results show a decrease in OUR (measured in triplicates) starting at $500 \mu \mathrm{g} / \mathrm{L}$ of the nanoparticles (Figure 4.2). A separate set of measurements for a wider concentration range shows a slightly further decrease in the OUR value at $2000 \mu \mathrm{g} / \mathrm{L}$ compared to $500 \mu \mathrm{g} / \mathrm{L}$ (Figure 4.3). This indicates that $\mathrm{TiO}_{2}$ can affect bacterial activity and the degree of damage was enlarged by the higher $\mathrm{TiO}_{2}$ concentrations. The results show that the 2-hour exposure did not cause significant effect on OUR for concentrations below $400 \mu \mathrm{g} / \mathrm{L}$. 


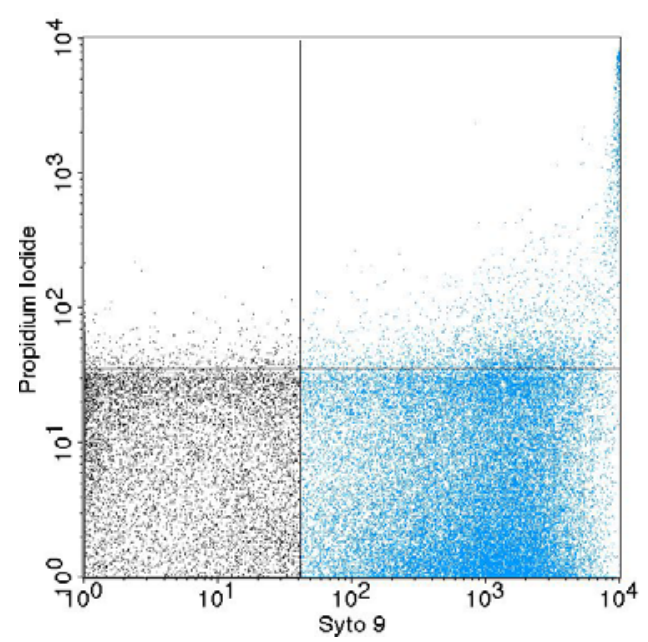

(a)

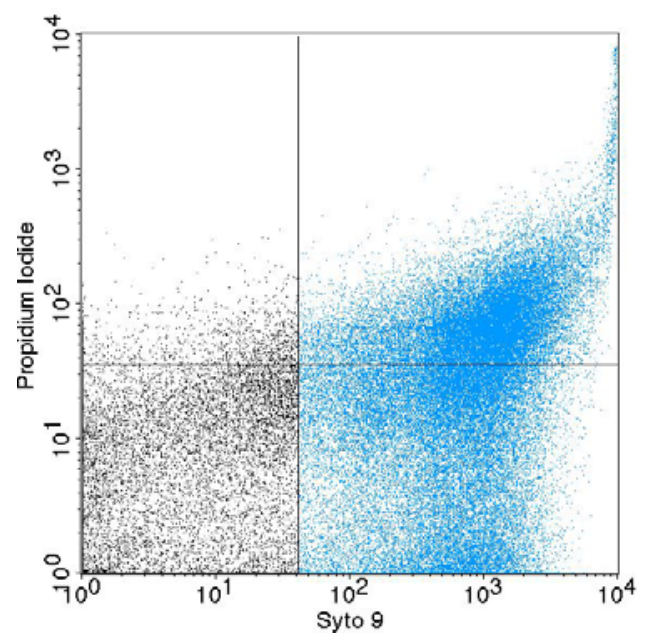

(b)

Figure 4.1. Cytogram for (a) a Control Sample of the Mixed Culture and (b) a $\mathrm{TiO}_{2} / \mathrm{UV}_{365}$ (10 $\mu \mathrm{g} / \mathrm{L}$ Degussa P25, $0.6 \mathrm{~mW} / \mathrm{cm}^{2}$ for 19 Hours) Treated Sample. The Bacterial Populations were Stained with Syto9 (Green Fluorescence) and Propidium Iodide (Red Fluorescence) to Indicate Bacterial Viability. 


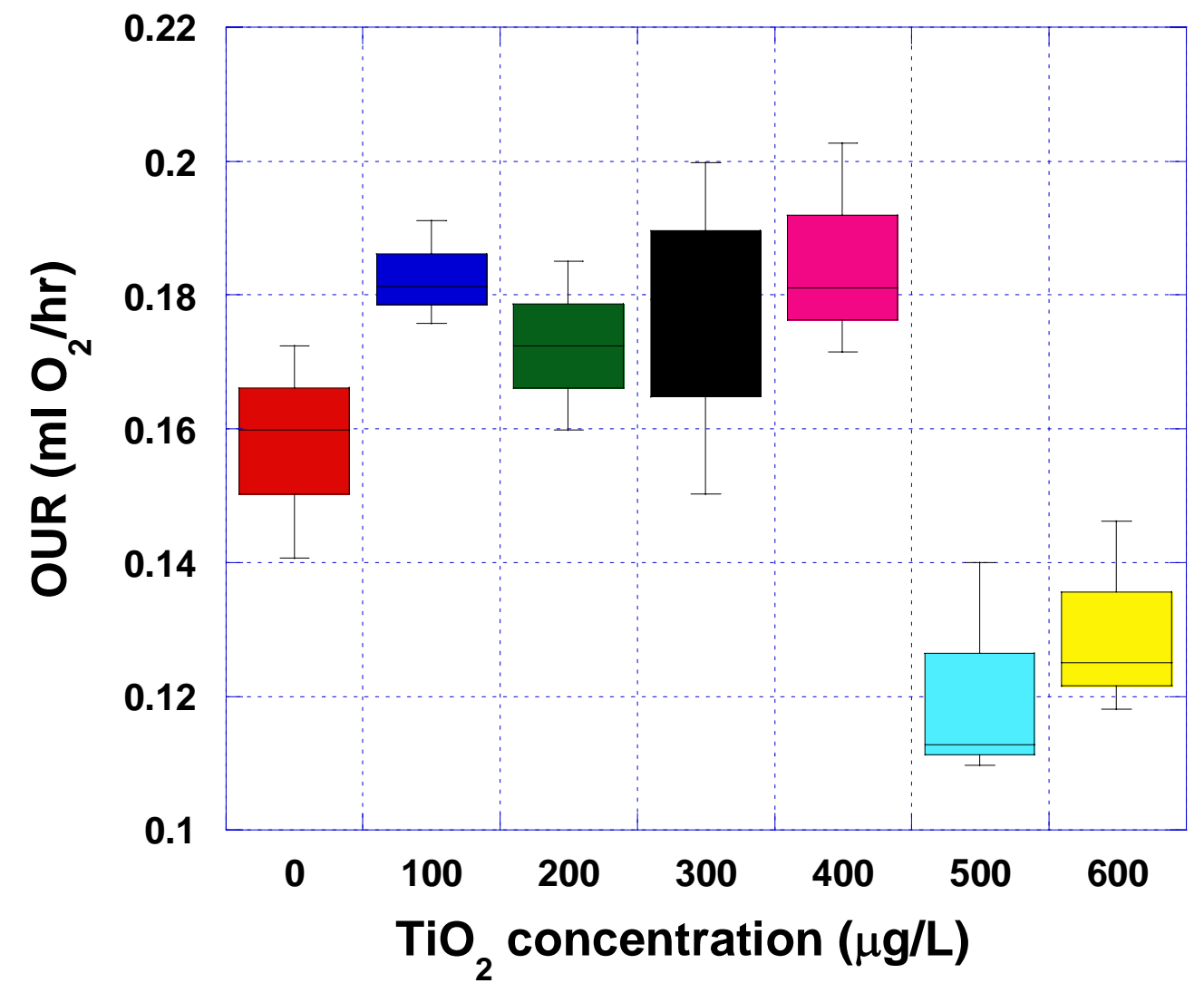

Figure 4.2. Oxygen Utilization Rate (OUR) of a Mixed Culture Exposed to $\mathrm{TiO}_{2}$ Nanoparticles (Degussa, P25) with Concentration Ranging from 0-600 $\mu \mathrm{g} / \mathrm{L}$, Expose to $365 \mathrm{~nm}$ UV at $0.6 \mathrm{mw} / \mathrm{cm}^{2}$ for 2 Hours. 


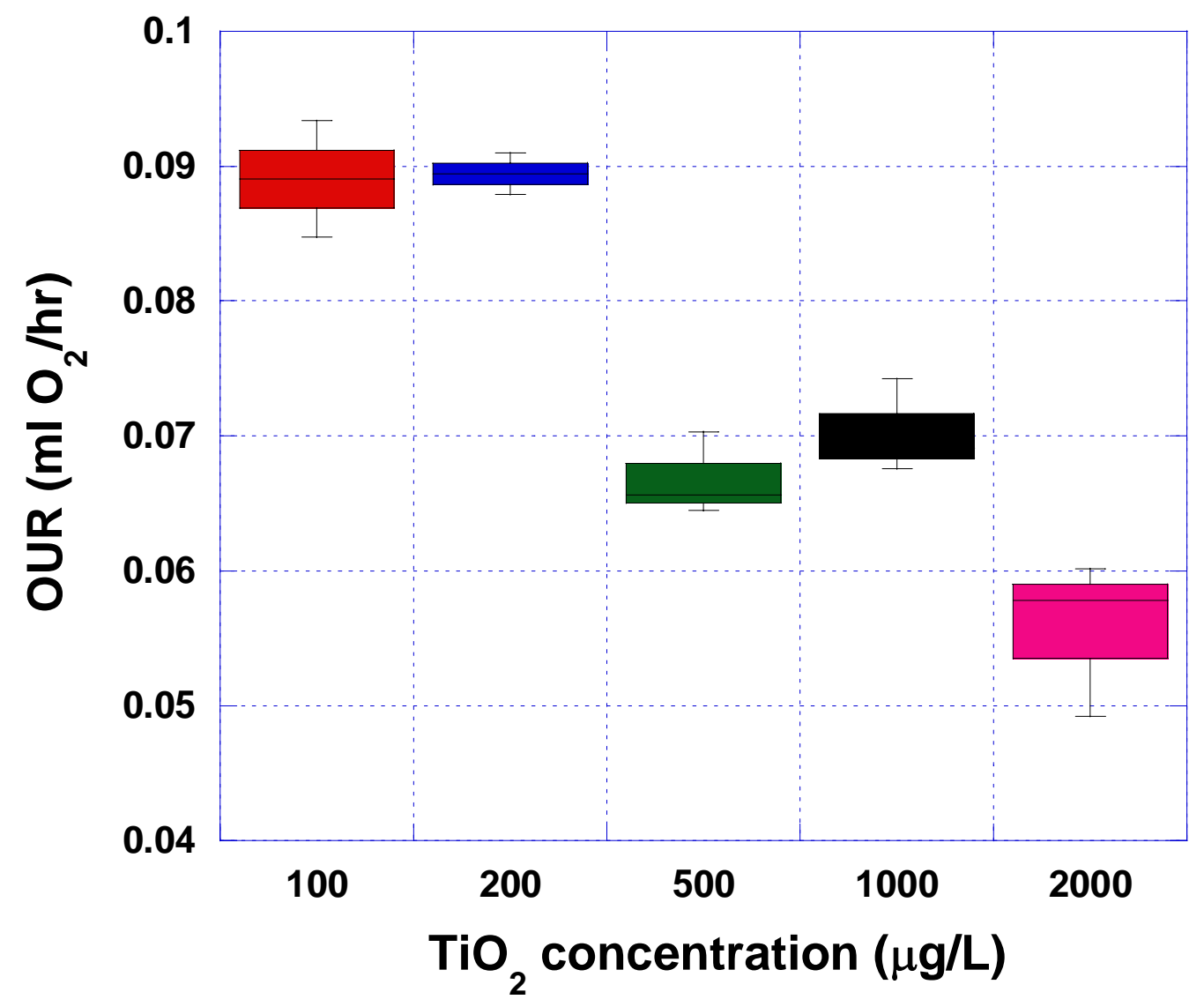

Figure 4.3. Oxygen Utilization Rate (OUR) of a Mixed Culture Exposed to $\mathrm{TiO}_{2}$ Nanoparticles (Degussa, P25) with Concentration Ranging from 0-2000 $\mu \mathrm{g} / \mathrm{L}$, Expose to $365 \mathrm{~nm} \mathrm{UV}$ at $0.6 \mathrm{mw} / \mathrm{cm}^{2}$ for 2 Hours. 
Figures 4.4 and 4.5 illustrate the effect of 2-hour treatment of $\mathrm{TiO}_{2}($ Degussa P25) and $\mathrm{UV}_{365}$ at $0.6 \mathrm{~mW} / \mathrm{cm}^{2}$. Both $\mathrm{OD}_{600}$ and fecal coliform counts of the treated cultures remained at a fairly constant level with a slight increasing trend in $\mathrm{OD}_{600}$ measurements. Note that the bacterial population did not show significant change between the control and treated cultures. This indicates that bacteria remained mostly viable for concentrations under the oxidative treatment. OUR was measured in triplicate and its median values for the treated samples show a slight decrease from those of their control sample. This suggests that the oxidative stress can cause sublethal effect that hinders respiratory activity. 


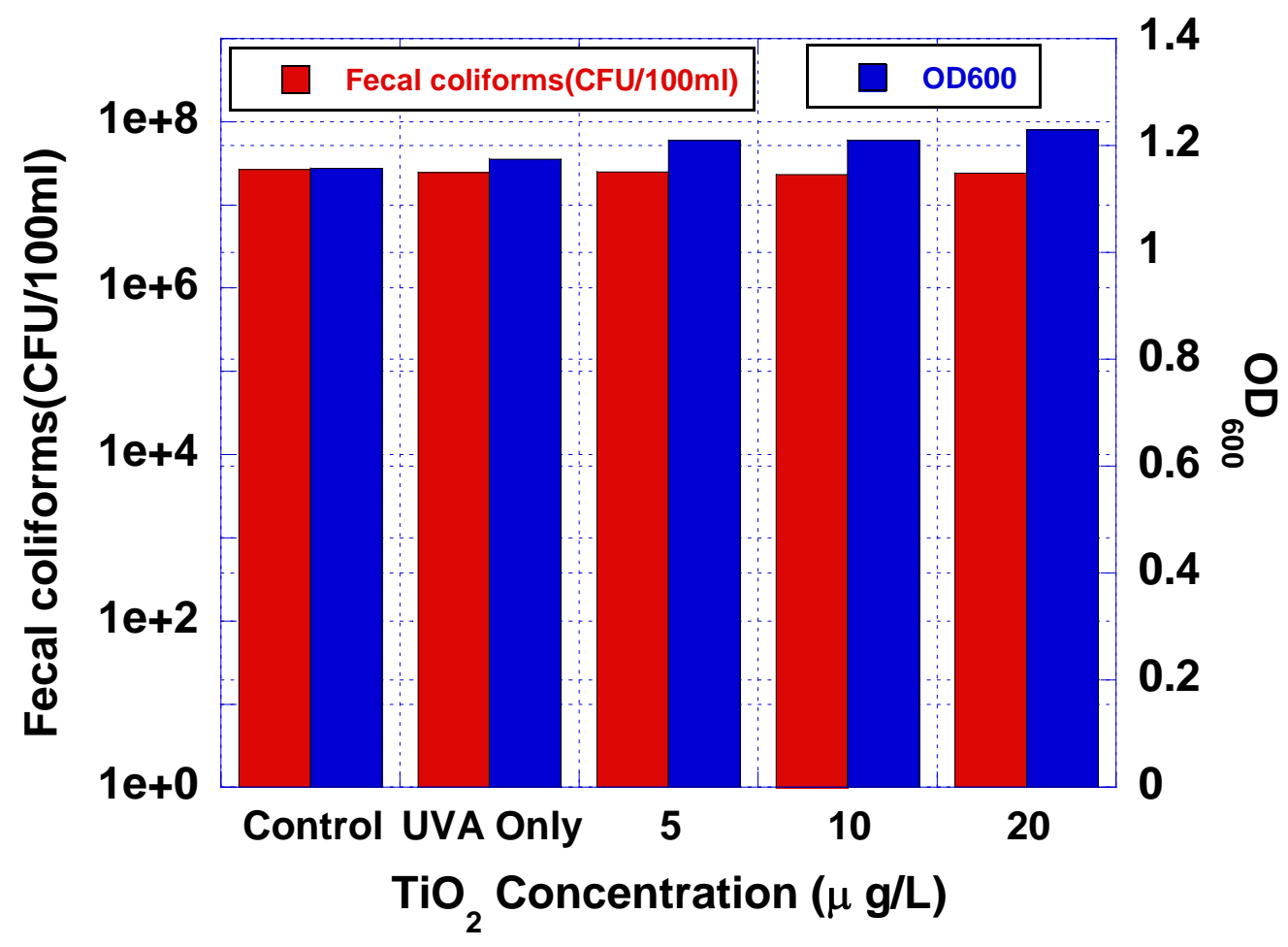

Figure 4.4. Viable Fecal Coliform Concentrations and Optical Density of the Mixed Culture Treated with Degussa P25 and $\mathrm{UV}_{365}$ at $0.6 \mathrm{~mW} / \mathrm{cm}^{2}$ for 2 Hours. 


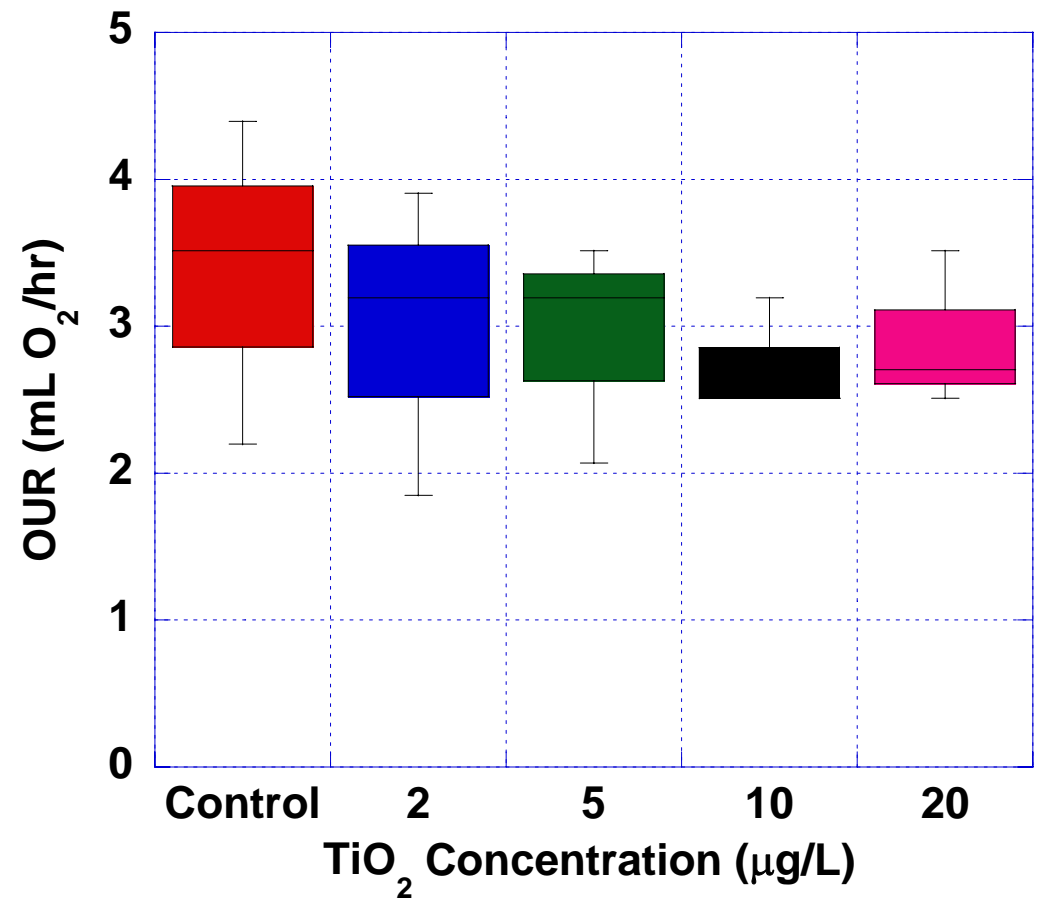

Figure 4.5. Oxygen Utilization Rate Values of the Mixed Culture Treated with Degussa $P 25$ and $U^{365}$ at $0.6 \mathrm{~mW} / \mathrm{cm}^{2}$ for 2 Hours. 
A longer exposure to oxidative stress was conducted and the results are illustrated in Figures 4.6 and 4.7. During 19 hours of exposure, $0.5 \mathrm{~mL}$ of the synthetic wastewater solution per $10 \mathrm{~mL}$ of the mixed culture sample was fed every 6 hours to sustain bacterial growth. Figure 4.6 shows that $\mathrm{OD}_{600}$ and fecal coliform counts of the treated cultures (including the culture treated with UVA only) showed a step decrease compared to the control culture. The fecal count data give the same trend as $\mathrm{OD}_{600}$, which indicates that the average effect caused by UVA and $\mathrm{TiO}_{2}$ to the mixed culture species is similar to fecal coliform species. Note that increase in the nanoparticle concentration from 5 to $20 \mu \mathrm{g} / \mathrm{L}$ did not cause further reduction of the population compared to culture exposed to UVA only, indicating that the oxidative stress caused by the nanoparticles was sublethal. The decrease in total population of the cultures can be attributed to growth delay and, to some degree, inactivation of the bacterial culture caused by the oxidative treatment. Both the photocatalytically induced oxidative stress by $\mathrm{TiO}_{2}$ particles (Kim et al., 2004) and UVA irraidation (Favre et al., 1985) can cause such growth delay of bacterial cultures. The fecal coliform populations in treated samples decreased from that of the control culture. However, both total population and fecal population remained at the same level among treated samples in Figure 4.6. Figure 4.7 shows a reduction in OUR values for nanoparticle concentration $2 \mu \mathrm{g} / \mathrm{L}$ and above compared to the control sample and magnitude of the reduction was substantially larger than those for the 2-hour treatment, indicating a larger degree of inhibiting respiratory activity with the longer exposure. 


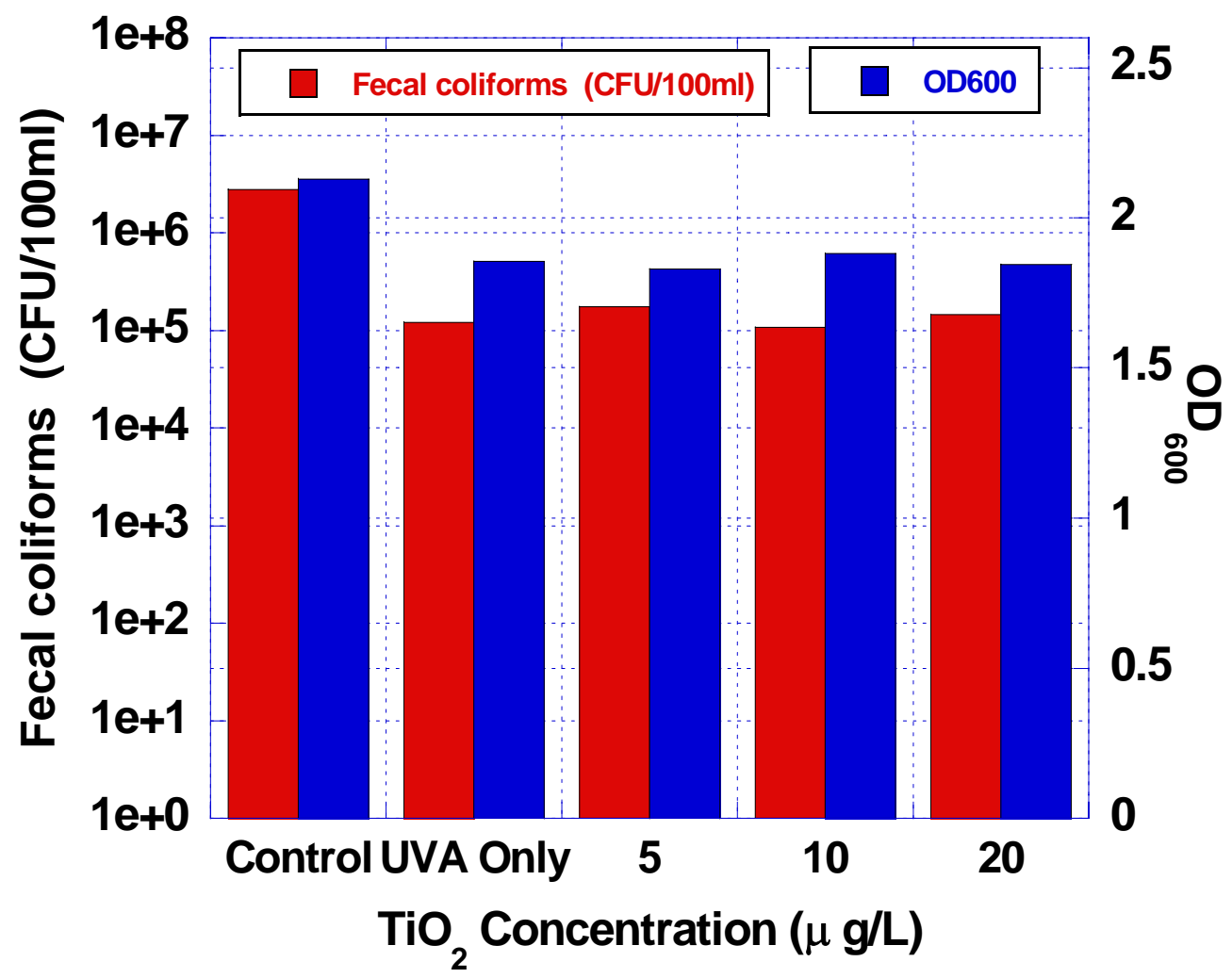

Figure 4.6. Viable Fecal Coliform Concentrations and Optical Density of the Mixed Culture Treated with Degussa P25 and UV 365 at $0.6 \mathrm{~mW} / \mathrm{cm}^{2}$ for 19 Hours. 


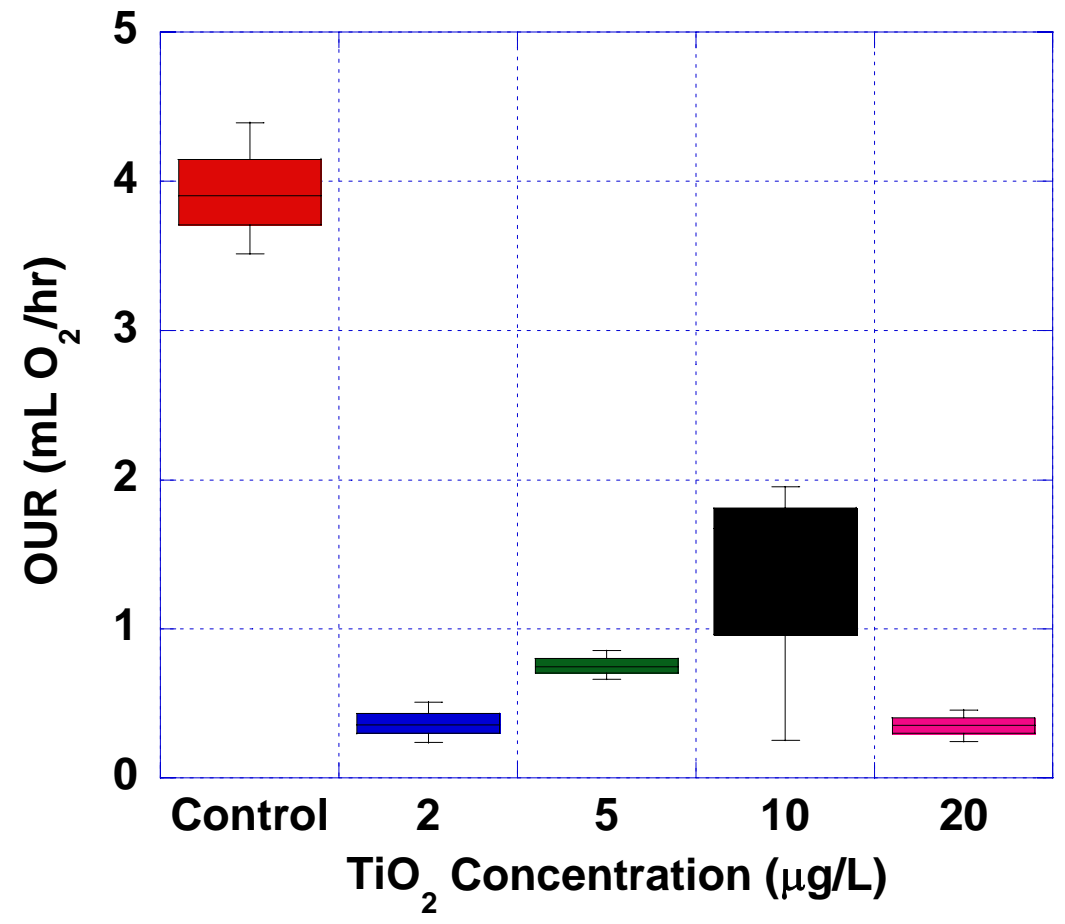

Figure 4.7. Oxygen Utilization Rate Values of the Mixed Culture Treated with Degussa $P 25$ and $U V_{365}$ at $0.6 \mathrm{~mW} / \mathrm{cm}^{2}$ for 19 Hours. 
A similar treatment with the sunscreen $\mathrm{TiO}_{2}$ nanoparticles was conducted and the results are shown in Figures 4.8 and 4.9. Note that the culture treated with UVA alone exhibited an approximately $1.5-\log$ reduction in fecal coliform counts compared to control culture in Figure 4.8, which was consistent with the result in Figure 4.6, both of which contained no $\mathrm{TiO}_{2}$ nanoparticles. However, the sunscreen nanoparticle caused a less $(\sim 1-\log )$ fecal coliform reduction compared to Degussa P25 nanoparticles $(\sim 1.5-\log )$ for the nanoparticle concentrations

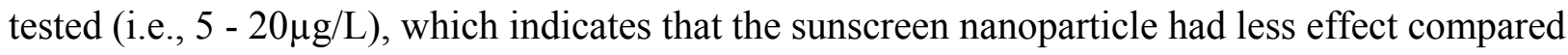
to Degussa P25. We also observe fecal coliform concentration remained the same for sunscreen nanopartical concentration $5-20 \mu \mathrm{g} / \mathrm{L}$, which suggests sublethal effect as in Figure 4.6. The OUR values in Figure 4.9 followed a similar trend as that in Figure 4.7. But the reduction of OUR values between the control sample and the treated samples was smaller $(\sim 1.5)$ compared to $\sim 3.5$ in Figure 4.7, which consistently indicates a smaller effect of oxidative stress with the sunscreen $\mathrm{TiO}_{2}$ nanoparticles. 


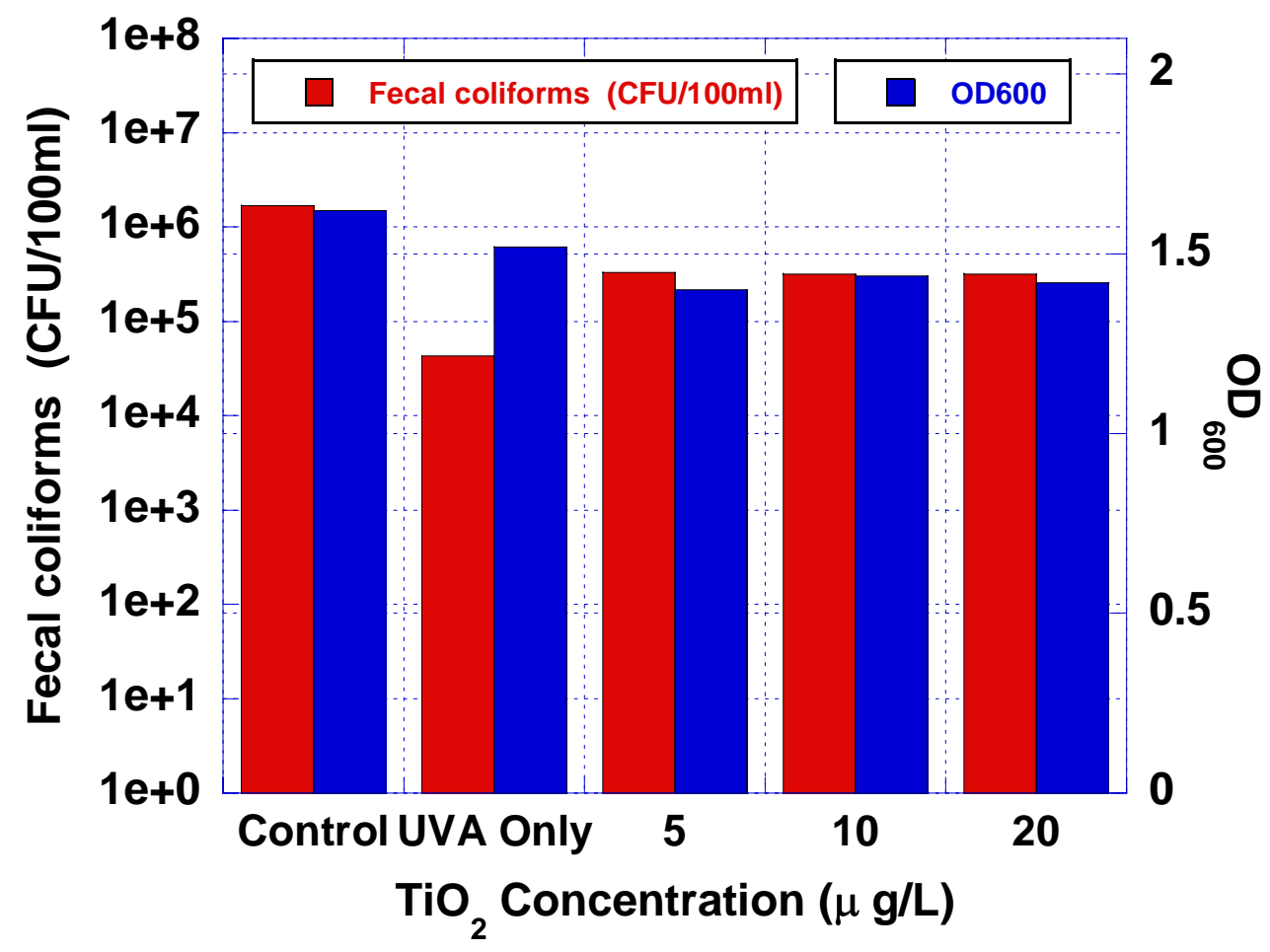

Figure 4.8. Viable Fecal Coliform Concentrations and Optical Density of the Mixed Culture Treated with Degussa P25 and UV 365 at $0.6 \mathrm{~mW} / \mathrm{cm}^{2}$ for 19 Hours. 


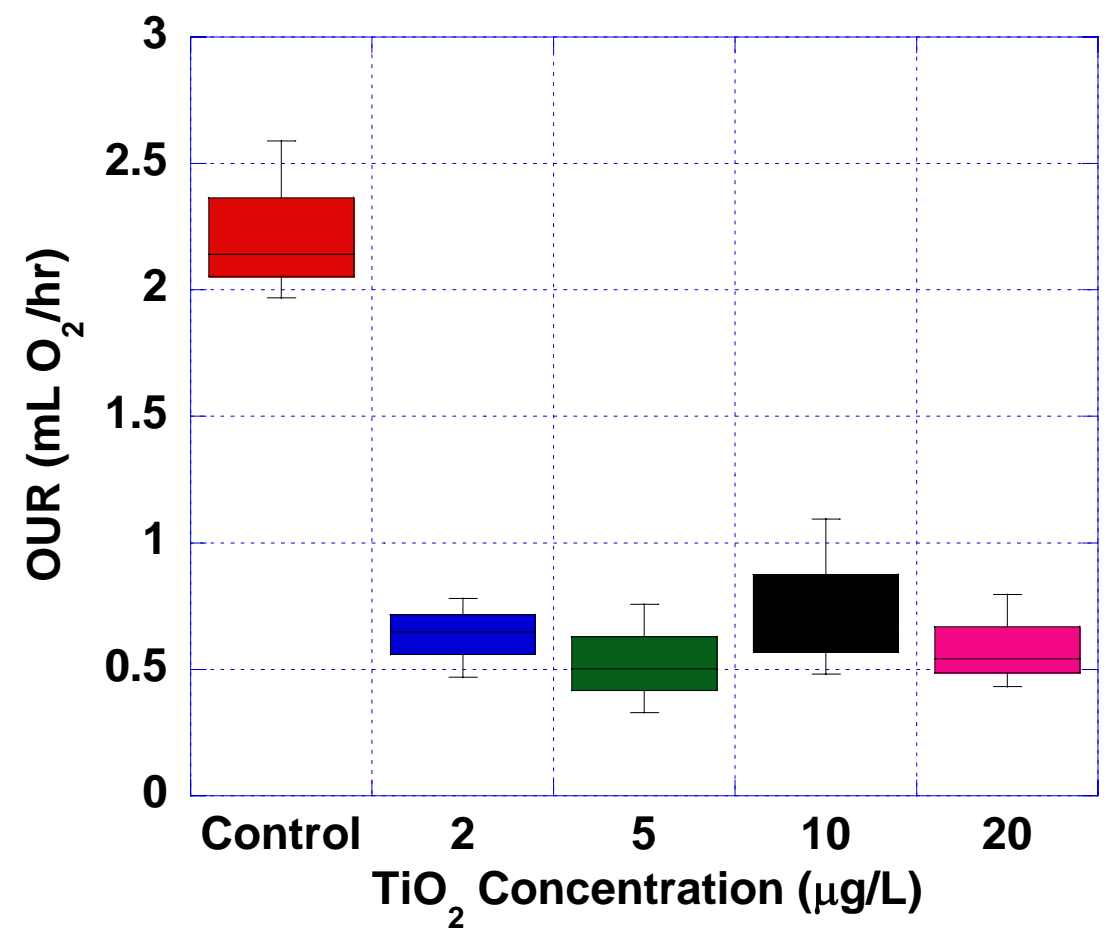

Figure 4.9. Oxygen Utilization Rate Values of the Mixed Culture Treated with Sunscreen $\mathrm{TiO}_{2}$ Nanoparticles and $\mathrm{UV}_{365}$ at $0.6 \mathrm{~mW} / \mathrm{cm}^{2}$ for 19 Hours. 


\subsection{Flow Cytometry Analysis and Validation}

Table 1 shows the mean values and statistics of the ratio of bacterial population with intact membranes to total bacterial population from the flow cytomtry analysis in Figure 4.10, Figure 4.11 and Figure 4.12. Ratio mean values remain at a fairly constant level for nanoparticle concentrations up to $10 \mu \mathrm{g} / \mathrm{L}$ and show a slight decrease for $20 \mu \mathrm{g} / \mathrm{L}$ for the 2-hour expousre. This indicates that bacterial cell membranes remained mostly intact for concentrations $2-10$ $\mu \mathrm{g} / \mathrm{L}$ based on the working principle with the fluorescent dyes used in the flow cytometry analysis. The slight decrease in the ratio values at $20 \mu \mathrm{g} / \mathrm{L}$ indicates a small degree of membrane damage. For the 19-hour treatment, mean values of the ratio were consistently lower than those for the 2-hour treatment, which could have resulted from natural death of microorganisms during the longer exposure period. The ratio value remains at a consistent level up to $5 \mu \mathrm{g} / \mathrm{L}$ and shows a decline for concentrations 10 and $20 \mu \mathrm{g} / \mathrm{L}$, which can be attributed to additional bacterial damage in the cell membranes due to higher oxidative stress. However, such decline in fecal coliforms shown in Figure 4.6 was not observed and need further study. A potential explanation is that the cell membrane damage could be repaired during the post-treatment incubation for fecal coliform colony formation.

The hypothesis of membrane repair is supported by cell sorting result with E. coli as in Figure 4.13. The calculated percent of colony counts (viable cells) to total 44 sorted cells for the “membrane-intact" cells and the "membrane-damaged" cells were $75 \%$ and $68 \%$ respectively. This difference in the viable percentages was not significant, suggesting the cells with damaged membranes can also form colonies. Similar experiment was done and the E. coli sample was treated with iodine instead of $\mathrm{UV}_{365}$. The calculated viable percentage for the "membrane-intact" cells and the "membrane-damaged" cells were $77 \%$ and $4 \%$ respectively. The 
result shows that the flow cytometry can differentiate cell membrane damage, however the cells with membrane damage caused by $\mathrm{UV}_{365}$ and $\mathrm{TiO}_{2}$ can grow again, probably due to membrane repair.

A similar trend was observed for the sunscreen $\mathrm{TiO}_{2}$ nanoparticles with the mean ratio values remained fairly constant for nanoparticle concentration up to $5 \mu \mathrm{g} / \mathrm{L}$ and showed a decrease for concentrations 10 and $20 \mu \mathrm{g} / \mathrm{L}$. The mean values were consistently larger than those obtained for the 19-hour Degussa particle treatment, which indicates a smaller effect with the sunscreen nanoparticles than Degussa P25. This smaller effect is consistent with the viable fecal coliform population and OUR results shown in Figures 4.8 and 4.9. 
Table 1. Mean Values $(\mu)$ and Standard Deviations $(\sigma)$ of the Ratio of Bacterial Concentration with Intact Membranes to Total Bacterial Concentration of the Mixed Culture Treated with $\mathrm{TiO}_{2}$ Nanoparticles and $\mathrm{UV}_{365}$ at $0.6 \mathrm{~mW} / \mathrm{cm}^{2}$. The Concentrations were Measured in Triplicate.

\begin{tabular}{|c|c|c|c|c|c|c|}
\hline \multirow[t]{2}{*}{$\mathrm{TiO}_{2}$ Conc. $(\mu \mathrm{g} / \mathrm{L})$} & \multicolumn{2}{|c|}{2 hours Degussa } & \multicolumn{2}{|c|}{19 hours Degussa } & \multicolumn{2}{|c|}{19 hours Sunscreen } \\
\hline & $\mu$ & $\pm \sigma$ & $\mu$ & $\sigma$ & $\mu$ & $\sigma$ \\
\hline $\mathbf{0}$ & 0.93 & 0.01 & 0.79 & 0.01 & 0.83 & 0.01 \\
\hline 2 & 0.94 & 0.01 & 0.82 & 0.03 & 0.84 & 0.01 \\
\hline 5 & 0.93 & 0.01 & 0.81 & 0.02 & 0.86 & 0.01 \\
\hline 10 & 0.94 & 0.01 & 0.53 & 0.03 & 0.78 & 0.02 \\
\hline 20 & 0.87 & 0.02 & 0.51 & 0.04 & 0.76 & 0.01 \\
\hline
\end{tabular}




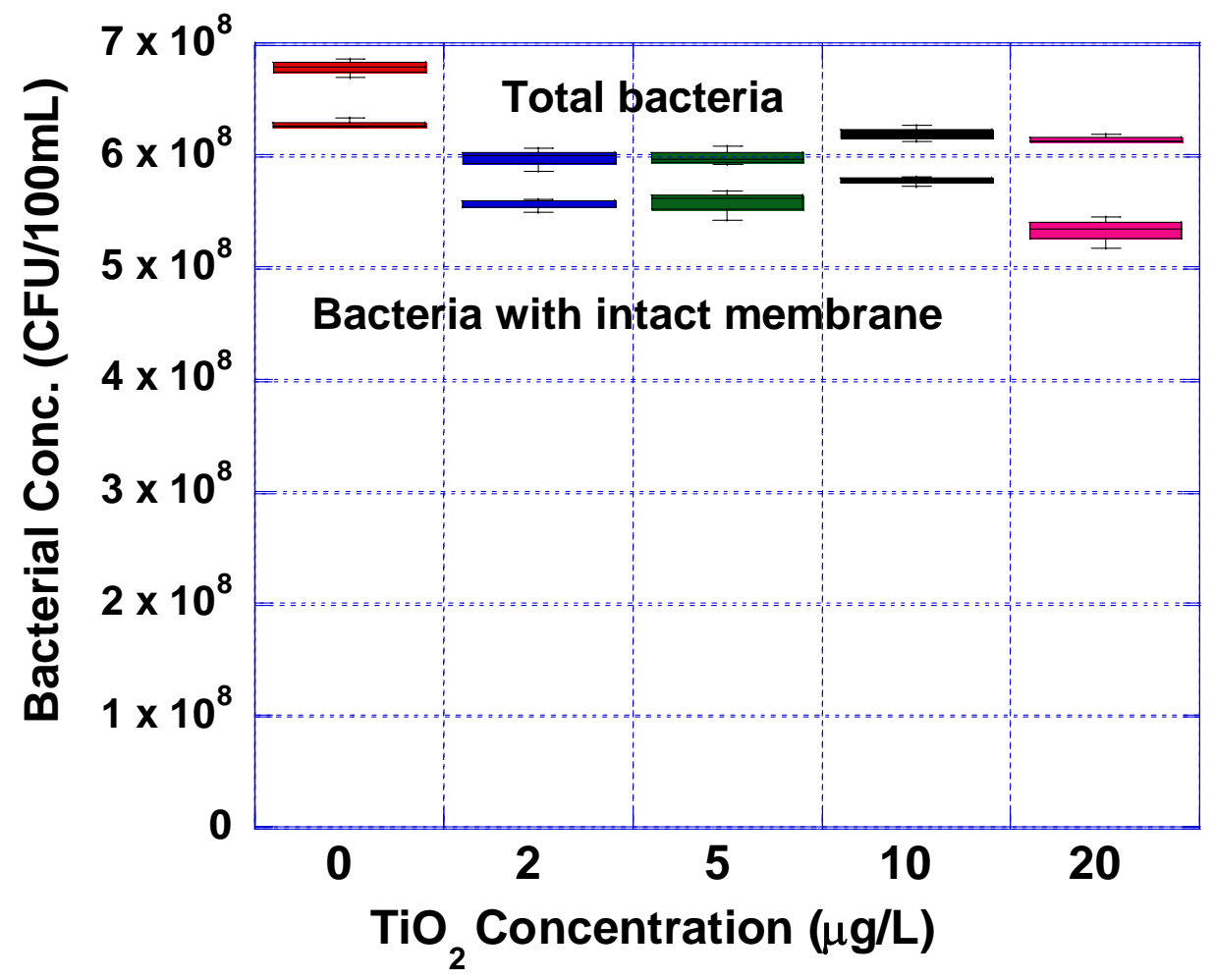

Figure 4.10. Total Bacterial Population (Upper Whisker Boxes), and Intact Cell Membrane Population (Lower Whisker Boxes) of the Mixed Culture Samples Treated with Different $\mathrm{TiO}_{2}$ (Degussa, P25) Concentration and $365 \mathrm{~nm} \mathrm{UV}\left(0.6 \mathrm{~mW} / \mathrm{cm}^{2}\right)$ for 2 Hours. 


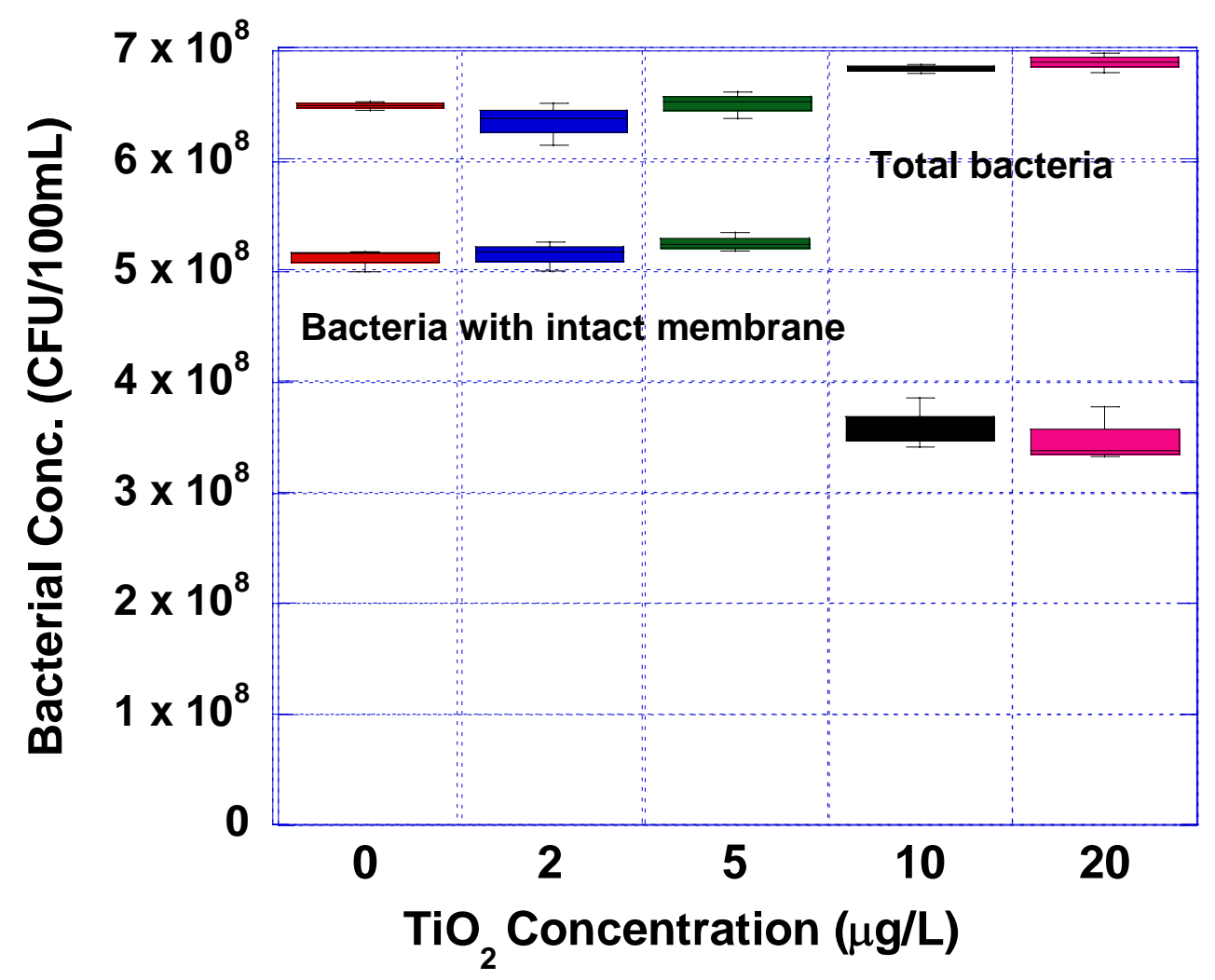

Figure 4.11. Total Bacterial Population (Upper Whisker Boxes), and Intact Cell Membrane Population (Lower Whisker Boxes) of the Mixed Culture Samples Treated with Different $\mathrm{TiO}_{2}$ (Degussa, P25) Concentration and $365 \mathrm{~nm} \mathrm{UV}\left(0.6 \mathrm{~mW} / \mathrm{cm}^{2}\right.$ ) for 19 Hours. 


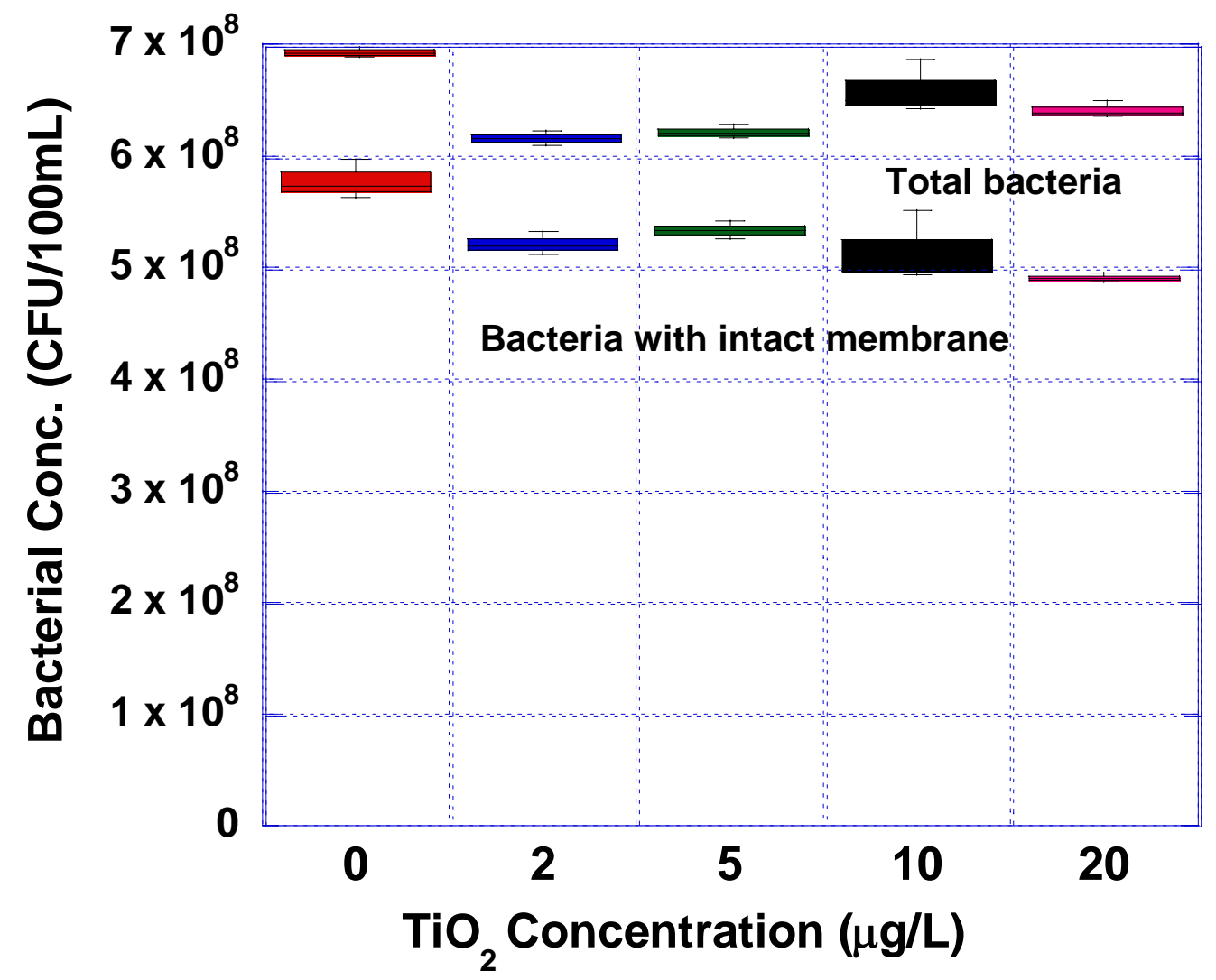

Figure 4.12. Total Bacterial Population (Upper Whisker Boxes), and Intact Cell Membrane Population (Lower Whisker Boxes) of the Mixed Culture Samples Treated with Different $\mathrm{TiO}_{2}$ (Sunscreen nanopartical) Concentration and 365 nm UV (0.6 $\mathrm{mW} / \mathrm{cm}^{2}$ ) for 19 Hours. 


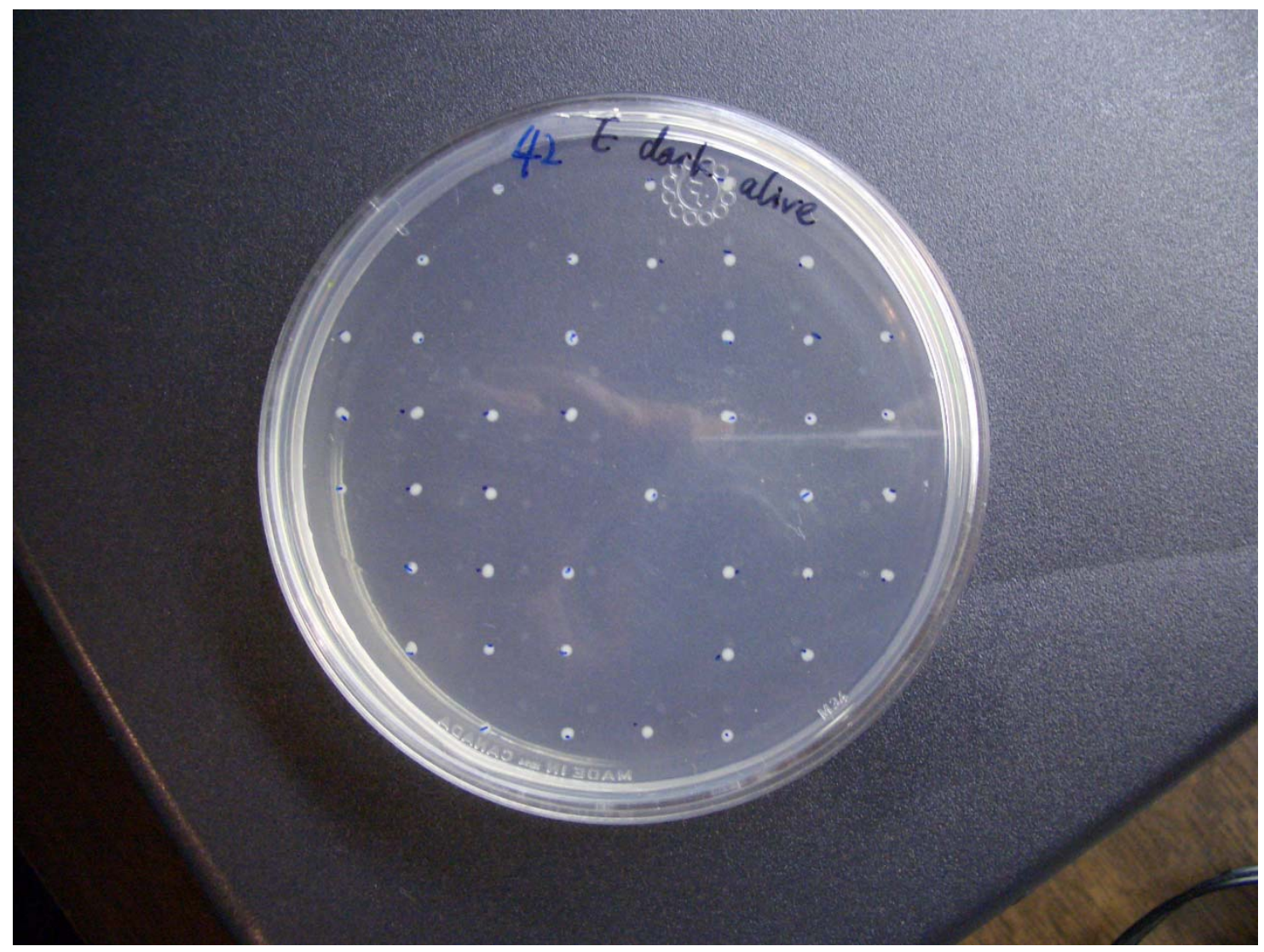

Figure 4.13. E. coli Cells Sort from Intact Cell Portion Recognized by Flow Cytometry and Grow in LB Agar Plate for 24 Hours. 


\subsection{Microbial Resistance}

Figure 4.14 show log-inactivation of fecal coliform concentrations $(\mathrm{N})$ for a control and treated samples from the $\mathrm{UV}_{254}$ irradiation. $\mathrm{The}_{\mathrm{TiO}} / \mathrm{UV}_{365}$ treated sample showed a higher survival than the control sample which was kept in dark and the sample was treated with UVA only, indicating an enhanced microbial resistance resulting from the oxidative stress treatment. In Figure $4.14 \mathrm{a}$, both curves level off at dose $20 \mathrm{~mJ} / \mathrm{cm}^{2}$ and above, which was a common feature for all microbial resistance experiments with $\mathrm{TiO}_{2}$ concentration $0-40 \mu \mathrm{g} / \mathrm{L}$ and $\mathrm{UV}_{365}$ intensity $0.6 \mathrm{~mW} / \mathrm{cm}^{2}$ conducted in this study. Figure $4.14 \mathrm{~b}$ shows the log-inactivation of fecal coliforms and regression lines for $\mathrm{UV}_{254}$ dose range from 0 to $20 \mathrm{~mJ} / \mathrm{cm}^{2}$. Slopes of the regression lines indicate an enhanced microbial resistance of the oxidative stress treated sample compared to the control sample. And this resistance was caused by the $\mathrm{TiO}_{2}$ nanoparticles in the presence of UVA. Throughout the study, the slopes of the regression lines for the control samples consistently fell in the range from -0.06 to $-0.1 \mathrm{~cm}^{2} / \mathrm{mJ}$. Slope difference between the control and treated samples reflects the degree of deviation in microbial resistance to $\mathrm{UV}_{254}$. With $\Delta \boldsymbol{S} \equiv$ slope $_{\text {treated }}$ slope $_{\text {control, }}$ positive $\Delta \boldsymbol{S}$ values indicate that the treated sample is more resistant to $\mathrm{UV}_{254}$ than the control sample, and negative values indicate the opposite (i.e., more susceptible). 


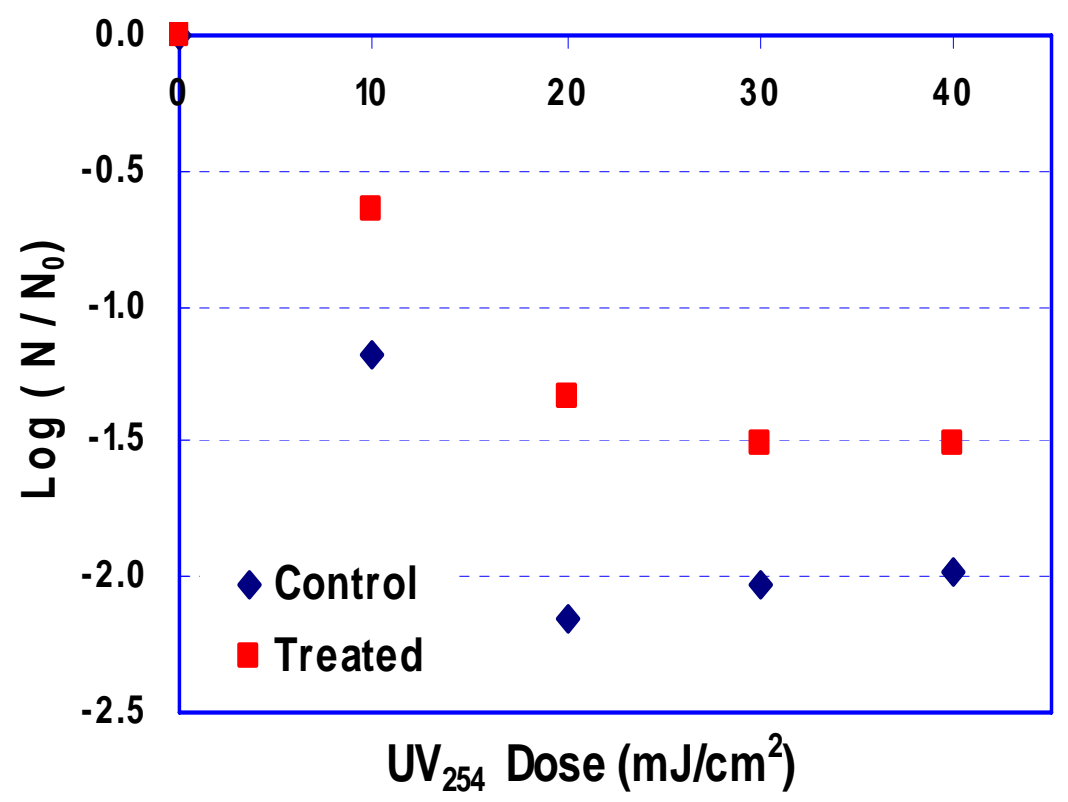

(a)

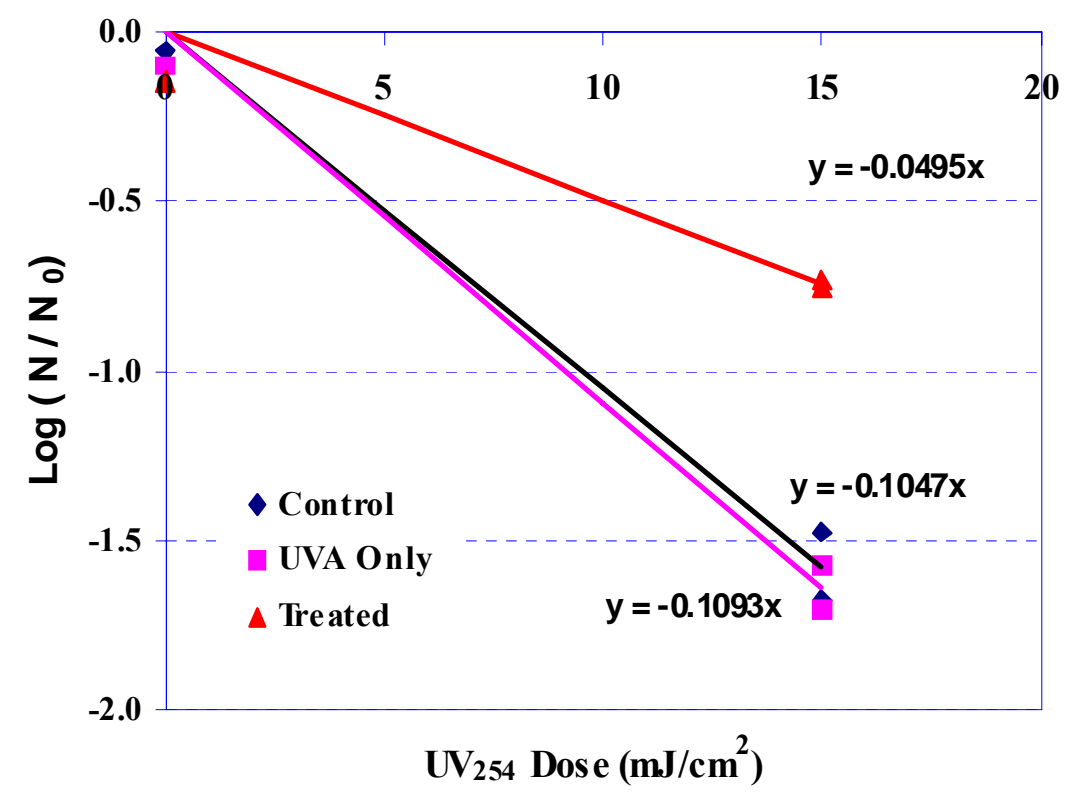

(b)

Figure 4.14. Log-inactivation of Fecal Coliforms as a Result of UV Disinfection (254 nm) for a Control and a Sample Treated with $\mathrm{UV}_{365}$ at $0.6 \mathrm{~mW} / \mathrm{cm}^{2}$ and (a) $20 \mu \mathrm{g} / \mathrm{L}$ and (b) $5 \mu \mathrm{g} / \mathrm{L}$ of Degussa P25 for 19 Hours. 
Figure 4.15 shows the $\Delta S$ values calculated from slopes of the dose response curves, which were determined by log-inactivation fecal coliform concentrations for dose range from 0 to $20 \mathrm{~mJ} / \mathrm{cm}^{2}$. The $\Delta \boldsymbol{S}$ values are all positive, indicating an enhanced microbial resistance caused by the oxidative stress treatment. The slope differences from separate sets of measurements were highly variable. This can be attributed to the highly dynamic nature of the microbial community in response to the oxidative stress. However, we can still see the resistance ability increases with the $\mathrm{TiO}_{2}$ concentration and exposure time. The overall resistance ability increase with $\mathrm{TiO}_{2}$ concentration slows down at $10 \mu \mathrm{g} / \mathrm{L}$, even has a little decrease at $20 \mu \mathrm{g} / \mathrm{L}$, which indicates a maximum level of resistance. The enhancement in resistance for 2 and $5 \mu \mathrm{g} / \mathrm{L}$ may have corresponded to alteration of bacterial structure and/or enzymatic activities that lead to higher resistance to $\mathrm{UV}_{254}$. For concentrations 10 and $20 \mu \mathrm{g} / \mathrm{L}$, the enhanced resistance was enlarged by the larger oxidative stress. The higher survival percentage can be attributed to two possible reasons. First, the oxidative treatment may have caused a bacterial community shift due to diverse bacterial sensitivity to oxidative damages among different species. Second, the oxidative stress can induce bacterial defense mechanisms such as induction of ROS-counteracting enzymes and those that repair DNA damages so that the bacterial species show higher resistance to the oxidative damages caused by UVC irradiation. A general increasing trend of $\boldsymbol{\Delta S}$ as a function of exposure time was observed for Degussa P25 (Figure 4.16). Collectively, the bacterial resistance to UV irradiation increases with oxidative stress for the nanoparticle concentrations tested in this study. Higher oxidative stress was found to trigger larger degree of defense activities, which result in higher resistance to $\mathrm{UV}_{254}$ irradiation. 


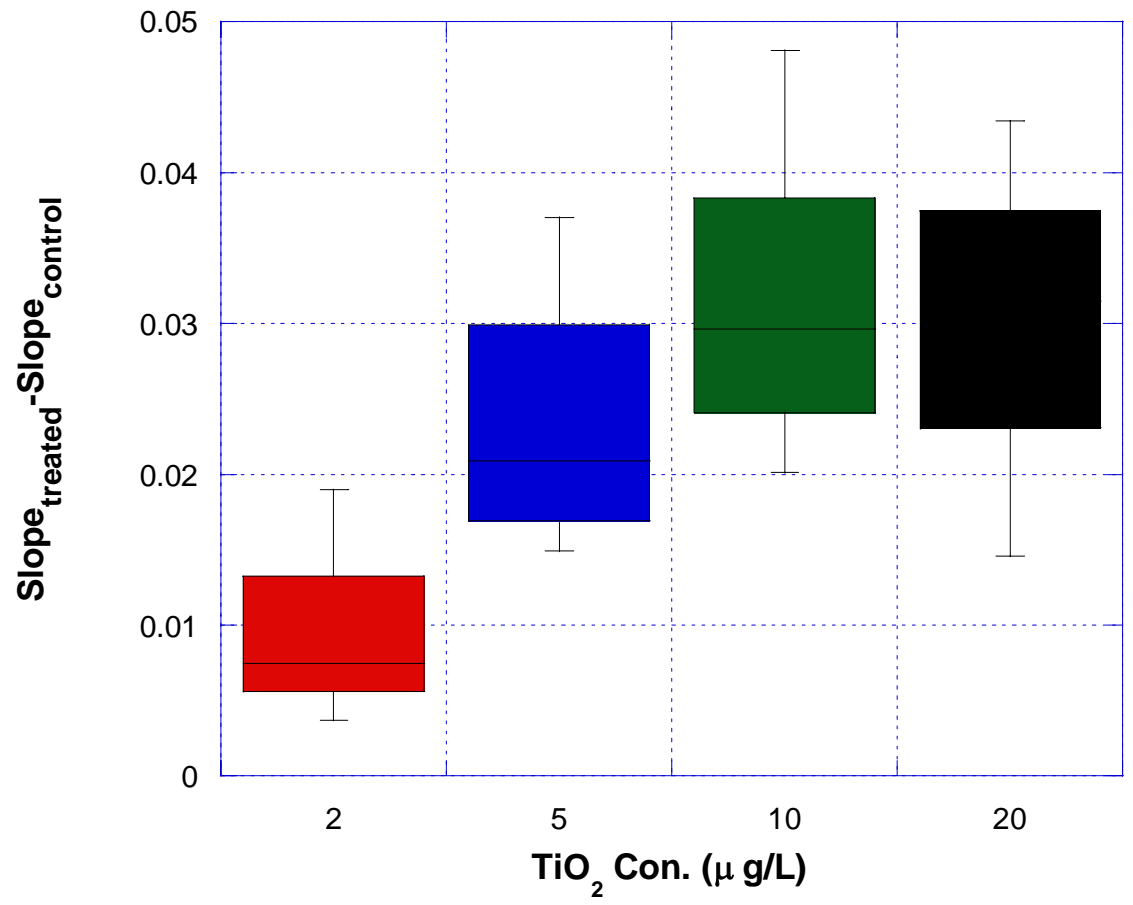

Figure 4.15. Values of $\Delta S$ for the Mixed Culture after Treatment of $U V_{365}$ at $0.6 \mathrm{~mW} / \mathrm{cm}^{2}$ and a Range of Degussa P25 and Sunscreen Nanoparticle Concentration for 19 Hours. 


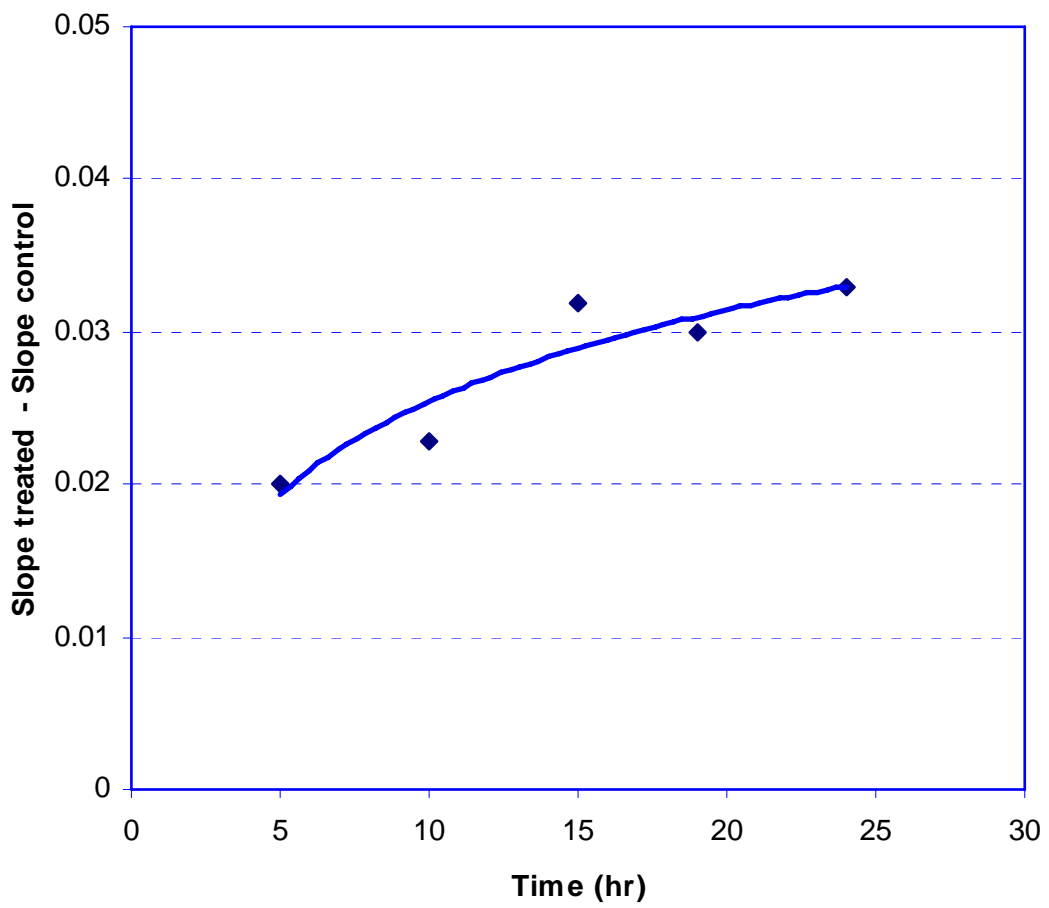

Figure 4.16. Values of $\Delta S$ for the Mixed Culture after Treatment of $U V_{365}$ at $0.6 \mathrm{~mW} / \mathrm{cm}^{2}$ and $5 \mu \mathrm{g} / \mathrm{L}$ of Degussa P25 for Various Exposure Times. 


\subsection{Intracellular ROS Level}

Figures 4.17, 4.18 and 4.19 show the mean fluorescent intensities of $\mathrm{CM}-\mathrm{H}_{2} \mathrm{DCF}$ of the mixed culture for a range of nanoparticle concentrations. The mean fluorescent intensity reflects intracellular ROS level. The results show a small decrease in intracellular ROS level after 2 hours of oxidative stress treatment (Figure 4.17) and a longer exposure time (19 hours) further reduced the ROS level (Figure 4.18). This suggests that the longer exposure triggered microbial defense processes that counteracted intracellular ROS, such as synthesis of SOD enzyme. The exposure times ( 2 and 19 hours) also reveal the time scale for such microbial defense process to become active. In addition, the ROS neutralizing mechanism(s) occurred for all $\mathrm{TiO}_{2}$ concentrations examined, including 2 and $5 \mu \mathrm{g} / \mathrm{L}$ which were mostly sublethal. The sunscreen nanoparticles induced a similar effect on the ROS level and the magnitude of the reduction was comparable with that caused by Degussa P25. Although the viable bacterial concentration treated with sunscreen nanoparticles and $\mathrm{UV}_{365}$ remained at a fairly constant level for all nanoparticle concentrations (Figure 4.8), the ROS level showed a further decrease at $10 \mu \mathrm{g} / \mathrm{L}$ and above (Figure 4.19), indicating a greater effect of the defense mechanisms in counteracting intracellular ROS at the high nanoparticle concentrations. Recent studies have shown that, in addition to formation of pyrimidine dimers, UVC could also induce lethality through ROS generation and subsequent oxidative DNA damage (Gomes, A.2005; Nagira, T., 2002). The data suggest that induction of bacterial activities that counteracting intracellular ROS is a cause for the enhanced resistance observed in this study. 


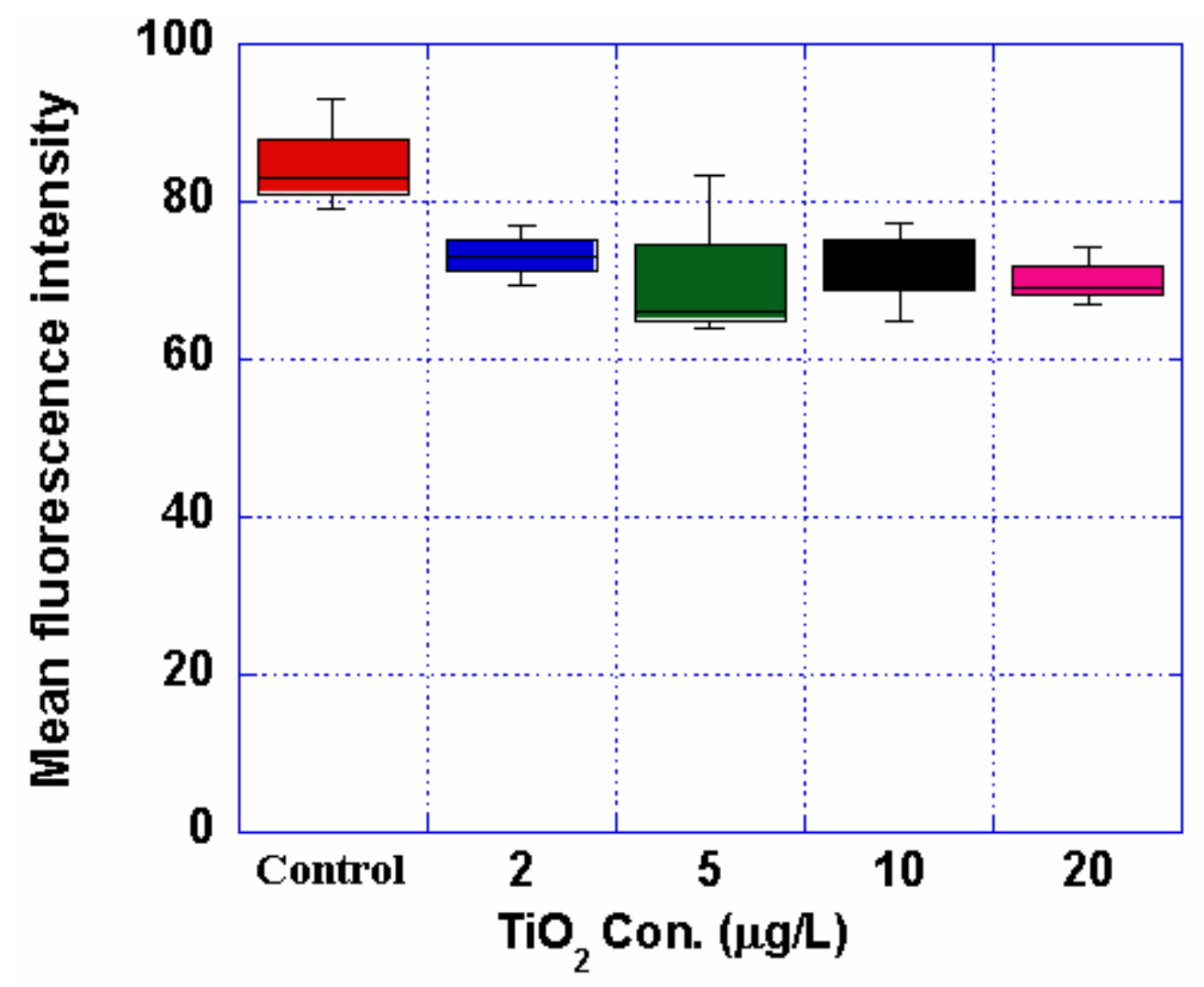

Figure 4.17. Intracellular ROS Level Indicated by Mean CM-H $\mathrm{H}_{2}$ DCF Fluorescent Intensity after Exposure to $\mathrm{UV}_{365}$ at $0.6 \mathrm{~mW} / \mathrm{cm}^{2}$ and Degussa P25 for 2 Hours. 


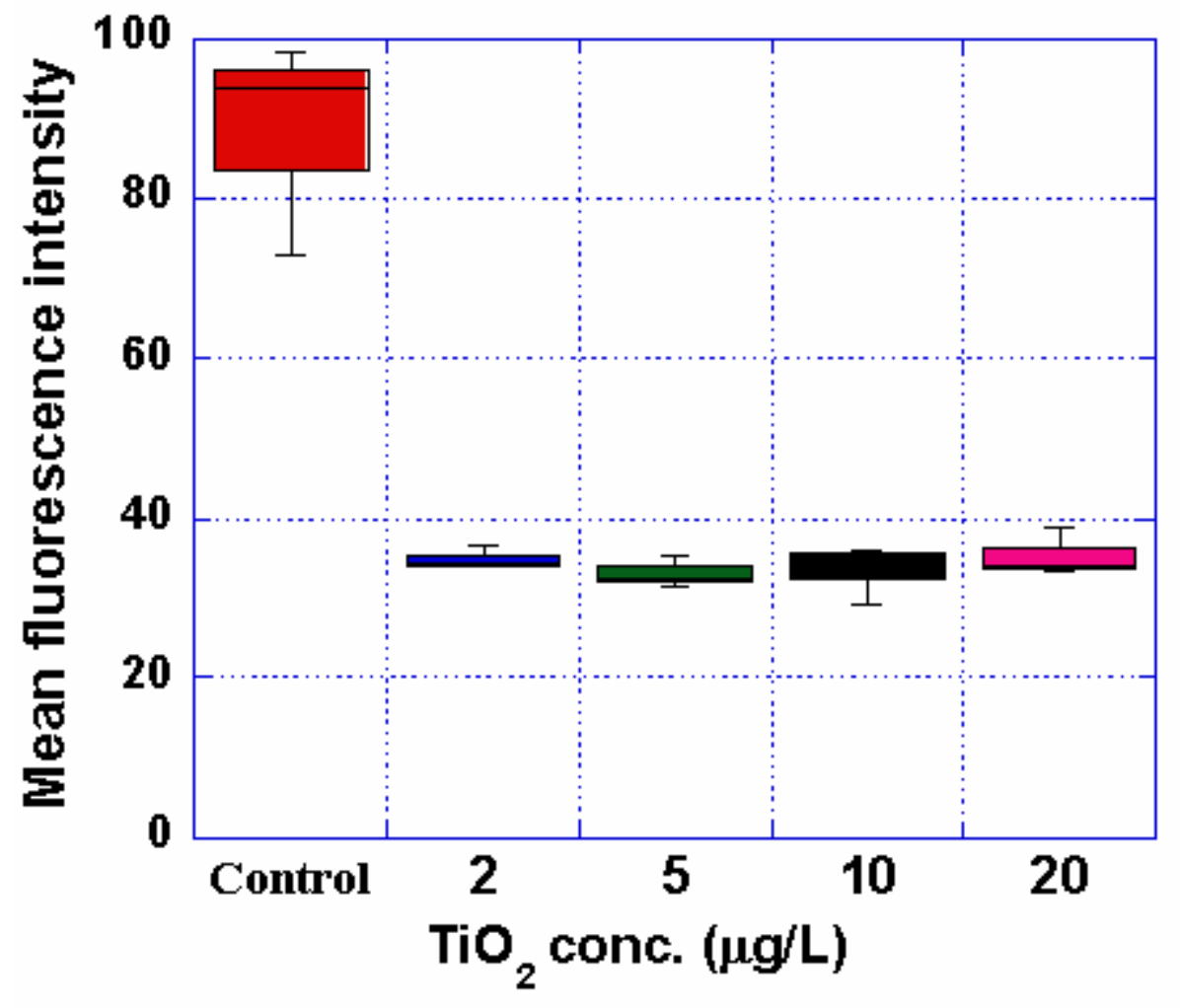

Figure 4.18. Intracellular ROS Level Indicated by Mean CM- $\mathrm{H}_{2} \mathrm{DCF}$ Fluorescent Intensity after Exposure to $\mathrm{UV}_{365}$ at $0.6 \mathrm{~mW} / \mathrm{cm}^{2}$ and Degussa P25 for 19 Hours. 


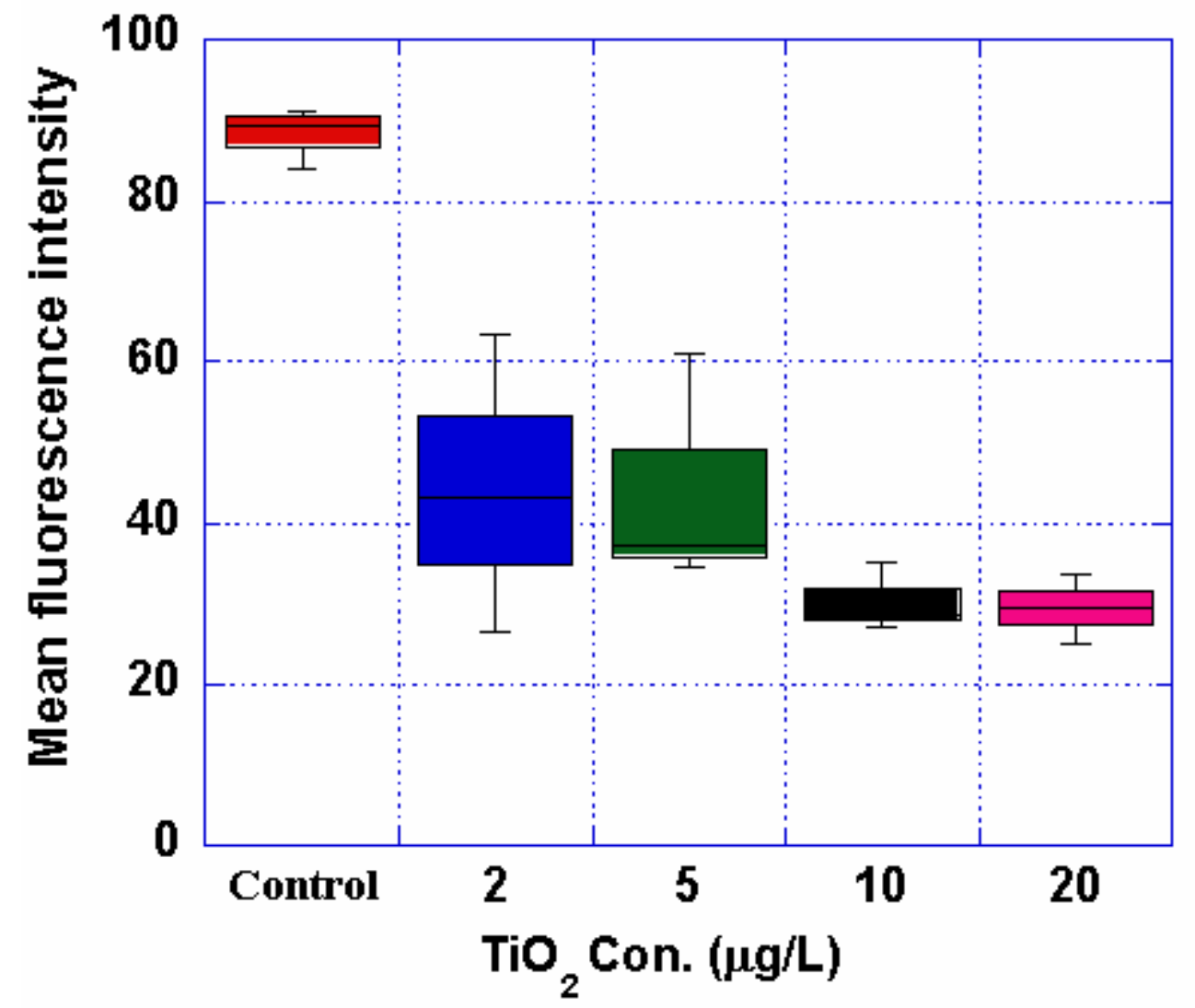

Figure 4.19. Intracellular ROS Level Indicated by Mean CM- $\mathrm{H}_{2} \mathrm{DCF}$ Fluorescent Intensity after Exposure to $\mathrm{UV}_{365}$ at $0.6 \mathrm{~mW} / \mathrm{cm}^{2}$ and Sunscreen Nanoparticles for 19 Hours. 


\subsection{Microbial Resistance of Pure Culture}

The E. coli culture was first suspended in a LB medium during the UVA exposure, which kept the cells in growing phase. No consistent resistance was found under the condition that keep cell sublethal (Appendix D). Another set of experiment was conduced in which E. coli culture was suspended in a PBS $(0.1 \mathrm{M}, \mathrm{pH}=7)$ instead of the LB medium. The bacterial culture was expected to be in the stationary phase and more susceptible to the oxidative treatment. Therefore, the UVA intensity was lowered to $0.3 \mathrm{~mW} / \mathrm{cm}^{2}$ and the exposure time was shorten to 3 hours to keep the exposure sublethal. When the $\mathrm{TiO}_{2}$ concentration is lower than $20 \mu \mathrm{g} / \mathrm{L}$, the $\Delta \boldsymbol{S}$ values were small, hovering around zero, which indicates that there was no significant change in the bacterial resistance (Appendix E). For $20 \mu \mathrm{g} / \mathrm{L} \mathrm{TiO}_{2}, 1.5$-hour post irradiation incubation also resulted in small positive and negative $\Delta \boldsymbol{S}$ values. However, 3-hour post irradiation incubation resulted in an enhanced resistance of the treated culture to $\mathrm{UV}_{254}$ compared to the control sample in the dark and the sample treated with UVA only (Figure 4.20). Figure 4.20 shows both a loginactivation and percent survival of the E. coli cells. The experiment was repeated for 3 times and all the results were consistent.

The dependence of oxidative stress-induced resistance to UVC disinfection on posttreatment incubation time was examined and results are shown in Figure 4.21 (data listed in Appendix F). The observed increasing survival percentage of $\mathrm{UVA} / \mathrm{TiO}_{2}$ treated sample reached a maximum at around 4 hours of post treatment incubation. The kinetics of bacterial defense mechanism(s) that are responsible for the high survival percentage is consistent with a similar study reported in the literature. Uppal et al. (2003) showed that UVA exposure introduced phr gene in E. coli, which played a major role in DNA repair mechanisms, and the highest phr gene level was observed after 3.5-hour incubation post UVA irradiation. In our research, the results 
show an enhanced resistance to $\mathrm{UV}_{254}$ after 3 hours of post-treatment incubation, which was not observed after 1.5-hour incubation (Appendix E).

To investigate if the enhanced resistance of $E$. coli culture can pass down to the next generation, colonies on the LB agar plate of the UVC irradiated (dose: $30 \mathrm{~J} / \mathrm{m}^{2}$ ) culture after 4hour incubation were picked and grown in a LB medium in a shaker (150 rpm) overnight at $37{ }^{\circ} \mathrm{C}$. Separately, colonies of the control culture (without $\mathrm{TiO}_{2} / \mathrm{UVA}$ treatment) without UVC irradiation and after 4-hour incubation were grown for comparison. Both bacterial cultures were transferred to a PBS separately and subjected to UVC irradiation the next day and survival rate compared. Figure 4.22 shows that the cells grown from the $\mathrm{TiO}_{2} / \mathrm{UVA}$ treated sample exhibited a higher survival percentage against UVC than those grown from the control sample. This can be attributed to two possible reasons. One reason is that $\mathrm{TiO}_{2} / \mathrm{UVA}$ treated cells survived from UVC irradiation were phylogenetically more resistant to UVC so that their offspring exhibited higher survival rate. Another reason is that the oxidative stress introduced by $\mathrm{TiO}_{2} / \mathrm{UVA}$ caused some changes at the genetic level, and the changes pass down to the offspring so that they were more resistent to UVC inactivation. Further studies are needed to elucidate the potential mechanisms.

The effect of nanopartical concentration on the E. coli resistant against UVC was showed in Figure 4.23. The bacterial resistance to UV irradiation increases with nanoparticle concentrations in this study, which had been seen in mix culture too. Higher oxidative stress was found to trigger larger degree of defense activities, which result in higher resistance to $\mathrm{UV}_{254}$ irradiation. 


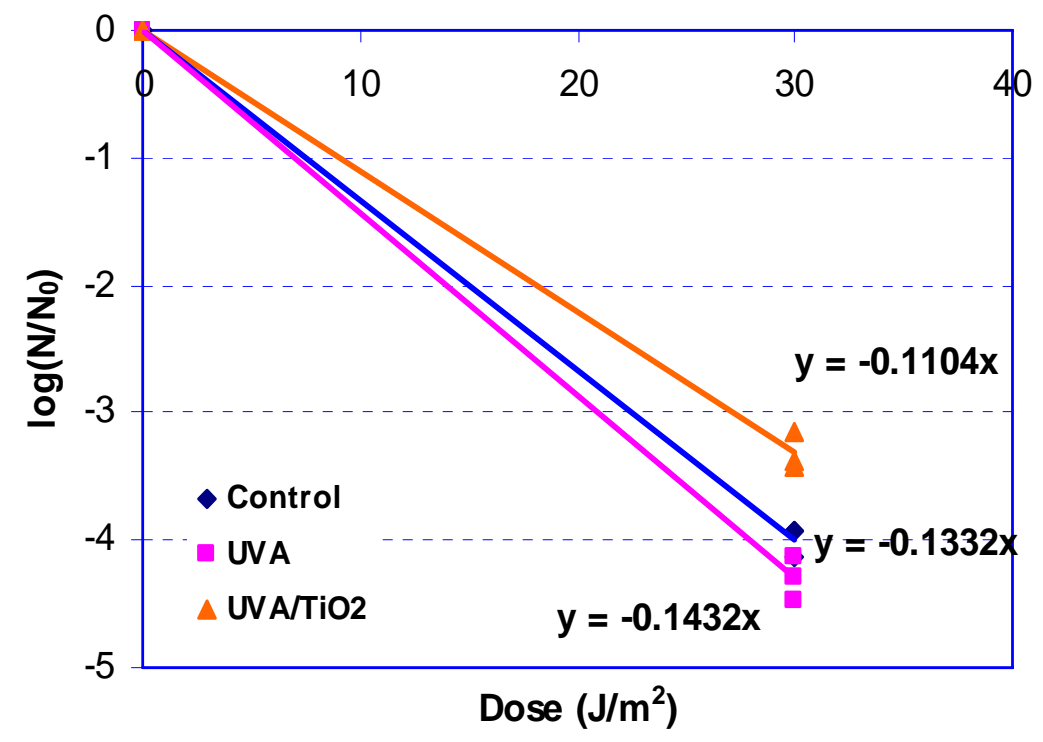

(a)

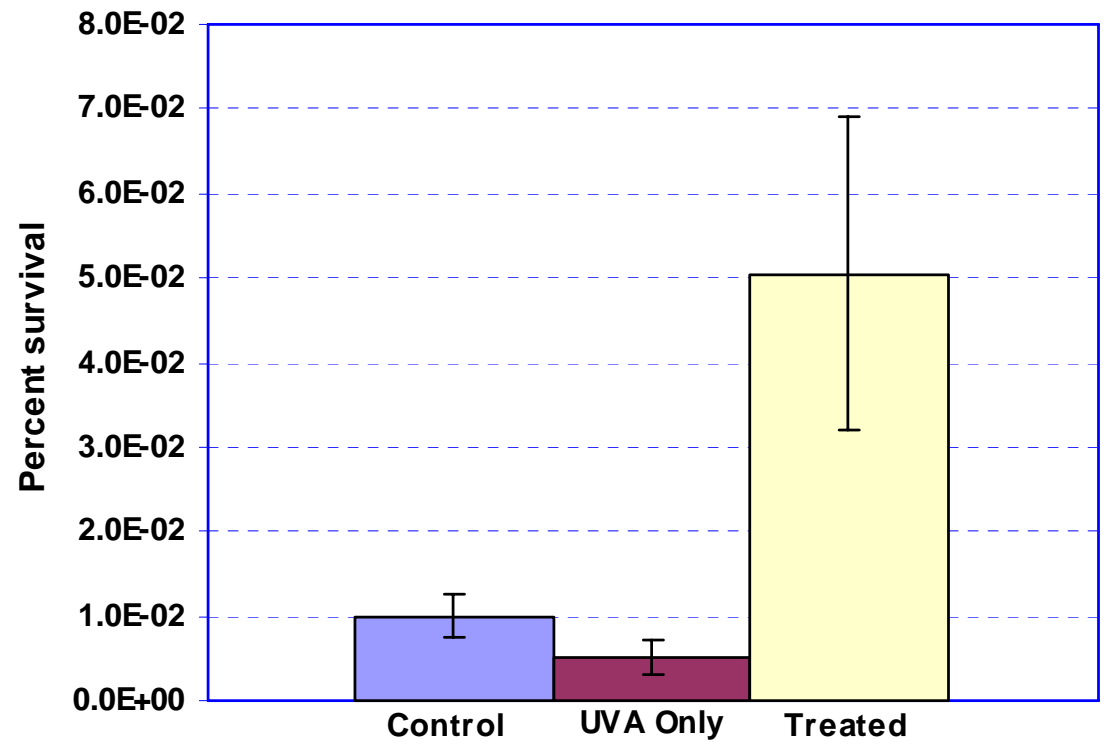

(b)

Figure 4.20. (a) Log-inactivation and (b) Percent Survival of E. coli as a Result of UV 254 Disinfection (intensity: $0.07 \mathrm{~mW} / \mathrm{cm}^{2}$, Dose: $30 \mathrm{~J} / \mathrm{m}^{2}$ ) for Control and Treated Samples with $\mathrm{UV}_{365}$ at $0.3 \mathrm{~mW} / \mathrm{cm}^{2}, 20 \mu \mathrm{g} / \mathrm{L}$ of Degussa P25 for 3 Hours and after $3 \mathrm{hrs}$ Post Irradiation Incubation. 


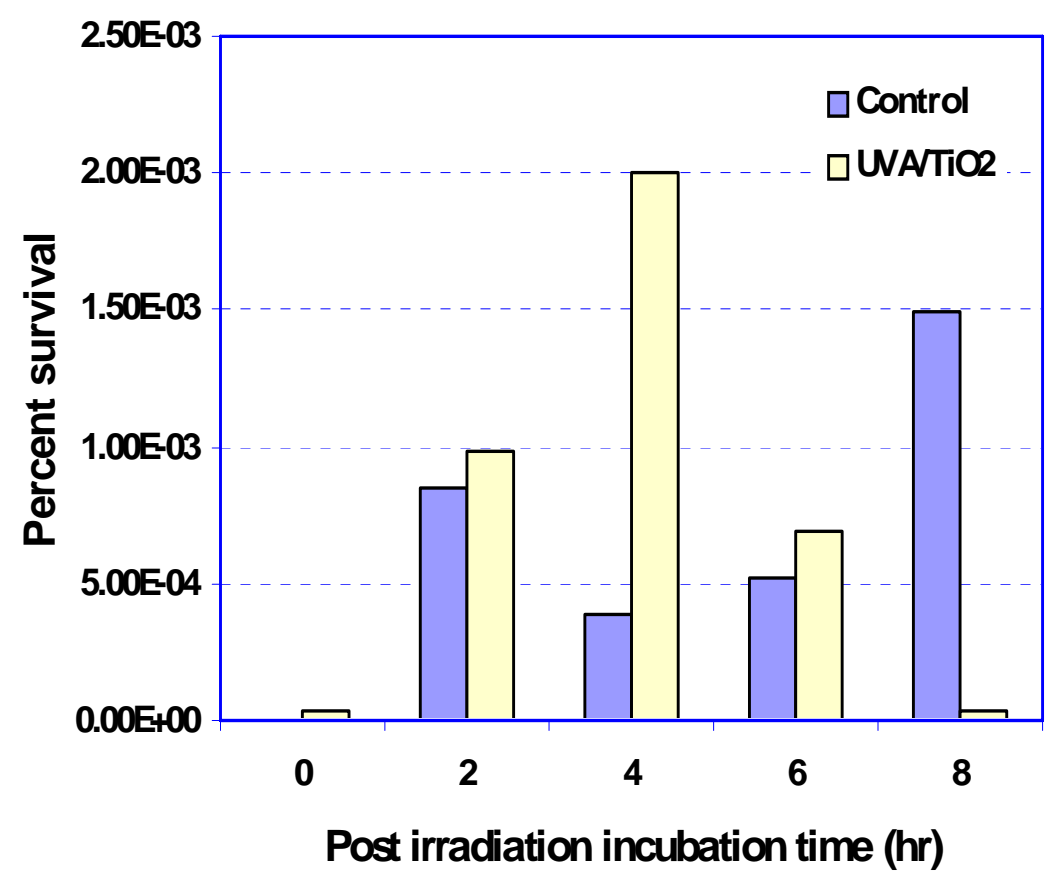

Figure 4.21. Percent Survival of $E$. coli from $U^{254}$ Disinfection (intensity: $0.07 \mathrm{~mW} / \mathrm{cm}^{2}$, dose: $30 \mathrm{~J} / \mathrm{m}^{2}$ ). The results are for a Control Culture (No Nanoparticles and $\mathbf{U V}_{365}$ ) and a Culture Treated with $\mathrm{TiO}_{2} 20 \mu \mathrm{g} / \mathrm{L}$ and $\mathrm{UV}_{365}\left(0.3 \mathrm{~mW} / \mathrm{cm}^{2}\right)$ for $3 \mathrm{Hours}$, Followed by Different Post-irradiation Incubation Times in a LB Medium at $37^{\circ} \mathrm{C}$. 


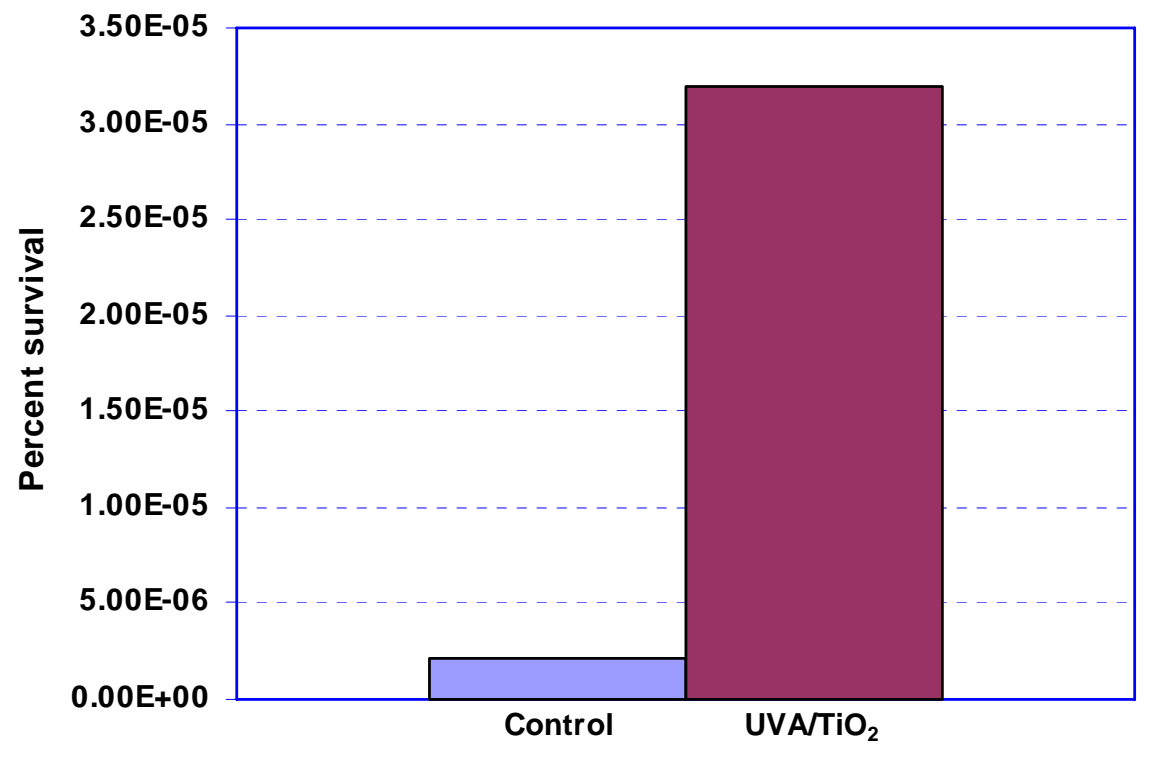

Figure 4.22 Percent Survival of E. coli to UVC Irradiation (Dose: $30 \mathrm{~J} / \mathrm{m}^{2}$ ) of Offspring of a $\mathrm{TiO}_{2} / \mathrm{UVA}$ Treated Culture after 4-hour Post-treatment Incubation and of a Control Culture without UVC Irradiation after 4-hour Incubation. 


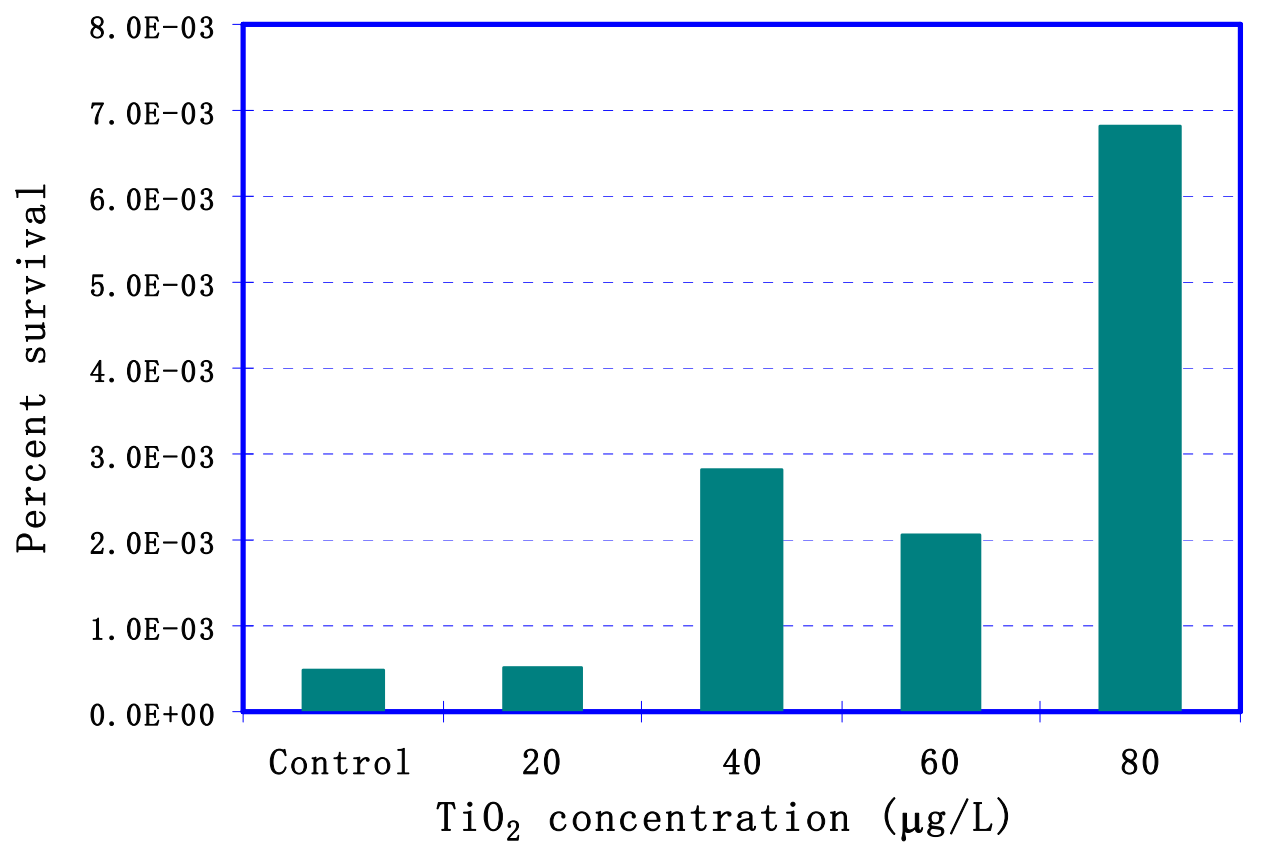

Figure 4.23. Percent Survival of $E$. coli from $U^{254}$ Disinfection (Intensity: $0.07 \mathrm{~mW} / \mathrm{cm}^{2}$, Dose: $30 \mathrm{~J} / \mathrm{m}^{2}$ ). The Results are for a Control Culture (No Nanoparticles and $\mathrm{UV}_{365}$ ) and a Culture Treated with Different $\mathrm{TiO}_{2}$ Concentration and $\mathrm{UV}_{365}\left(0.3 \mathrm{~mW} / \mathrm{cm}^{2}\right)$ for 3 Hours, Followed by 4 Hours Post-irradiation Incubation Times in a LB Medium at $37^{\circ} \mathbf{C}$. 


\subsection{Growth Delay Effect}

Figure 4.24 shows growth curve for a control, UVA treated, and $\mathrm{TiO}_{2} / \mathrm{UVA}$ treated cultures. The significant growth delay observed in the UVA irradiated E. coli cultures during the first few hours is in agreement with the previous reports of growth delay of bacterial cells following exposure to UVA (A. Favre et al., 1985) and $\mathrm{TiO}_{2} / \mathrm{UVA}$ (Kim et al., 2004) The growth delay effect was overcome by re-incubation of the cells in nutrient medium after 3 to 4 hours, and there is no difference between UVA only and $\mathrm{UVA} / \mathrm{TiO}_{2}$ treated samples. Figure 4.24 confirms the sublethal effect of the $\mathrm{TiO}_{2}$ nanoparticles in low ppb concentration, during and after UVA exposure. The population in $\mathrm{UVA} / \mathrm{TiO}_{2}$ treated samples remained close to UVA treated sample (Figure 4.6). However, the $\mathrm{TiO}_{2}$ nanoparticles in the low ppb concentrations induced an enhanced UVC resistance (Figures 4.14 and 4.20), which was not observed with UVA treatment alone.

\subsection{Effect of ROS Scavengers on Microbial Resistance}

After oxidative treatment, the treated sample with $\mathrm{NaN}_{3}$ had a similar population as the sample containing only $\mathrm{TiO}_{2}$, while sample with methanol showed a large population. This suggests that $\cdot \mathrm{OH}$ is responsible for UVA induced DNA damage because this effect was reduced by the $\cdot \mathrm{OH}$ scavenger $(\mathrm{MeOH})$. Figure 4.25 shows that the $\mathrm{UVA} / \mathrm{TiO}_{2}$ treated sample was more resistant to UVC irradiation than the control and the samples with the ROS scavengers. Note also that the samples with the ROS scavengers were more susceptible to UVC irradiation than the control. This suggests that the UVC resistance may have resulted from the effect of oxidative stress and the resistance diminished when the oxygen stress is removed by the ROS scavengers. 


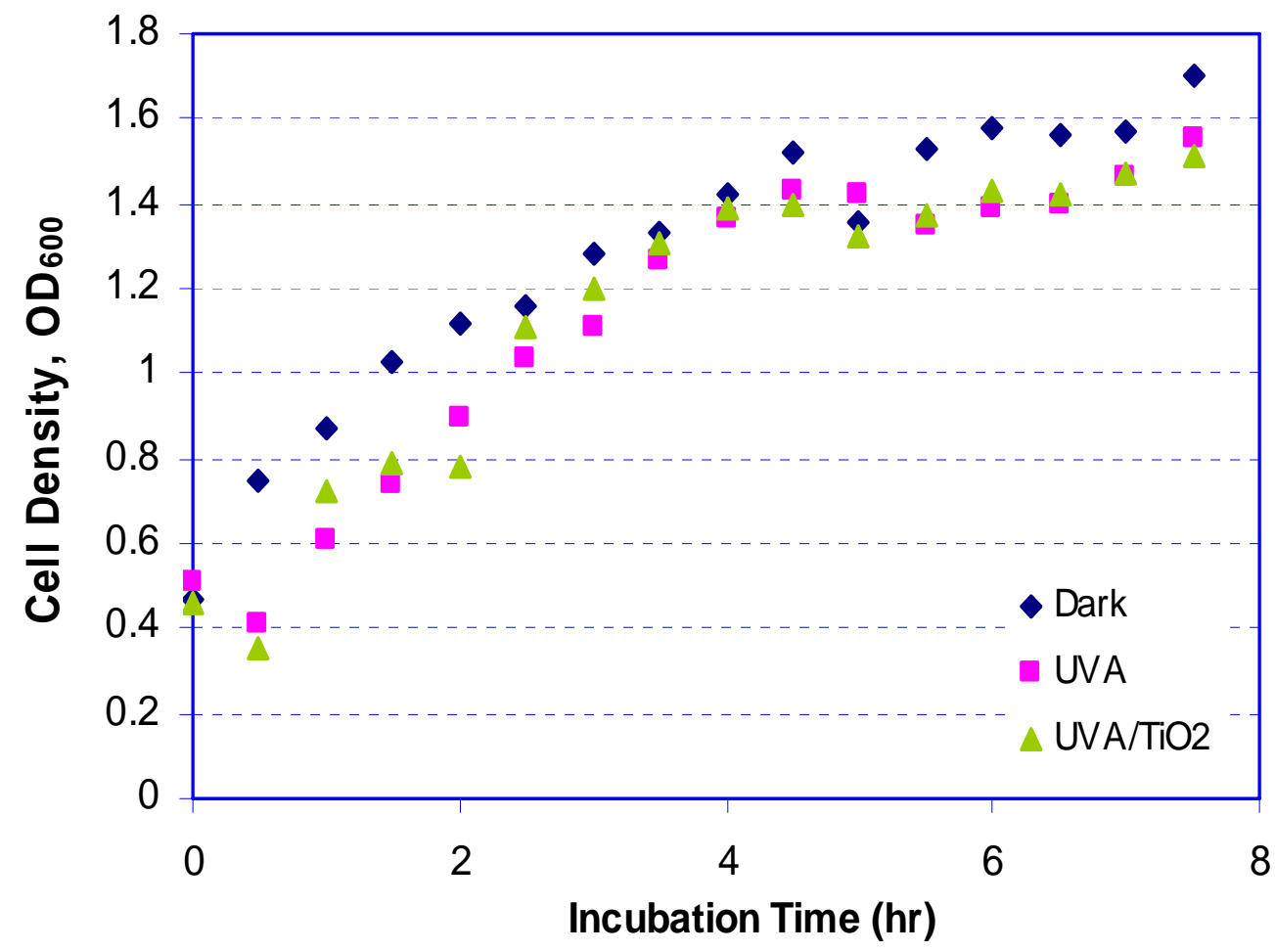

Figure 4.24. Growth Curve of $E$. coli for Control and Treated Samples after $\mathrm{UV}_{365}$ at 0.3 $\mathrm{mW} / \mathrm{cm}^{2}$ for 3 hours with Degussa P25 $20 \mu \mathrm{g} / \mathrm{L}$. 


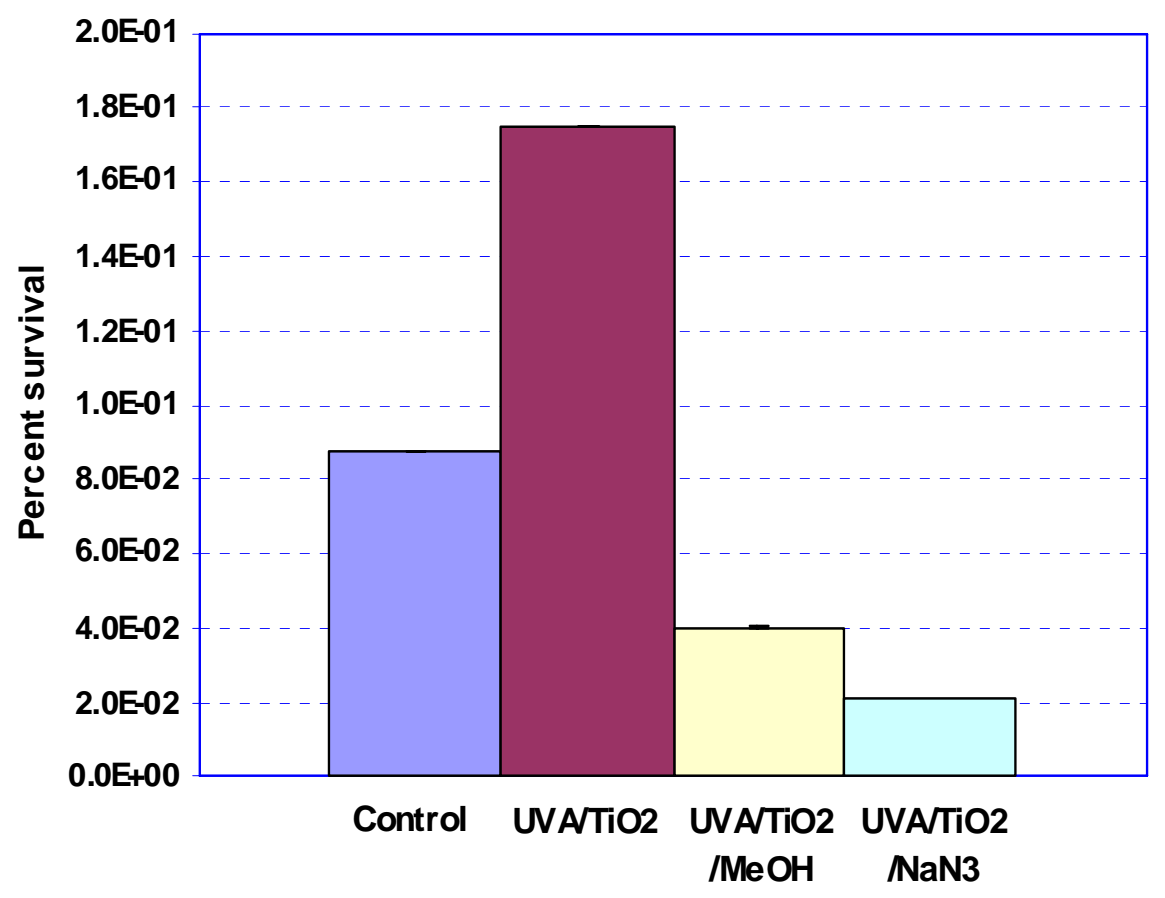

Figure 4.25. Percent survival of $E$. coli as a result of $U V$ disinfection $(254 \mathrm{~nm}$, Dose: 20 $\left.\mathrm{mJ} / \mathrm{cm}^{2}\right)$ for control and $\mathrm{TiO}_{2} / \mathrm{UVA}$ treated samples $\left(7.5 \mu \mathrm{g} / \mathrm{L}, 0.7 \mathrm{~mW} / \mathrm{cm}^{2}\right.$ for 20 hours) with methanol $30 \mathrm{mM}$ or sodium azide $1 \mathrm{mM}$. 


\section{CHAPTER 5: CONCLUTION}

We studied how oxidative stress caused by engineered $\mathrm{TiO}_{2}$ nanoparticles in the low ppb range can affect bacterial viability and resistance to UVC irradiation of a mixed culture and pure culture. The following conclusions are derived:

1) The oxidative treatment can cause sublethal effect that hinder bacterial respiratory activity. The effect was minimum after 2-hour exposure and became apparent after 19-hour oxidative treatment.

2) Flow cytometry and cultural analyses suggest that damaged cell membranes caused by lowlevel oxidative stress does not significantly affect bacterial colony forming ability.

3) $\mathrm{The} \mathrm{TiO}_{2}$ nanoparticles extracted from a commercial sunscreen product showed less effect than Degussa P25 nanoparticles.

4) Log-inactivation of fecal coliforms in the mixed culture demonstrated that the oxidative treatment induced an enhanced bacterial resistance to $\mathrm{UV}_{254}$ irradiation and the degree of enhancement was enlarged by nanoparticle concentration and the exposure time to oxidative stress. For bacterial culture treated with UVA alone, the enhanced resistance was not observed.

5) The enhanced resistance was attributed to two possible reasons: microbial community shift due to diverse sensitivity to the oxidative treatment and induction of microbial defense mechanisms that counteracted the oxidative stress and its damages.

6) Intracellular ROS measurements provided evidence that the augmented bacterial ability for counteracting intracellular ROS induced by the oxidative treatment contributed to the enhanced bacterial resistance to $\mathrm{UV}_{254}$. 
7) Pure E. coli culture exhibited a similar resistance to UVC irradiation from the oxidative treatment. The result corroborates that induction of microbial activities of counteracting oxidative stress and its damages is a cause for the enhanced resistance.

8) The enhanced resistance of E. coli was enlarged by nanoparticle concentration and reach highest expression at 4-hour post-irradiation incubation time. The resistant ability can pass down to the next generation.

9) Resistance diminished when the oxygen stress removed by the ROS scavengers. 


\section{REFERENCES}

Amézaga-Madrid, P., R. Silveyra-Morales, L. Córdoba-Fierro, G. V. Nevárez-Moorillón, M. Miki-Yoshida, E. Orrantia-Borunda, and F. J. Solís (2003) TEM Evidence of Ultrastructural Alteration on Peudomonas aeruginosa by Photocatalytic $\mathrm{TiO}_{2}$ Thin Films, J. Photochem. Photobiol. B, 70, 45-50.

APHA (1998) Standard Methods for the Examination of Water and Wastewater, 20th ed. American Public Health Association, Washington, DC.

Cho, M., H. Chung, W. Choi, and J. Yoon (2005) Different Inactivation Bahavior of MS-2 Phage and Escherichia coli in $\mathrm{TiO}_{2}$ Photocatalytic Disinfection, Appl Environ Microbiol, 71(1), $270-275$.

Coronado, J. M., J. Soria, J. C. Conesa, R. Bellod, C. Adán, H. Yamaoka, V. Loddo, and V. Augugliaro (2005) Photocatalytic Inactivation of Legionella pneumophila and an Aerobic Bacteria Consortium in Water over $\mathrm{TiO}_{2} / \mathrm{SiO}_{2}$ Fibres in a Continuous Reactor, Top Catal, 35(3-4), 279-286.

Daughton, C. H.; Ternes, T. A. (1999) Special Report: Pharmaceutical and personal care products in the environment: Agents of subtle change, Environ. Health Perspect. Vol. 107, p 907

Dizdaroglu M, Karahalil B, Senturker S, Buckley TJ, Roldan-Arjona T (1999), Excision of products of oxidative DNA base damage by human NTH1 protein, Biochemistry, 38 (1): $243-246$ 
Dunford, R., A. Salinaro, L. Cai, N. Serpone, S. Horikoshi, H. Hidaka, and J. Knowland (1997) Chemical Oxidation and DNA Damage Catalysed by Inorganic Sunscreen Ingredients, FEBS Letters, 418, 87-90.

Favre A., Hajnsdorf E., Thiam K., Caldeira de, A.A. (1985) Mutagenesis and growth delay induced in Escherichia coli by near-ultraviolet radiations, Biochimie 67, 335-342.

Finkel, T. and N. J. Holbrook (2000) Oxidants, Oxidative Stress and the Biology of Aging, Nature, 408(9) 239-247.

Fortini, P., B. Pascucci, E. Parlanti, M. D’Errico, V. Simonelli, and E. Dogliotti (2003) 8Oxoguanine DNA Damage: at the Crossroad of Alternative Repair Pathways, Mutation Research, 531, 127-139.

Gomes, A. A., A. C. T. Silva-Júnior, E. B. Oliveira, L. M. B. O. Asad, N. C. S.C. Reis, I. Felzenszwalb, K. Kovary, and N. R. Asad (2005) Reactive Oxygen Species Mediate Lethality Induced by far-UV in Escherichia coli Cells, Redox Rep, 10(2), 91-95.

Gort, A. S. and J. A. Imlay (1998) Balance between Endogenous Superoxide Stress and Antioxidant Defenses, Journal of Bacteriology, 180(6), 1402-1410.

Haas, C. N., and R.S. Englebrect (1980) Physiological Alterations of Vegetative Microorganisms Resulting from Chlorination, J. Water Pollut. Control Fed., 52, 1976-1989.

Häder, D.P. and R.P. Sinha (2005) Solar Ultraviolet Radiation-Induced DNA Damage in Aquatic Organisms: Potential Environmental Impact, Mutation Research, 571, 221-233.

Jagger, J. (1967) Introduction to Research in Ultraviolet Photobiology, Prentice-Hall, Inc., Englewood Cliffs, N.J.

Kaur, B. and P. W. Doetsch (2000) Ultraviolet Damage Endonuclease (Uve1p): A Structure and Strand-Specific DNA Endonuclease, Biochemistry, 39, 5788-5796. 
Keyer, K. and J. A. Imlay (1996) Superoxide Accelerates DNA Damage by Elevating Free-iron Levels, Proc. Natl. Acad. Sci., 93, 13635-13640.

Kim, B., D. Kim, D. Cho, and S. Cho (2003) Bactericidal Effect of $\mathrm{TiO}_{2}$ Photocatalyst on Selected Food-Borne Pathogenic Bacteria, Chemosphere, 52(1), 277-281.

Kim, S. Y., M. Nishioka, and M. Taya (2004) Promoted Proliferation of an SOD-deficient Mutant of Escherichia coli under Oxidative Stress Induced by Photoexcited $\mathrm{TiO}_{2}$, FEMS Microbiology Letters, 236, 109-114.

Kim, S. Y., M. Nishioka, S. Hayashi, H. Honda, T. Kobayashi, and M. Taya (2005) The Gene yggE Functions in Restoring Physiological Defects of Esherichia coli Cultivated under Oxidative Stress Conditions, Appl. Environ. Microbiol., 71(5), 2762-2765.

Kiwi, J. and V. Nadtochenko (2005) Evidence for the Mechanism of Photocatalytic Degradation of the Bacterial Wall membrane at the $\mathrm{TiO}_{2}$ Interface by ATR-FTIR and Laser Kinetic Spectroscopy, Langmuir, 21, 4631-4641.

Lehmann, A.R. (1995) Nucleotide excision repair and the link with transcription, TIBS, 20:402405.

Maness, P.C., S. Smolinski, D. M. Blake, Z. Huang, E. J. Wolfrum, and W. A. Jacoby (1999) Bactericidal Activity of Photocatalytic TiO2 Reaction: toward an Understanding of Its Killing Mechanism, Appl. Environ. Microbiol., 65(9), 4094-4098.

Nagira, T., J. Narisawa, K. Teruya, Y. Katakura, S.Y. Shim, K.I. Kusumoto, S. Tokumaru, K. Tokumaru, D. W. Barnes, and S. Shirahata (2002) Suppression of UVC-induced Cell Damage and Enhancement of DNA Repair by the Fermented Milk, Kefir, Cytotechnology, 40, 125-137. 
Nebe-von Caron G.; Badley R. A. (1995) Viability Assessment of Bacteria in Mixed Populations Using Flow Cytometry, Journal of microscopy, vol. 179 (1), pp. 55-66

NSF (2001) Societal Implications of Nanoscience and Nanotechnology, ed. by M. Roco and W. Bainbridge, Kluwer, Netherlands.

Oberdörster, G., E. Oberdörster, and J. Oberdörster (2005) Nanotoxicology: An Emerging Discipline Evolving from Studies of Ultrafine Particles, Environ Health Perspect, 113, 823-839.

Oguma K., Katayama H., and Ohgaki S. (2002), Photoreactivation of Escherichia coli after Lowor Medium-Pressure UV Disinfection Determined by an Endonuclease Sensitive Site Assay, Applied and Environmental Microbiology, Vol. 68, No. 12

Olga Blokhina, Eija Virolainen and Kurt V. Fagerstedt, Antioxidants, Oxidative Damage and Oxygen Deprivation Stress: a Review, Annals of Botany, 91: 179-194, 2003.

Paull R, Wolfe J, Hebert P, et al. (2003), Investing in nanotechnology, Nature Biotechnology, 21 (10): 1144-1147

Rincón, A. G. and C. Pulgarin (2004a) Bactericidal Action of Illuminated $\mathrm{TiO}_{2}$ on Pure Escherichia coli and Natural Bacterial Consortia: Post-irradiation Events in the Dark and Assessment of the Effective Disinfection Time, Appl Catal, B, 49, 99-112.

Rincón, A. G. and C. Pulgarin (2004b) Effect of pH, Inorganic Ions, Organic Matter and $\mathrm{H}_{2} \mathrm{O}_{2}$ on E-coli K12 Photocatalytic Inactivation by $\mathrm{TiO}_{2}$ - Implications in Solar Water Disinfection, Appl Catal, B, 51(4), 283-302.

Sancar, A. and M. Tang (1993) Nucleotide excision repair, Photochem. Photobiol., 57:905-921. Seeberg, E., L. Eide, and M. Bjoras (1995) The Base Excision Repair Pathway, TIBS, 20, 391397. 
Shiota, S. and H. Nakayama (1997) UV Endonuclease of Micrococcus luteus, a Cyclobutane Pyrimidine Dimer-DNA Glycosylase/abasic Lyase: Cloning and Characterization of the Gene, Proc. Natl. Acad. Sci., 94, 593-598.

Slupphaug, G., B. Kavli, and H. E. Krokan (2003) The Interacting Pathways for Prevention and Repair of Oxidative DNA Damage, Mutation Research, 531, 231-251.

Srinivasan, C. and N. Somasundaram (2003) Bactericidal and Detoxification Effects of Irradiated Semiconductor Catalyst, $\mathrm{TiO}_{2}$, Current Science, 85(10), 1431-1438.

Sunada, K., T. Watanabe, and K. Hashimoto (2003) Bactericidal Activity of Copper-Deposited $\mathrm{TiO}_{2}$ Thin Film under Weak UV Light Illumination, Environ Sci Technol, 37, 47854789.

The Royal Society \& The Royal Academy of Engineering (2004) Nanoscience and Nanotechnologies: Opportunities and Uncertainties.

USEPA (1996) Ecological Effects Test Guidelines: Modified Activated Sludge, Respiration Inhibition Test for Sparingly Soluble Chemicals, EPA712-C-96-168, U.S. Environmental Protection Agency, Washington, DC

USEPA (2005) Nanotechnology White Paper (external review draft), prepared by members of the Nanotechnology Workgroup, a group of EPA's Science Policy Council, Washington, DC.

Wiseman, H. and B. Hallinwell (1996) Damage to DNA by Reactive Oxygen and Nitrogen Species: Role in Inflammatory Disease and Progression to Cancer, Biochem. J., 313, 1729. 
Wei, H., Cai, Q., Rahn, R., Zhang, X. (1997) Singlet oxygen involvement in ultraviolet radiation-induced formation of 8-hydroxy-deoxyguanosine. Free Radic. Biol. Med. 34:148-154.

Yamakoshi, Y., N. Umezawa, A. Ryu, K. Arakane, N. Miyata, Y. Goda (2003) Active Oxygen Species Generated from Photoexcited Fullerene $\left(\mathrm{C}_{60}\right)$ as Potential Medicines: $\mathrm{O}_{2}{ }^{-*}$ versus ${ }^{1} \mathrm{O}_{2}$, J Am Chem Soc, 125, 12803-12809.

Yoon J.-H., Lee C.-S., T.R. O’Connor, A. Yasui, G.P. Pfeifer (2000), The DNA damage spectrum produced by simulated sunlight, J. Mol. Biol. 299, 681-693.

Zhang X, Rosestein BS, Wang Y et al. (1997) Identification of possible reactive oxygen species involved in ultraviolet radiation-induced oxidative DNA damage. Free Radic Biol. Med., 23: $980-985$. 


\section{APPENDIX A}

Table A. Log-inactivation of Fecal Coliforms to UV Disinfection (254 nm) after Treated with Different TiO $\mathrm{Concentration}_{2}$ and 365nm UV $\left(0.6 \mathrm{~mW} / \mathrm{cm}^{2}\right)$ 19hrs.

\begin{tabular}{|c|c|c|c|c|c|}
\hline $\begin{array}{c}\mathrm{TiO}_{2} \text { conc. } \\
(\mu \mathrm{g} / \mathrm{L})\end{array}$ & $\begin{array}{c}\text { Control cell } \\
(\mathrm{CFU} / 100 \mathrm{ml}) \text { at } 0 \text { dose }\end{array}$ & $\begin{array}{c}\text { Treated cell } \\
(\mathrm{CFU} / 100 \mathrm{ml}) \text { at } 0 \text { does }\end{array}$ & $\begin{array}{c}\text { Slope of control } \\
\text { equation }\end{array}$ & $\begin{array}{c}\text { Slope of treated } \\
\text { equation }\end{array}$ & $\begin{array}{l}\Delta \text { Slope of } \\
\text { equations }\end{array}$ \\
\hline 2 & $8.00 \times 10^{4}$ & $8.00 \times 10^{4}$ & $Y=-0.0577 x$ & $Y=-0.0540 x$ & 0.0037 \\
\hline 5 & $3.76 \times 10^{6}$ & $4.78 \times 10^{6}$ & $Y=-0.1036 x$ & $Y=-0.0808 x$ & 0.0228 \\
\hline 5 & $2.44 \times 10^{6}$ & $2.38 \times 10^{6}$ & $Y=-0.0695 x$ & $Y=-0.0325 x$ & 0.0370 \\
\hline 5 & $1.50 \times 10^{6}$ & $0.45 \times 10^{6}$ & $Y=-0.0908 x$ & $Y=-0.0718 x$ & 0.0190 \\
\hline 10 & $1.50 \times 10^{6}$ & $0.37 \times 10^{6}$ & $Y=-0.0908 x$ & $Y=-0.0593 x$ & 0.0315 \\
\hline 10 & $3.00 \times 10^{4}$ & $0.60 \times 10^{4}$ & $Y=-0.1094 x$ & $Y=-0.0851 x$ & 0.0243 \\
\hline 10 & $1.56 \times 10^{5}$ & $1.44 \times 10^{5}$ & $Y=-0.0695 x$ & $Y=-0.0325 x$ & 0.0370 \\
\hline 10 & $2.24 \times 10^{5}$ & $7.80 \times 10^{5}$ & $Y=-0.1001 x$ & $Y=-0.0618 x$ & 0.0383 \\
\hline 20 & $1.50 \times 10^{6}$ & $0.33 \times 10^{6}$ & $Y=-0.0908 x$ & $Y=-0.0612 x$ & 0.0296 \\
\hline 20 & $7.80 \times 10^{4}$ & $4.60 \times 10^{4}$ & $Y=-0.1098 x$ & $Y=-0.0664 x$ & 0.0434 \\
\hline
\end{tabular}




\section{APPENDIX B}

Table B. Log-inactivation of Fecal Coliforms to UV Disinfection (254 nm) after Treated with $\mathrm{TiO}_{2} \mathrm{Concentration} 5 \mu \mathrm{g} / \mathrm{L}$ and $365 \mathrm{~nm}$ UV (0.6 mW/cm $\left.{ }^{2}\right)$ in Different Exposure Time.

\begin{tabular}{lccccc}
\hline Exposure time (hrs) & 5 & 10 & 15 & 19 & 24 \\
\hline$\triangle$ Slope of equations & 0.0201 & 0.0228 & 0.0319 & 0.037 & 0.0506 \\
\hline
\end{tabular}




\section{APPENDIX C}

Table C. Log-inactivation of Fecal Coliforms to UV Disinfection $(254 \mathrm{~nm})$ after Treated with Different $\mathrm{Sunscren}_{\mathrm{TiO}}$ Concentration and $365 \mathrm{~nm}$ UV $\left(0.6 \mathrm{~mW} / \mathrm{cm}^{2}\right)$ 19hrs.

\begin{tabular}{|c|c|c|c|c|c|}
\hline $\begin{array}{c}\mathrm{TiO}_{2} \text { conc. } \\
(\mu \mathrm{g} / \mathrm{L})\end{array}$ & $\begin{array}{c}\text { Control cell } \\
(\mathrm{CFU} / 100 \mathrm{ml}) \text { at } 0 \text { dose }\end{array}$ & $\begin{array}{c}\text { Treated cell } \\
(\mathrm{CFU} / 100 \mathrm{ml}) \text { at } 0 \text { does }\end{array}$ & $\begin{array}{c}\text { Slope of control } \\
\text { equation }\end{array}$ & $\begin{array}{c}\text { Slope of treated } \\
\text { equation }\end{array}$ & $\begin{array}{l}\Delta \text { Slope of } \\
\text { equations }\end{array}$ \\
\hline 2 & $4.92 \times 10^{6}$ & $4.00 \times 10^{6}$ & $Y=-0.0520 x$ & $Y=-0.0445 x$ & 0.0075 \\
\hline 5 & $3.37 \times 10^{6}$ & $4.13 \times 10^{6}$ & $Y=-0.0976 x$ & $Y=-0.0827 x$ & 0.0149 \\
\hline 10 & $4.80 \times 10^{5}$ & $0.15 \times 10^{5}$ & $Y=-0.1080 x$ & $Y=-0.0599 x$ & 0.0481 \\
\hline 10 & $1.70 \times 10^{6}$ & $1.50 \times 10^{6}$ & $Y=-0.0814 x$ & $Y=-0.0719 x$ & 0.0095 \\
\hline 10 & $2.05 \times 10^{5}$ & $1.95 \times 10^{5}$ & $Y=-0.1020 x$ & $Y=-0.0896 x$ & 0.0124 \\
\hline 10 & $2.05 \times 10^{5}$ & $0.95 \times 10^{5}$ & $Y=-0.1020 x$ & $Y=-0.0819 x$ & 0.0201 \\
\hline 10 & $2.05 \times 10^{5}$ & $1.05 \times 10^{5}$ & $Y=-0.1020 x$ & $Y=-0.0779 x$ & 0.0241 \\
\hline 20 & $9.10 \times 10^{6}$ & $4.16 \times 10^{6}$ & $Y=-0.0880 x$ & $Y=-0.0734 x$ & 0.0146 \\
\hline
\end{tabular}




\section{APPENDIX D}

Table D. Log-inactivation of $E$. coli to UV Disinfection (254 nm) after Treated with Different $\mathrm{TiO}_{2} \mathrm{Concentration} \mathrm{UV}_{365}$ Intensity and Exposure Time.

(Irradiation process to UVA and UVC were both done in LB medium, cells were in growing stage.)

\begin{tabular}{|c|c|c|c|c|c|c|c|}
\hline $\begin{array}{c}\mathrm{UV}_{365} \text { Intensity } \\
\left(\mathrm{mW} / \mathrm{cm}^{2}\right)\end{array}$ & $\begin{array}{c}\mathrm{TiO}_{2} \text { conc. } \\
(\mu \mathrm{g} / \mathrm{L})\end{array}$ & $\begin{array}{c}\mathrm{UV}_{365} \text { exposure } \\
\text { time (hours) }\end{array}$ & $\begin{array}{l}\text { Control cell } \\
\text { (CFU/1 ml) at } 0 \text { dose }\end{array}$ & $\begin{array}{c}\text { Treated cell } \\
\text { (CFU/1ml) at } 0 \text { does }\end{array}$ & $\begin{array}{c}\text { Slope of control } \\
\text { equation }\end{array}$ & $\begin{array}{c}\text { Slope of treated } \\
\text { equation }\end{array}$ & $\begin{array}{l}\Delta \text { Slope of } \\
\text { equations }\end{array}$ \\
\hline 0.7 & 7.5 & 20 & $7.50 \times 10^{8}$ & $6.30 \times 10^{3}$ & $Y=-0.0608 x$ & $Y=-0.0374 x$ & 0.0234 \\
\hline 0.7 & 3 & 5 & $2.70 \times 10^{9}$ & $1.40 \times 10^{9}$ & $Y=-0.0717 x$ & $Y=-0.0896 x$ & $\begin{array}{c}-0.0179 \\
\end{array}$ \\
\hline 0.3 & 2 & 10 & $1.80 \times 10^{9}$ & $1.17 \times 10^{9}$ & $Y=-0.0877 x$ & $Y=-0.0691 x$ & 0.0186 \\
\hline 0.15 & 2 & 20 & $1.38 \times 10^{8}$ & $1.25 \times 10^{9}$ & $Y=-0.0670 x$ & $Y=-0.0705 x$ & 0.0035 \\
\hline 0.15 & 5 & 20 & $4.10 \times 10^{9}$ & $3.20 \times 10^{9}$ & $Y=-0.0778 x$ & $Y=-0.0595 x$ & 0.0183 \\
\hline 0.15 & 5 & 20 & $1.35 \times 10^{10}$ & $1.45 \times 10^{10}$ & $Y=-0.1011 x$ & $Y=-0.0696 x$ & 0.0315 \\
\hline 0.15 & 5 & 20 & $5.00 \times 10^{9}$ & $1.60 \times 10^{10}$ & $Y=-0.0965 x$ & $Y=-0.1108 x$ & $\begin{array}{c}-0.0143 \\
\end{array}$ \\
\hline 0.15 & 5 & 20 & $2.15 \times 10^{9}$ & $1.35 \times 10^{9}$ & $Y=-0.0651 x$ & $Y=-0.0609 x$ & 0.0042 \\
\hline 0.15 & 5 & 20 & $2.15 \times 10^{9}$ & $1.35 \times 10^{9}$ & $Y=-0.0651 x$ & $Y=-0.1013$ & $\begin{array}{l}-0.0362 \\
\end{array}$ \\
\hline
\end{tabular}




\section{APPENDIX E}

Table E. Log-inactivation of $E$. coli to UV Disinfection (254 nm) after Treated with Different $\mathrm{TiO}_{2} \mathrm{Concentration} \mathrm{UV}_{365}$ Intensity, $\mathbf{U V}_{365}$ Exposure Time and Post-irradiation Incubation Time.

(Irradiation process to UVA and UVC were both done in PBS, cells were in stationary phase)

\begin{tabular}{|c|c|c|c|c|c|c|c|}
\hline $\begin{array}{c}\mathbf{U V}_{365} \text { Intensity } \\
\left(\mathrm{mW} / \mathrm{cm}^{2}\right)\end{array}$ & $\begin{array}{r}\mathrm{TiO}_{2} \text { conc. } \\
(\mu \mathrm{g} / \mathrm{L})\end{array}$ & $\begin{array}{l}\text { UVA exposure time } \\
\text { (post incubation time) }\end{array}$ & $\begin{array}{l}\text { Control cell } \\
(\mathrm{CFU} / 1 \mathrm{ml}) \text { at } 0 \text { dose }\end{array}$ & $\begin{array}{c}\text { Treated cell } \\
(\mathrm{CFU} / 1 \mathrm{ml}) \text { at } 0 \text { does }\end{array}$ & $\begin{array}{c}\text { Slope of control } \\
\text { equation }\end{array}$ & $\begin{array}{c}\text { Slope of treated } \\
\text { equation }\end{array}$ & $\begin{array}{l}\Delta \text { Slope of } \\
\text { equations }\end{array}$ \\
\hline 0.3 & 5 & $3(1.5)$ & $9.20 \times 10^{8}$ & $5.20 \times 10^{8}$ & $Y=-0.1691 x$ & $Y=-0.2014$ & -0.0323 \\
\hline 0.3 & 5 & $3(3.0)$ & $1.28 \times 10^{9}$ & $1.23 \times 10^{9}$ & $Y=-0.1731 x$ & $Y=-0.1923$ & -0.0192 \\
\hline 0.3 & 7.5 & $3(3.0)$ & $8.70 \times 10^{8}$ & $8.20 \times 10^{8}$ & $Y=-0.1664 x$ & $Y=-0.1539$ & 0.0125 \\
\hline 0.3 & 10 & $3(3.0)$ & $1.08 \times 10^{9}$ & $9.40 \times 10^{8}$ & $Y=-0.1469 x$ & $Y=-0.1425$ & 0.0044 \\
\hline 0.3 & 10 & $3(1.5)$ & $9.70 \times 10^{8}$ & $5.20 \times 10^{8}$ & $Y=-0.1165 x$ & $Y=-0.1451$ & -0.0286 \\
\hline 0.3 & 10 & $3(3.0)$ & $1.87 \times 10^{9}$ & $1.22 \times 10^{9}$ & $Y=-0.1464 x$ & $Y=-0.1252$ & 0.0212 \\
\hline 0.3 & 15 & $3(1.5)$ & $1.05 \times 10^{9}$ & $5.10 \times 10^{8}$ & $Y=-0.1599 x$ & $Y=-0.1691$ & -0.0092 \\
\hline 0.3 & 15 & $3(3.0)$ & $1.39 \times 10^{9}$ & $1.03 \times 10^{9}$ & $Y=-0.1226 x$ & $Y=-0.1312$ & -0.0086 \\
\hline 0.3 & 20 & $3(1.5)$ & $7.60 \times 10^{8}$ & $4.30 \times 10^{8}$ & $Y=-0.1681 x$ & $Y=-0.1981$ & $-\mathbf{0 . 0 3 0 0}$ \\
\hline 0.3 & 20 & $3(3.0)$ & $1.45 \times 10^{9}$ & $1.14 \times 10^{9}$ & $Y=-0.203 x$ & $Y=-0.1429$ & 0.0601 \\
\hline 0.3 & 20 & $3(1.5)$ & $1.11 \times 10^{9}$ & $6.00 \times 10^{8}$ & $Y=-0.1818 x$ & $Y=-0.177$ & 0.0048 \\
\hline 0.3 & 20 & $3(3.0)$ & $1.00 \times 10^{9}$ & $9.60 \times 10^{8}$ & $Y=-0.2011 x$ & $Y=-0.144$ & 0.0571 \\
\hline
\end{tabular}




\section{APPENDIX F}

Table F. Percent Survival of $E$. coli to $\mathrm{UV}_{254}$ Disinfection $\left(0.16 \mathrm{~mW} / \mathrm{cm}^{2}\right) 30$ Does after Treated with $\mathrm{TiO}_{2} 20 \mu \mathrm{g} / \mathrm{L}$, $\mathrm{UV} 365$ $\left(0.3 \mathrm{~mW} / \mathrm{cm}^{2}\right) 3$ Hours and Different Post-irradiation Incubation Time.

(Irradiation process to UVA was done in PBS, post-irradiation incubation was in LB medium)

\begin{tabular}{cccc}
\hline Post irradiation & Control cell & UVA Treated only cell & Treated cell \\
incubation time (hr) & survival percentage & survival percentage & survival percentage \\
\hline 0 & 0 & $2.94 \times 10^{-6}$ & $3.33 \times 10^{-7}$ \\
\hline 2 & $8.45 \times 10^{-6}$ & $3.88 \times 10^{-6}$ & $9.80 \times 10^{6}$ \\
\hline 4 & $3.90 \times 10^{-6}$ & $1.22 \times 10^{-5}$ & $2.00 \times 10^{-5}$ \\
\hline 6 & $5.20 \times 10^{-6}$ & $2.99 \times 10^{-5}$ & $6.96 \times 10^{6}$ \\
\hline 8 & $1.49 \times 10^{-5}$ & $1.11 \times 10^{-6}$ & $3.54 \times 10^{-7}$ \\
\hline
\end{tabular}




\section{VITA}

Hang Li was born in Nanning, Guangxi Province, People's Republic of CHINA. She enrolled in Zhejiang University, Hangzhou, Zhejiang Province in Sep. 2001 and received her Bachelor Degree in Chemical Engineering in Jul. 2005. After graduation, she was admitted into West Virginia University in Aug. 2005, studying for her Master degree in Civil and Environmental Engineering. She worked under the advisement of Dr. Lian-shin Lin and her work focused on wastewater UV disinfection effect by nanoparticles. 